\title{
COMPARAÇÃO ENTRE A DISPONIBILIDADE DE FERRO NA PRESENÇA DE VITAMINA A E BETA-CAROTENO EM ALIMENTOS E MEDICAMENTOS
}

\author{
FABIANA CRISTINA CAMARGO MARTINI
}

\begin{abstract}
Dissertação apresentada à Escola Superior de Agricultura "Luiz de Queiroz", Universidade de São Paulo, para obtenção do título de Mestre em Ciências, Área de Concentração: Ciência e Tecnologia de Alimentos.
\end{abstract}

PIRACICABA

Estado de São Paulo - Brasil

Julho -2002 


\title{
COMPARAÇÃO ENTRE A DISPONIBILIDADE DE FERRO NA PRESENÇA DE VITAMINA A E BETA-CAROTENO EM ALIMENTOS E MEDICAMENTOS
}

\author{
FABIANA CRISTINA CAMARGO MARTINI \\ Farmacêutico
}

Orientadora Prof $^{\mathrm{a}}$. Dr ${ }^{\mathrm{a}}$. SOLANGE GUIDOLIN CANNIATTI-BRAZACA

\begin{abstract}
Dissertação apresentada à Escola Superior de Agricultura "Luiz de Queiroz", Universidade de São Paulo, para obtenção do título de Mestre em Ciências, Área de Concentração: Ciência e Tecnologia de Alimentos.
\end{abstract}

\author{
PIRACICABA \\ Estado de São Paulo - Brasil \\ Julho -2002
}


Dados Internacionais de Catalogação na Publicação (CIP)

DIVISÃO DE BIBLIOTECA E DOCUMENTAÇÃO - ESALQ/USP

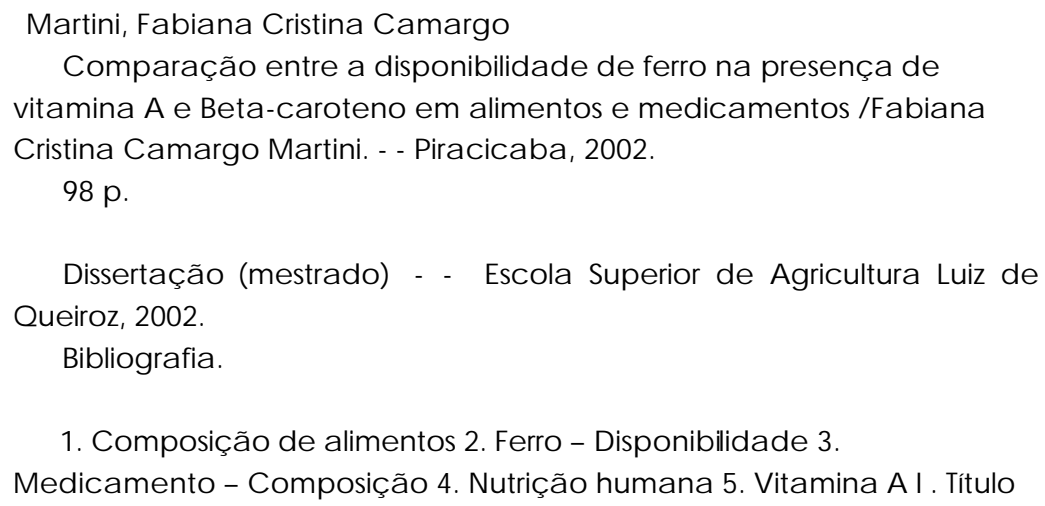

CDD 641.1

\section{"Permitida a cópia total ou parcial deste documento, desde que citada a fonte - $O$ autor"}


Aos meus pais Reynaldo e Neusa

Ao meu marido Geraldo

Ao meu filho João Pedro

Pelo amor e incentivo

Dedico 


\section{AGRADECIMENTOS}

A Deus.

À Escola Superior de Agricultura "Luiz de Queiroz", especialmente ao Departamento de Agroindústria, Alimentos e Nutrição, pela acolhida.

À Prof ${ }^{\mathrm{a}}$. Dr ${ }^{\mathrm{a}}$. Solange Guidolin Canniatti Brazaca, pelo apoio, incentivo e pelo carinho com que me recebeu e orientou na realização desta pesquisa.

À Técnica Maria de Lourdes Perin Storer, pela colaboração na realização das análises laboratoriais.

Às Secretárias Raquel Iracema da Silva e Regina Lúcia de Mello Lourenço, pela cooperação.

Às Bibliotecárias, pela ajuda e pelas correções de referências bibliográficas.

Ao Prof. Dr. Jorge Horii, pela atenção dada.

À minha Banca de Qualificação: Prof $f^{\mathrm{a}}$. Dr ${ }^{\mathrm{a}}$. Marília Oetterer, Prof ${ }^{\mathrm{a}}$. Dr ${ }^{\mathrm{a}}$. Marina Vieira da Silva e Prof ${ }^{\mathrm{a}}$. Dr ${ }^{\mathrm{a}}$. Marta Helena Fillet Spoto, pelas sugestões.

Ao Corpo Técnico do Laboratório de Nutrição Mineral de Plantas, pela realização das análises de minerais.

À CAPES, Coordenação de Aperfeiçoamento de Pessoal em nível superior, pelo suporte financeiro.

À FAPESP, Fundação de Amparo à Pesquisa do Estado de São Paulo, pelo suporte financeiro de auxílio à pesquisa.

Aos meus colegas do curso de pós-graduação, pelos momentos compartilhados.

À minha família, pela compreensão, apoio e paciência. 


\section{SUMÁRIO}

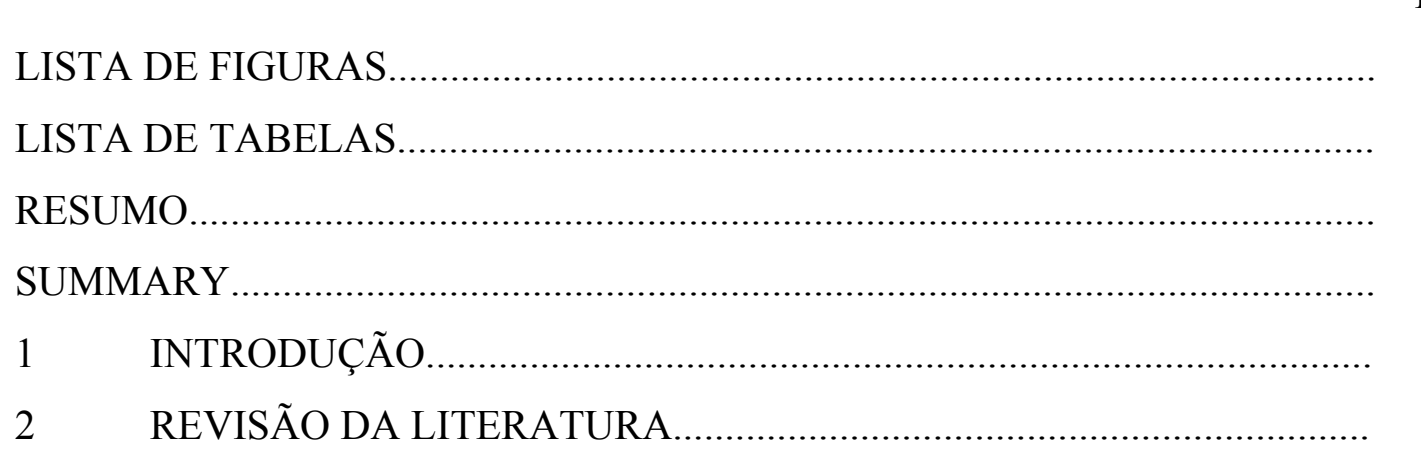

Página

viii

2.1 Ferro e sua importância nutricional........................................................ 3

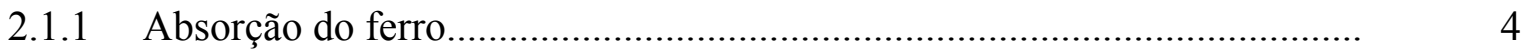

2.1.2 Forma química: ferro heme e não-heme............................................... 5

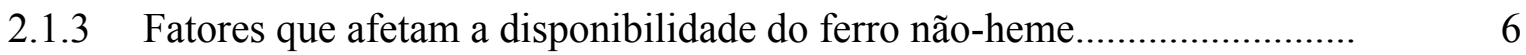

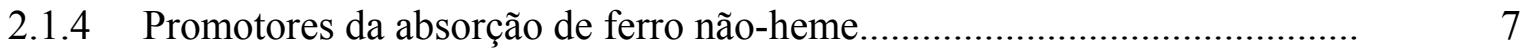

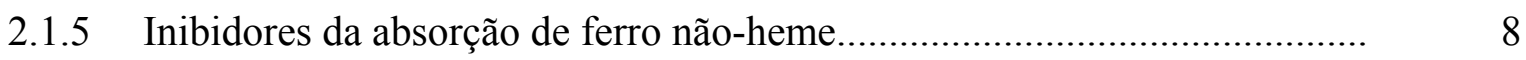

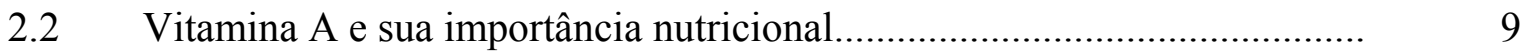

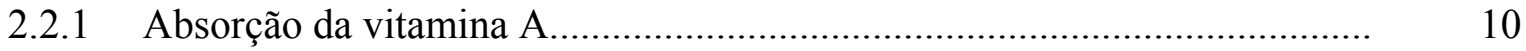

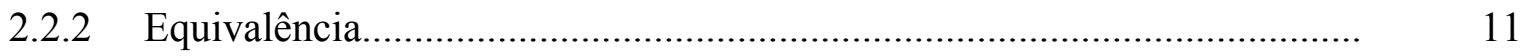

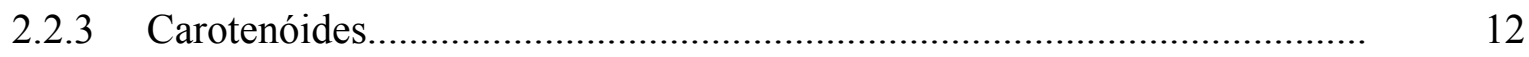

2.3 Interação entre ferro e vitamina A........................................................... 14

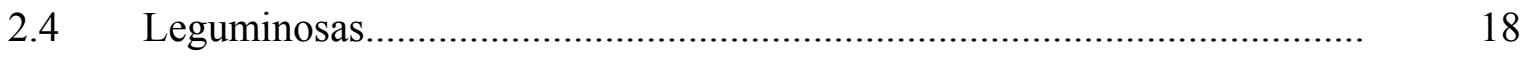

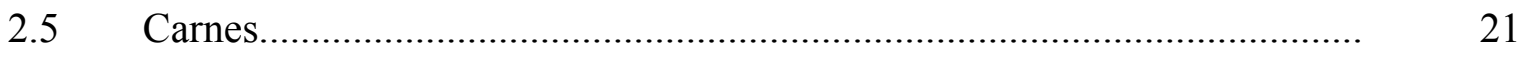

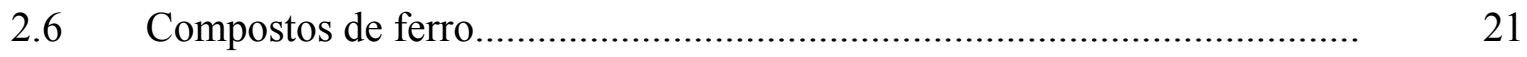

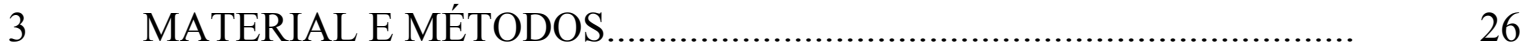




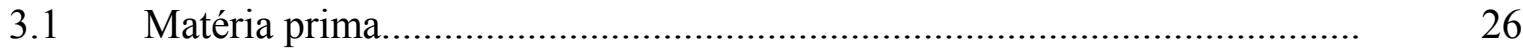

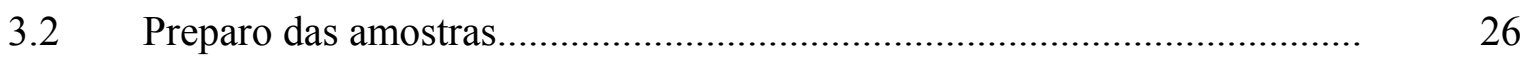

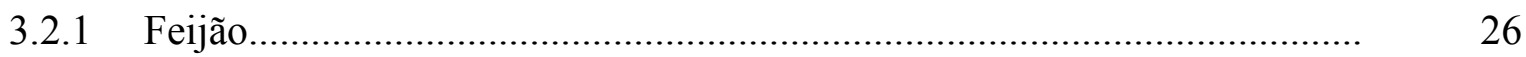

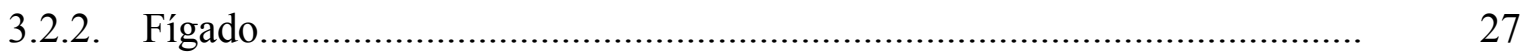

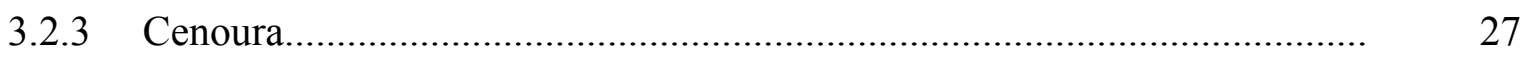

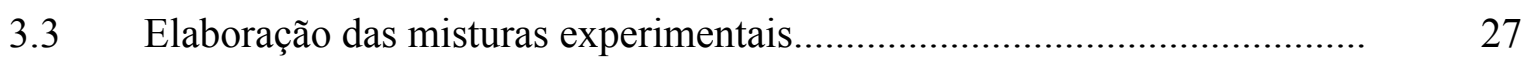

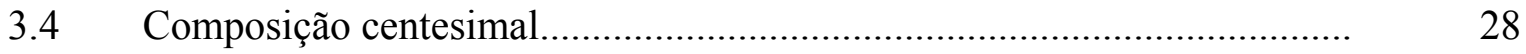

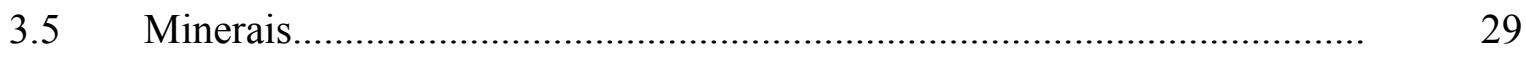

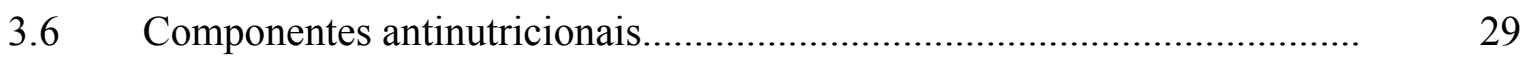

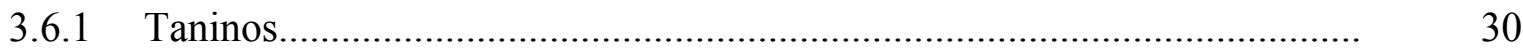

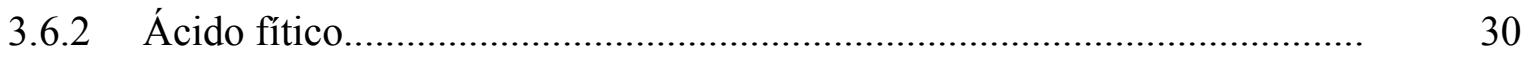

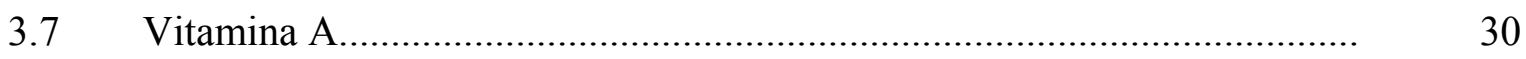

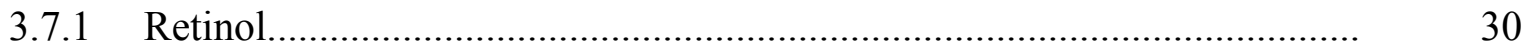

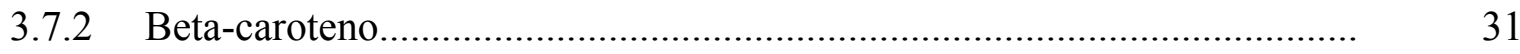

3.8 Ferro heme e ferro não-heme......................................................... 31

3.8.1 Determinação do ferro heme............................................................. 31

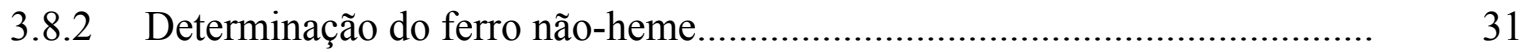

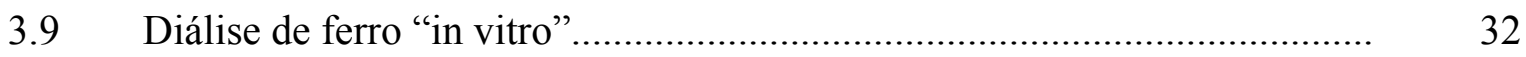

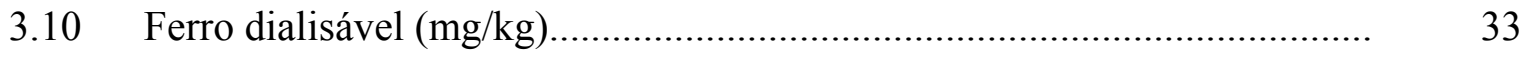

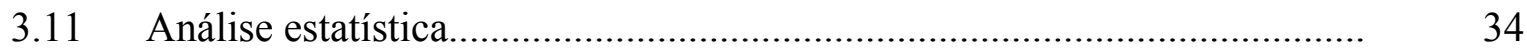

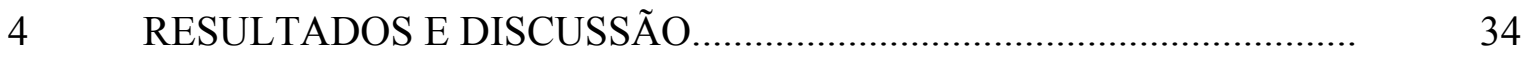

4.1 Composição centesimal.................................................................. 34

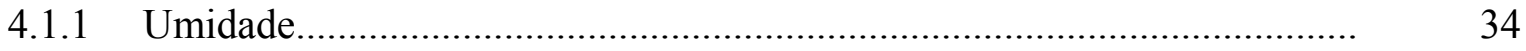

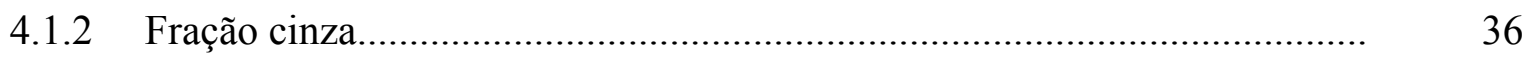

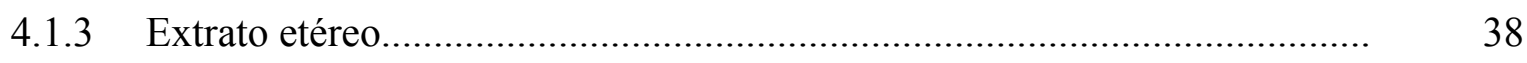

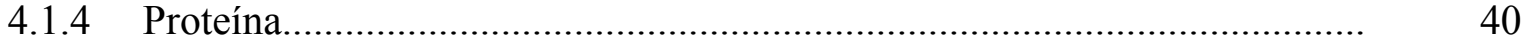

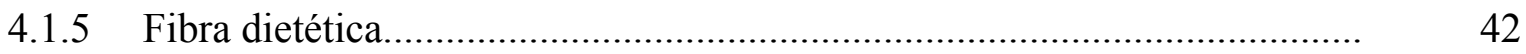

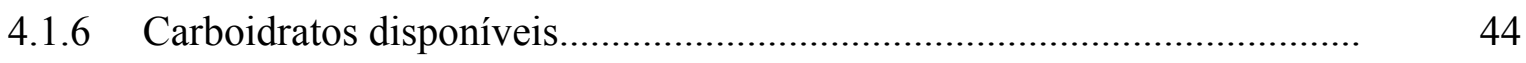

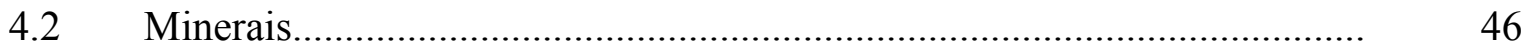

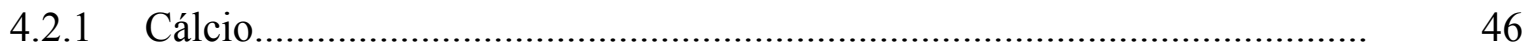




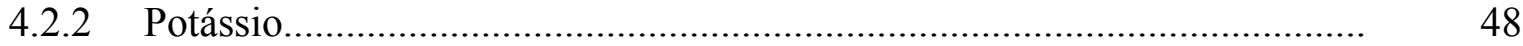

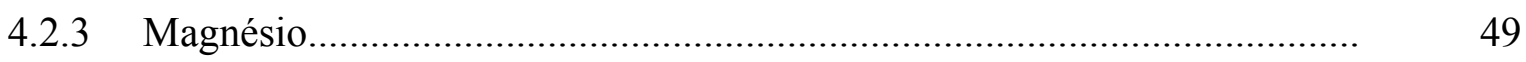

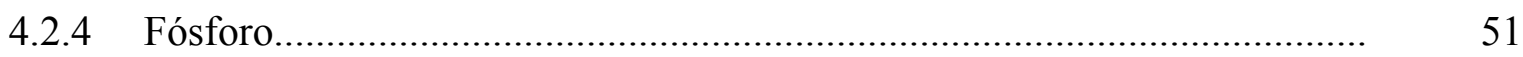

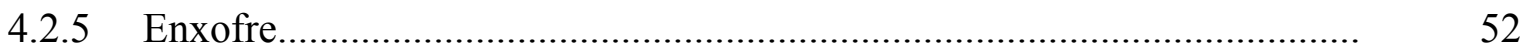

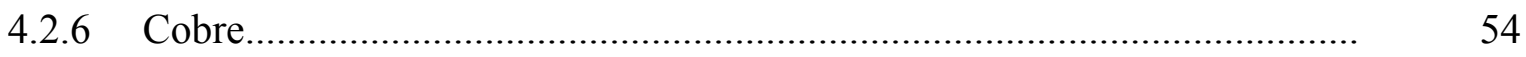

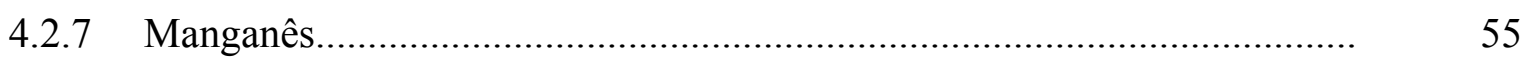

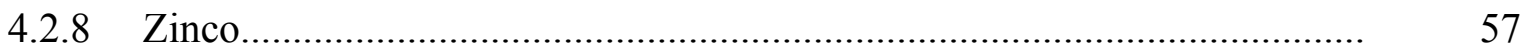

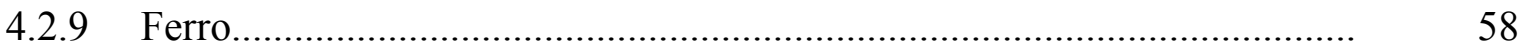

4.3 Antinutricionais: taninos e ácido fítico......................................................... 60

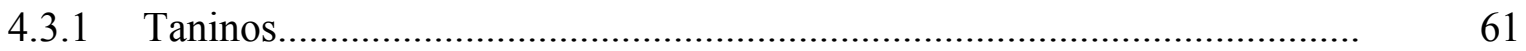

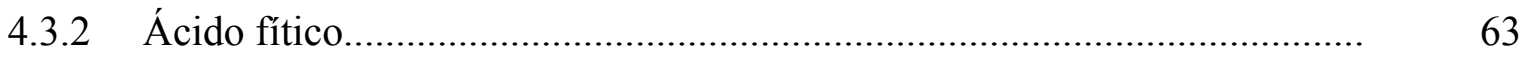

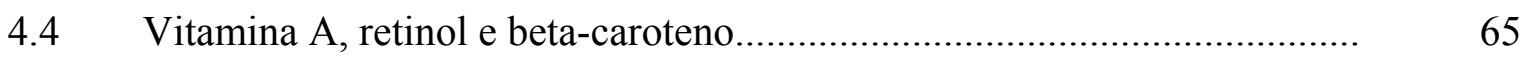

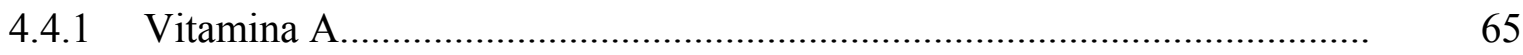

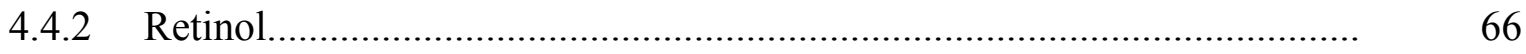

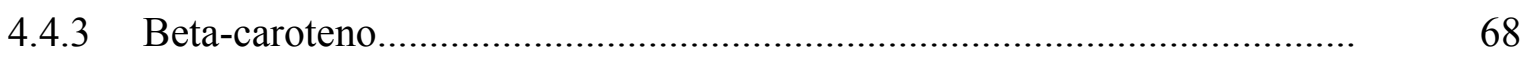

4.5 Ferro heme e não-heme....................................................................

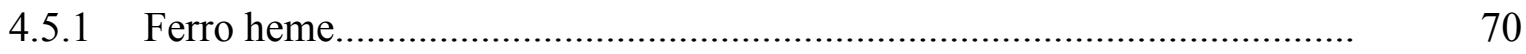

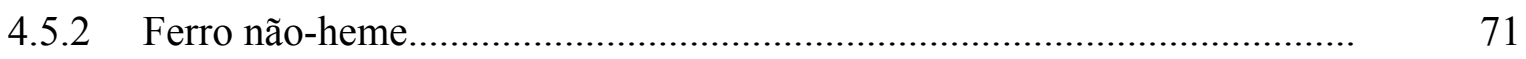

4.6 Diálise de ferro "in vitro".......................................................................

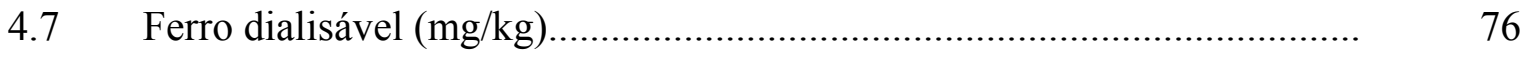

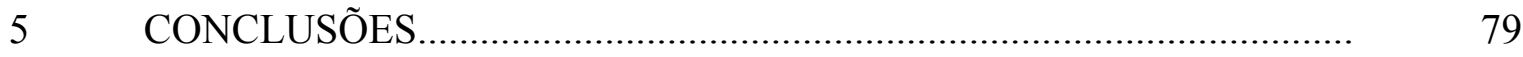

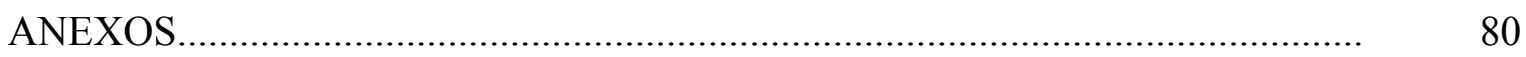

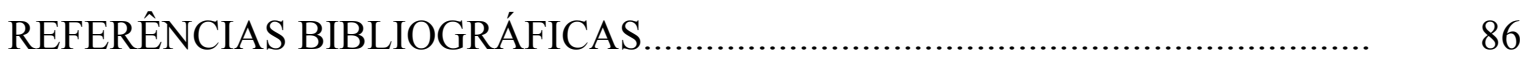




\section{LISTA DE FIGURAS}

Página

1 Porcentagem de umidade, em base úmida.............................................. 35

2 Porcentagem da fração cinza, em base úmida............................................. 36

3 Porcentagem de extrato etéreo, em base úmida.............................................. 38

4 Porcentagem de proteína, em base úmida................................................. 40

5 Porcentagem de fibra dietética, em base úmida....................................... 42

6 Porcentagem de carboidratos, em base úmida............................................. 44

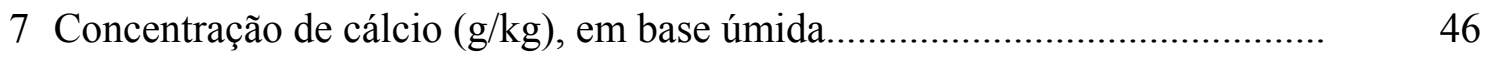

8 Concentração de potássio $(\mathrm{g} / \mathrm{kg})$, em base úmida........................................ 48

9 Concentração de magnésio $(\mathrm{g} / \mathrm{kg})$, em base úmida................................... 50

10 Concentração de fósforo $(\mathrm{g} / \mathrm{kg})$, em base úmida......................................... 51

11 Concentração de enxofre $(\mathrm{g} / \mathrm{kg})$, em base úmida.......................................... 53

12 Concentração de cobre $(\mathrm{mg} / \mathrm{kg})$, em base úmida.......................................... 54

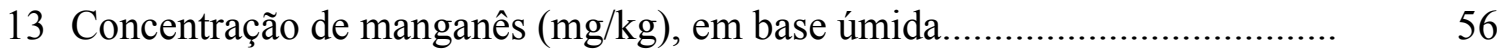

14 Concentração de zinco $(\mathrm{mg} / \mathrm{kg})$, em base úmida......................................... 57

15 Concentração de ferro $(\mathrm{mg} / \mathrm{kg})$, em base úmida........................................... 59 


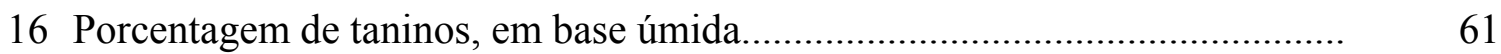

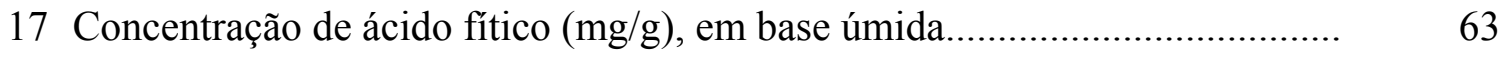

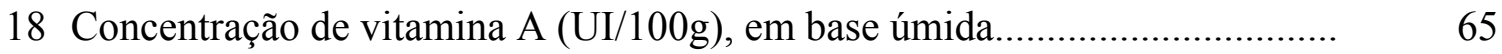

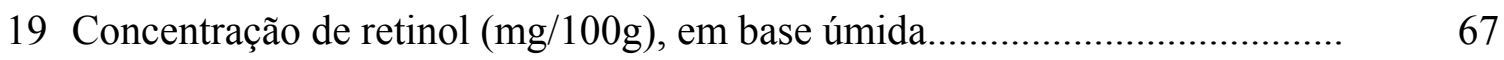

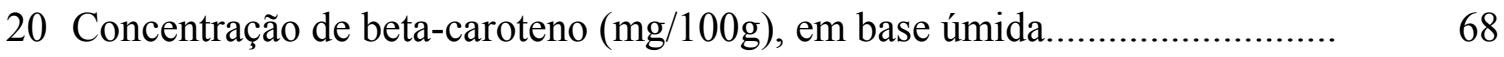

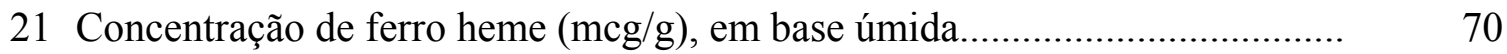

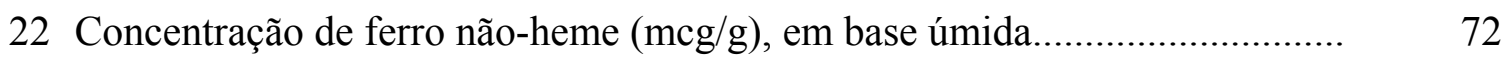

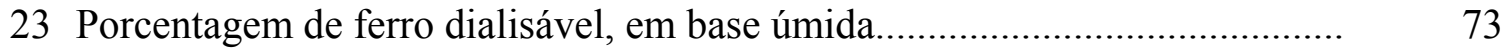

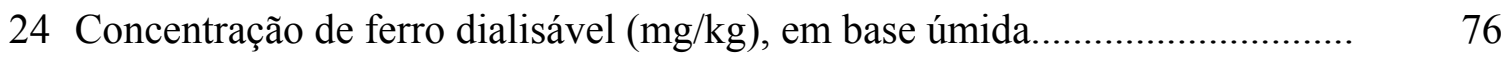




\section{LISTA DE TABELAS}

Página

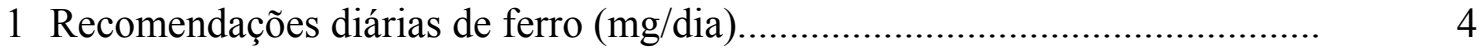

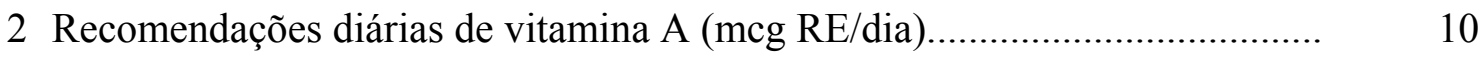




\title{
COMPARAÇÃO ENTRE A DISPONIBILIDADE DE FERRO NA PRESENÇA DE VITAMINA A E BETA-CAROTENO EM ALIMENTOS E MEDICAMENTOS
}

\author{
Autora: FABIANA CRISTINA CAMARGO MARTINI \\ Orientadora Prof ${ }^{\mathrm{a}}$. SOLANGE GUIDOLIN CANNIATTI BRAZACA
}

\section{RESUMO}

O ferro e a vitamina A são nutrientes essenciais para o desenvolvimento e a manutenção do organismo. Este trabalho teve por objetivos verificar a disponibilidade de ferro na presença de vitamina $A$, presente nos alimentos: feijão comum (F), fígado bovino (Fi) e cenoura (C) e medicamentos: Fer-In-Sol ${ }^{\circledR}$ (Fer), $\operatorname{Arovit}^{\circledR}$ (A) e Neutrofer ${ }^{\circledR}(\mathrm{N})$, bem como suas combinações; quantificar a composição centesimal, minerais, antinutricionais, ferro heme e não-heme, retinol e beta-caroteno, dos alimentos e suas combinações com medicamentos. A quantidade de medicamentos adicionada aos alimentos foi calculada em função de uma prévia análise da composição de ferro e betacaroteno dos alimentos. As quantidades de ferro sulfato (Fer1) e ferro aminoquelato (N1) correspondem à quantidade de ferro encontrada na amostra de feijão. Fer2 e N2 correspondem à concentração de ferro encontrada na amostra de fígado. A vitamina $\mathrm{A}$ (A1) foi calculada através da conversão do beta-caroteno da cenoura. Dos alimentos e medicamentos, originaram as seguintes combinações: $(\mathrm{C}),(\mathrm{C}+\mathrm{A} 1),(\mathrm{C}+\mathrm{N} 1),(\mathrm{C}+\mathrm{N} 2)$, $(\mathrm{C}+\mathrm{Fer} 1),(\mathrm{C}+\mathrm{Fer} 2),(\mathrm{C}+\mathrm{F}),(\mathrm{F}),(\mathrm{F}+\mathrm{A} 1),(\mathrm{F}+\mathrm{Fer} 2),(\mathrm{F}+\mathrm{N} 2),(\mathrm{F}+\mathrm{Fi}),(\mathrm{Fi}),(\mathrm{Fi}+\mathrm{A} 1)$, 
(Fi+Fer1), (Fi+N1) e $(\mathrm{Fi}+\mathrm{C})$. Os resultados obtidos foram analisados estatisticamente através do teste de Tukey (5\%), empregando-se o programa SAS. A amostra (C) apresentou maior umidade $(88,12 \%)$ e beta-caroteno $(6,42 \mathrm{mg} / 100 \mathrm{~g})$. A amostra (F), maior concentração de carboidratos (10,68 \%), fibra dietética (7,47 \%), sendo também determinados os taninos $(0,05 \%)$ e ácido fítico $(2,71 \mathrm{mg} / \mathrm{g})$. A amostra $(\mathrm{Fi})$, maior concentração de fração cinza $(2,13 \%)$, extrato etéreo $(7,01 \%)$, proteínas $(31,35 \%)$, sendo também determinados vitamina A (71285 UI/100g), ferro heme $(31,85 \mathrm{mcg} / \mathrm{g})$ e concentração de ferro dialisável $(8,10 \mathrm{mg} / \mathrm{kg})$. Foram avaliadas as concentrações de minerais. As concentrações de vitamina A das amostras variaram de $2247 \mathrm{UI} / 100 \mathrm{~g}$ $(\mathrm{C}+\mathrm{F})$ a $71285 \mathrm{UI} / 100 \mathrm{~g}(\mathrm{Fi})$, e foram calculadas através da conversão da concentração de retinol e de beta-caroteno das amostras analisadas. Foram determinadas as quantidades de ferro heme e não-heme, somente para as amostras contendo fígado. Esses valores variaram de $13,06 \mathrm{mcg} / \mathrm{g}(\mathrm{F}+\mathrm{Fi})$ a $31,85 \mathrm{mcg} / \mathrm{g}(\mathrm{Fi})$ e $2,54 \mathrm{mcg} / \mathrm{g}(\mathrm{Fi}+\mathrm{C})$ a 9,48 $\mathrm{mcg} / \mathrm{g}$ (Fi+Fer1), respectivamente. Para quantificar a porcentagem de ferro disponível das amostras, foi realizada a diálise do ferro "in vitro". Para o cálculo da diálise, nas amostras contendo fígado, considerou-se o ferro não-heme, mais $25 \%$ da concentração de ferro heme das amostras. A concentração de ferro dialisável variou de $0,12 \mathrm{mg} / \mathrm{kg}(\mathrm{F})$ a $8,10 \mathrm{mg} / \mathrm{kg}$ (Fi). Não houve influência de outros minerais avaliados sobre a disponibilidade de ferro. Os antinutricionais taninos e ácido fítico exerceram efeito inibitório sobre a disponibilidade de ferro. A vitamina A e o beta-caroteno exerceram efeito positivo sobre a porcentagem de diálise do ferro. A cenoura e o fígado apresentaram melhor porcentagem de ferro dialisável do que os respectivos medicamentos em concentrações semelhantes. Portanto, pode-se concluir que houve influência da vitamina A sobre a diálise do ferro, sendo as misturas contendo fígado as que obtiveram melhores concentrações de ferro dialisável, e que, de acordo com as quantidades necessárias para se atingir as exigências diárias de ferro, são viáveis ao consumo. 


\title{
COMPARISON BETWEEN IRON AVAILABILITY IN PRESENCE OF VITAMIN A AND BETA-CAROTENE IN FOODS AND MEDICINES
}

\author{
Author: FABIANA CRISTINA CAMARGO MARTINI \\ Advisor: Prof. SOLANGE GUIDOLIN CANNIATTI BRAZACA
}

\section{SUMMARY}

Iron and vitamin A are essential nutrients for the development and maintenance of human body. This study aims to check the availability of iron in presence of vitamin A, in carrot, bean, bovine liver and in the medicines Arovit ${ }^{\mathrm{TM}}$ Neutrofer ${ }^{\mathrm{TM}}$ and Fer-In$\mathrm{Sol}^{\mathrm{TM}}$, as well as in their combinations. Also it aimed to quantify the proximate composition, minerals, antinutritionals, heme and nonheme iron, retinol and betacarotene in foods and their combinations with medicines. The amount of medicines added to foods was figured based on a previous analysis of the iron and beta-carotene food composition. The amount of iron sulfate (Fer1) and iron aminoquelate (N1), corresponds to the amount of iron found in the bean samples. Fer2 and N2 correspond to the iron concentration found in the bovine liver samples. Vitamin A was figured through carrot beta-carotene conversion. The combination of foods and medicines showed: $(\mathrm{C})$, $(\mathrm{C}+\mathrm{A} 1),(\mathrm{C}+\mathrm{N} 1),(\mathrm{C}+\mathrm{N} 2),(\mathrm{C}+\mathrm{Fer} 1),(\mathrm{C}+\mathrm{Fer} 2),(\mathrm{C}+\mathrm{F}),(\mathrm{F}),(\mathrm{F}+\mathrm{A} 1),(\mathrm{F}+\mathrm{Fer} 2),(\mathrm{F}+\mathrm{N} 2)$, $(\mathrm{F}+\mathrm{Fi}),(\mathrm{Fi}),(\mathrm{Fi}+\mathrm{A} 1),(\mathrm{Fi}+\mathrm{Fer} 1),(\mathrm{Fi}+\mathrm{N} 1)$ and $(\mathrm{Fi}+\mathrm{C})$. The results obtained were analyzed statistically through the Tukey test (5\%), making use of the SAS System. The carrot samples showed higher moisture $(88,12 \%)$ and beta-carotene $(6,42 \mathrm{mg} / 100 \mathrm{~g})$. The bean samples showed higher concentration of carbohydrates (10,68\%), dietetic 
fiber $(7,47 \%)$, being also determined the tannins $(0,05 \%)$ and phytic acid $(2,71 \mathrm{mg} / \mathrm{g})$. The bovine liver samples showed higher concentration of ash $(2,13 \%)$, crude fat $(7,01$ $\%)$, proteins $(31,35 \%)$, being also determined vitamin A (71285 UI/100g), heme iron $(31,85 \mathrm{mcg} / \mathrm{g})$ and iron available. Mineral concentrations were also measured. The vitamin A concentrations ranged from $2247 \mathrm{UI} / 100 \mathrm{~g}(\mathrm{C}+\mathrm{F})$ to $71285 \mathrm{UI} / 100 \mathrm{~g}$ (Fi) and it was figured through the conversion of the retinol and beta-carotene concentration of the samples. The heme and nonheme iron amount were determined only in the liver sample, and ranged from $13,06 \mathrm{mcg} / \mathrm{g}(\mathrm{F}+\mathrm{Fi})$ to $31,85 \mathrm{mcg} / \mathrm{g}(\mathrm{Fi})$ and from $2,45 \mathrm{mcg} / \mathrm{g}(\mathrm{Fi}+\mathrm{C})$ to $9,48 \mathrm{mcg} / \mathrm{g}$ (Fi+Fer1) respectively. The "in vitro" iron dialyse was used to quantify the amount of iron available in the samples. In the liver samples, it was considered the nonheme iron plus $25 \%$ of the heme iron part. The iron available concentration ranged from $0,12 \mathrm{mg} / \mathrm{kg}(\mathrm{F})$ to $8,10 \mathrm{mg} / \mathrm{kg}$ (Fi). There was no minerals influence on the iron availability. The antinutricional tannins and phytic acid had an inhibitor effect on the iron availability. Vitamin $\mathrm{A}$ and beta-carotene had a positive effect on the iron availability. The carrot and bovine liver showed better iron dialyze percentage than their respective medicines of similar concentration. Therefore, it was concluded that vitamin A had a positive effect on the iron availability and, being the bovine liver samples the ones which showed better iron available concentration and are feasible to consume according to the daily needs of iron. 


\section{INTRODUÇÃO}

Anemia ferropriva e hipovitaminose A são problemas comuns entre a população. A maior ocorrência se dá em classes com condições sócio - econômicas precárias, sendo geralmente as crianças e gestantes as mais acometidas.

O ferro é um elemento essencial para os processos metabólicos como transporte de oxigênio, metabolismo oxidativo e crescimento celular. A vitamina A é essencial para visão, crescimento dos ossos, reprodução e integridade do sistema imune. Deficiências dessa vitamina resultam em problemas de pele e sintomas de cegueira noturna, que podem evoluir para cegueira definitiva. A anemia ferropriva tem por principal causa a ingestão insuficiente, perda excessiva ou a absorção inadequada de ferro (Silva, 1994). $\mathrm{A}$ associação entre ferro e vitamina $\mathrm{C}$ no combate à anemia ferropriva vem sendo muito usada, devido à capacidade do ácido ascórbico em promover a absorção do ferro.

Recentemente, estudos têm mostrado que a vitamina A tem grande importância sobre as condições hematológicas do ferro no organismo. Deficiência dessa vitamina afeta o transporte de ferro, proporcionando baixa dosagem de ferro no soro e elevada concentração nos depósitos de armazenamento, principalmente no fígado, o que resulta em uma condição com características de ferropriva que, no entanto, só responde à medicação à base de ferro, após uma suplementação vitamínica (Mejia et al., 1979; Layrisse et al., 1997; Lynch, 1997).

Dentre as suas funções, a vitamina A também atua melhorando a absorção do ferro da dieta, principalmente em alimentos que apresentam componentes inibidores da absorção de ferro não-heme, tais como os cereais e as leguminosas. Essa ação tem grande importância, especialmente naquelas regiões em que os cereais e leguminosas constituem a base da alimentação (Garcia-Casal et al., 1998). 
A eficácia de um programa de suplementação de ferro, em regiões endêmicas, poderá ser prejudicada caso a população seja deficiente também em vitamina A. Dessa forma, a associação entre ferro e vitamina A, seja na dieta ou na forma medicamentosa, deverá atuar de maneira mais eficiente no combate à anemia do que a utilização de cada componente separadamente.

Devido aos efeitos deletérios que a deficiência em ferro tem sobre a saúde e o desenvolvimento intelectual, especialmente das crianças, e, sabendo-se da importância que a vitamina A representa no restabelecimento desse quadro clínico, é de grande interesse e contribuição verificar, dentre alimentos e medicamentos, qual é a forma mais eficaz de prevenção e combate a essas deficiências.

Este trabalho teve por objetivos verificar a disponibilidade de ferro na presença de vitamina $\mathrm{A}$, componentes de alimentos: feijão comum $(\mathrm{F})$, fígado bovino $(\mathrm{Fi})$ e cenoura (C) e combinações com medicamentos: Fer-In-Sol ${ }^{\circledR}($ Fer $), \operatorname{Arovit}^{\circledR}(\mathrm{A})$ e $\operatorname{Neutrofer}^{\circledR}(\mathrm{N})$; quantificar a composição centesimal, minerais, antinutricionais, ferro-heme e não heme, retinol e beta-caroteno dos alimentos e suas combinações com medicamentos. 


\section{REVISÃO DA LITERATURA}

\subsection{Ferro e sua importância nutricional}

O ferro é um dos elementos mais importantes no metabolismo das células vivas (Silva, 1994). Constituinte normal do corpo humano, o ferro se distribui amplamente tanto na forma orgânica quanto inorgânica, totalizando cerca de 3,5 a 4,5 g em um indivíduo adulto. Setenta por cento desse total são considerados ferro funcional, por desempenhar funções fisiológicas e ocorre na hemoglobina, mioglobina e enzimas intracelulares. Os $30 \%$ restantes constituem o ferro de armazenamento, ocorrendo na forma de ferritina ou hemosiderina (Korolkovas \& Burckhalter, 1988).

A absorção do ferro pelo organismo é controlada, a fim de evitar o seu excesso, pois tanto um suprimento inadequado de ferro nos tecidos, quanto um acúmulo excessivo no organismo conduzem à morbidade (Silva, 1994). Da mesma maneira, os componentes da dieta e o estado nutricional do indivíduo têm significativa influência sobre a absorção de ferro da dieta (Martínez et al., 1999). Em condições normais, um ótimo padrão alimentar contém 10 a $20 \mathrm{mg}$ de ferro, dos quais o indivíduo absorve cerca de 5 a $10 \%$. Essa absorção compensa perdas de ferro através da descamação de células da pele, vias digestivas, urinárias e respiratórias (Silva, 1994 ).

A tabela 1 apresenta as recomendações diárias de ferro expressas em $\mathrm{mg} / \mathrm{dia}$, de acordo com o National Research Council (NRC, 1989).

O ferro está amplamente distribuído em alimentos. Alguns tecidos animais contêm ferro na forma heme, ferritina e hemosiderina. Ovos e laticínios podem conter proteínas específicas como a lactoferrina e a ovotransferrina. As plantas contêm ferro na forma de metaloproteínas, planta ferritina e ferro complexado com componentes estruturais. De outra maneira, o ferro pode estar presente nos alimentos como um 
contaminante inorgânico, ou ainda, na forma de compostos de ferro adicionados durante o processamento com o objetivo de fortificação da dieta (Lynch, 1997).

Tabela 1. Recomendações diárias de ferro (mg/dia) de acordo com o National Research Council (NRC, 1989).

\begin{tabular}{|c|c|c|c|}
\hline Idade & Ferro (mg/dia) & Idade & Ferro $(\mathrm{mg} /$ dia $)$ \\
\hline Infância & & Crianças & \\
\hline $0-5$ meses & 6 & $1-3$ anos & 10 \\
\hline $5-10$ meses & 10 & $4-10$ anos & 10 \\
\hline Mulheres & & Gravidez & 30 \\
\hline $11-50$ anos & 15 & & \\
\hline Lactação primeiros & 15 & Lactação após & 15 \\
\hline 6 meses & & 6 meses & \\
\hline \multicolumn{4}{|l|}{ Homens } \\
\hline $11-18$ anos & 12 & & \\
\hline $19>51$ anos & 10 & & \\
\hline
\end{tabular}

Fonte: NRC, (1989)

\subsubsection{Absorção do ferro}

Em seres humanos, o ferro é absorvido através das células da mucosa intestinal, principalmente no duodeno, e é transportado na corrente sangüínea e fluido extracelular ligado a uma proteína plasmática denominada transferrina, a seguir, é estocado intracelularmente na forma de ferritina (Silva, 1994). Apesar de não ocorrer absorção a nível gástrico, o estômago libera ácido clorídrico e gastrina, ajudando a liberar o ferro do complexo ferro-proteína, e também, solubilizando-o, ao reduzi-lo da forma férrica para a 
ferrosa. A nível intestinal, ocorre aumento do $\mathrm{pH}$ devido à presença de bicarbonato, favorecendo a oxidação para forma férrica, conseqüentemente, diminuindo a absorção. Por outro lado, a presença de enzimas pancreáticas favorecem a liberação do ferro dos complexos ferro-proteína, tornando-o disponível para a absorção (Garcia-Casal \& Layrisse, 1998).

\subsubsection{Forma química: ferro heme e não-heme}

O ferro pode estar presente nos alimentos de duas formas: a forma heme, que é predominantemente encontrada em carnes e vísceras sob a forma de hemoglobina e mioglobina, e a forma não-heme, que é encontrada em alimentos de origem vegetal (Bianchi et al., 1992).

De acordo com a forma, o ferro é absorvido por caminhos independentes na mucosa intestinal. O ferro heme é solúvel nas condições do intestino delgado, sendo facilmente absorvido pela mucosa intestinal sob a forma ferro porfirina intacta; dentro da célula da mucosa, o ferro é liberado pela ação da enzima heme-oxigenase, seguindo, a partir daí, os mesmos caminhos do ferro não-heme. Por causa desse mecanismo absortivo único e sua solubilidade elevada no $\mathrm{pH}$ intestinal, o ferro heme não é afetado por fatores químicos ou alimentares que podem alterar a disponibilidade do ferro nãoheme. Por essa razão, a absorção do ferro heme é alta, cerca de $15 \%$ no indivíduo normal e $35 \%$ naqueles com baixa reserva de ferro (Cook, 1983).

Em contraste, a absorção de ferro não-heme é menor, cerca de 1 a $5 \%$ e varia substancialmente em função da presença de fatores químicos e alimentícios. Existem três proteínas envolvidas na transferência do ferro inorgânico (não-heme) da luz do intestino para o citossol. Inicialmente, as mucinas ligam-se ao ferro no $\mathrm{pH}$ do estômago para garantir a condição de solubilidade. Na superfície da mucosa intestinal o ferro ligase à integrina que facilita a passagem através da membrana celular. A proteína mobilferrina aceita o ferro no seu interior e o libera para a ferritina ou para a transferrina. Normalmente, uma parcela do ferro que penetra é liberado para a transferrina a maior parte é depositada sob a forma de ferritina e parte é perdida na descamação das células mucosas (Cotran et al., 1996; Bianchi et al., 1992). 


\subsubsection{Fatores que afetam a disponibilidade do ferro não-heme}

A quantidade total do ferro de um alimento ou dieta não indica a quantidade que será biodisponível, porque existem vários fatores que influenciam a absorção e utilização desse mineral. Dessa forma, para garantir suporte adequado de ferro, é necessário conhecer e diferenciar a quantidade total de ferro da quantidade biodisponível (Young \& Janghorbani, 1981). A quantidade de ferro biodisponível está relacionada à medida da fração de ferro alimentar capaz de ser absorvida pelo trato gastrointestinal e subseqüentemente armazenada e incorporada ao ferro heme (Consaul \& Lee, 1983).

A biodisponibilidade do ferro na dieta é tão importante quanto o teor global. Deficiência de ferro pode resultar de: carência dietética, dificuldade de absorção, aumento das necessidades ou perdas hemorrágicas.

Sabe-se que a disponibilidade de ferro muda de acordo com certos estados fisiológicos. Lactentes, crianças, adolescentes e mulheres, especialmente gestantes, possuem maiores necessidades, com conseqüente aumento da absorção (Cotran et al., 1996).

Quanto ao estado nutricional, a situação é de extrema importância, principalmente em países em desenvolvimento, onde em muitas regiões, o acesso aos alimentos é precário e as dietas são predominantemente vegetarianas, de absorção precária (Cotran et al., 1996).

Perdas hemorrágicas crônicas provenientes de hemorragias externas depletam as reservas de ferro, como por exemplo, as decorrentes a partir do tubo gastrintestinal (úlceras pépticas, gastrites hemorrágicas, carcinomas ou parasitas), a partir do tubo urinário (tumores renais, pélvicos ou vesicais) ou do tubo genital (menorragia, câncer uterino) (Cotran et al., 1996).

Normalmente o ferro é absorvido pelo organismo através da dieta. Fatores presentes no lúmen intestinal exercem forte influência sobre a habilidade do organismo em extrair ferro dos reservatórios de ferro não-heme. A secreção de ácido gástrico, a retenção e a mistura dos alimentos no estômago são necessários para otimizar a absorção. O ácido gástrico é importante para a solubilização do ferro não-heme no 
alimento. A absorção do ferro não-heme é máxima, quando um sal de ferro solúvel é administrado em jejum a um indivíduo com deficiência em ferro (Lynch, 1997).

$\mathrm{O}$ estado de oxidação do ferro varia de acordo com o ambiente químico. Na água e nos alimentos, existem estados de oxidação $\left(\mathrm{Fe}^{+2}\right)$ e $\left(\mathrm{Fe}^{+3}\right)$ que são os mais estáveis nesses meios. A maior solubilidade dos sais ferrosos sobre os férricos é, em parte, responsável pela maior biodisponibilidade dos íons ferrosos no trato gastrointestinal (Lee \& Clydesdale, 1979).

No meio ácido, os íons férricos e ferrosos não ocorrem no estado livre, são hidratados respectivamente para $\mathrm{Fe}\left(\mathrm{H}_{2} \mathrm{O}\right)_{6}{ }^{+2}$ e $\mathrm{Fe}\left(\mathrm{H}_{2} \mathrm{O}\right)_{6}{ }^{+3}$. Com o aumento do $\mathrm{pH}$, as moléculas de água doam prótons para formar hidróxidos insolúveis de ferro correspondentes. No pH 1 do estômago, o ferro é solúvel. No pH 7 há formação de hidróxidos insolúveis. Íons férricos, no meio alcalino intestinal, precipitam irreversivelmente e as macromoléculas resultantes de hidróxido férrico são muito grandes para serem absorvidas. A precipitação do ferro, formando complexos insolúveis em $\mathrm{pH}$ alcalino, pode ser inibida por agentes complexante ou quelante que formam complexos solúveis. A maior absorção dos sais ferrosos sobre os férricos parte da hipótese de que os sais férricos deveriam primeiramente ser reduzidos a sais ferrosos (Lee \& Clydesdale, 1979).

Alguns componentes dos alimentos podem atuar tanto promovendo quanto inibindo a absorção de ferro não-heme. $O$ balanço entre esses fatores determina a biodisponibilidade de ferro não-heme nas refeições. Esses componentes são chamados de promotores e inibidores da absorção de ferro.

\subsubsection{Promotores da absorção de ferro não-heme}

Fatores que mantêm a solubilidade do ferro, em virtude do aumento do $\mathrm{pH}$, como o estado de oxidação (forma ferrosa), as mucinas secretadas pela mucosa e agentes quelantes como o ácido áscórbico, por exemplo, são de grande importância para promover a absorção de ferro não-heme (MacPhail, 2001).

O ácido ascórbico, quando ingerido juntamente com o ferro, potencializa sua absorção, mantendo-o na forma de quelato solúvel no intestino delgado (Mahan \& Arlin, 
1995). Outros ácidos orgânicos, como ácido cítrico e o málico, também estão associados ao aumento da biodisponibilidade de ferro (Lynch, 1997).

As proteínas de origem animal, principalmente a carne em si, possuem um efeito promotor na absorção de ferro não-heme, entretanto, as proteínas contidas nos ovos, queijo e leite, reduzem significativamente a absorção de ferro (Mahan \& Arlin, 1995). No entanto, o mecanismo pelo qual as proteínas melhoram a absorção de ferro nãoheme, não é totalmente conhecido. Em revisão realizada por Lynch (1997), foi sugerido que os peptídeos, liberados durante a digestão proteolítica pela pepsina no estômago, podem melhorar a solubilidade do ferro inorgânico. Esse aumento da absorção pode ser atribuído à propriedade dos aminoácidos, especialmente a cisteína, a qual se ligaria ao ferro inorgânico, mantendo-o solúvel e disponível para a absorção.

\subsubsection{Inibidores da absorção de ferro não-heme}

Dentre os inibidores da absorção de ferro não-heme, os principais são os fitatos contidos em cereais, leguminosas e na maioria dos alimentos ricos em fibras, e os polifenóis encontrados em alta concentração em chás e café (Layrisse et al., 1997). De acordo com Torre et al. (1991), o ácido fítico é capaz de interagir com proteínas e íons metálicos, formando complexos insolúveis e indisponíveis para absorção. Dentre os polifenóis, os taninos são os mais importantes, agem através da formação de complexos entre os grupos hidroxila dos componentes fenólicos e a molécula de ferro, tornando o ferro indisponível para absorção (Lynch, 1997).

A adição de cálcio, seja na forma de leite ou sal inorgânico a um alimento, reduz a porcentagem de absorção de ferro não-heme (Lynch, 1997). Como também constatado por Cook et al. (1991), o cálcio presente atua como inibidor da absorção de ferro nãoheme da dieta ou de medicamentos à base de sulfato ferroso, quando ingerido em quantidades maiores do que $500 \mathrm{mg}$. Outros minerais que possuem ações inibitórias sobre a absorção de ferro não-heme, devido a propriedades físico-químicas semelhantes, são: o manganês, quando presente em proporção 300 vezes maior que o ferro, e o zinco quando o conteúdo é 5 vezes maior que o conteúdo de ferro (Rossander-Hulten et al., 1991). 


\subsection{Vitamina A e sua importância nutricional}

A vitamina A tem importante papel na mobilização do ferro no organismo, além de ser um nutriente de extrema importância para visão, crescimento dos ossos, diferenciação celular, reprodução e integridade do sistema imune (Silva, 1994).

Pode ser obtida através de medicamentos, alimentos fortificados ou naturalmente ricos em vitamina A (Pee \& West, 1996). Em relação aos medicamentos, a vitamina A é comercializada tanto na forma livre, quanto na forma de ésteres: acetato, palmitato e propionato. A dose usual em casos de deficiência leve ou moderada é de 25.000 a 50.000 UI diárias; e em casos graves varia de 50.000 a 100.000 UI diárias, conforme a intensidade (Korolkovas \& Burckhalter, 1988).

De acordo com a fonte da dieta, os alimentos podem ser classificados em: ricos em vitamina A ou retinol, também chamados de vitamina A pré formada (leites e derivados, ovos, carnes vermelhas, aves, peixes e óleos), e alimentos fonte de provitamina A referente aos carotenóides, que são precursores biologicamente ativos (vegetais, frutas e folhas escuras) (Booth et al., 1992).

Dentre os carotenóides, o mais importante é o beta-caroteno, havendo também

outras formas como os alfa-caroteno e as alfa e beta-criptoxantinas, os quais têm aproximadamente metade da atividade do beta-caroteno (McCance \& Widdowson, 1994).

A tabela 2 apresenta a concentração de vitamina A expressa em mcg RE/dia, de acordo com as recomendações diárias descritas na NRC (1989). 
Tabela 2. Recomendações diárias de vitamina A (mcg RE/dia), de acordo com NRC (1989).

\begin{tabular}{|c|c|c|c|}
\hline Idade & $\begin{array}{c}\text { Vitamina A } \\
\text { (mcg RE/dia) }\end{array}$ & Idade & $\begin{array}{l}\text { Vitamina A } \\
\text { (mcg RE/dia) }\end{array}$ \\
\hline Infância & & Crianças & \\
\hline $0-5$ meses & 375 & $1-3$ anos & 400 \\
\hline \multirow[t]{2}{*}{$5-10$ meses } & 375 & $4-6$ anos & 500 \\
\hline & & $7-10$ anos & 700 \\
\hline Mulheres & & Gravidez & 800 \\
\hline $11-50$ anos & 800 & & \\
\hline Lactação primeiros & 1300 & Lactação após & 1200 \\
\hline 6 meses & & 6 meses & \\
\hline \multicolumn{4}{|l|}{ Homens } \\
\hline $11-51$ anos & 1000 & & \\
\hline
\end{tabular}

Fonte: NRC, (1989)

\subsubsection{Absorção da vitamina $\mathrm{A}$}

A absorção da vitamina $\mathrm{A}$ diz respeito à atividade pré-formada, do ácido retinóico e do beta-caroteno ou outros carotenóides, sendo que cerca de $90 \%$ da vitamina A pré-formada é absorvida sob a forma de ésteres de retinol, usualmente como retinil palmitato (Franco, 1992). Essa absorção é feita no intestino delgado e é facilitada pela presença de sais biliares, proteínas, lipase pancreática e alimentos gordurosos. Os sais biliares exercem efeito antioxidante, favorecendo a estabilização da vitamina A, além de veículo na passagem de vitamina A pela parede intestinal. A lipase pancreática é necessária para a hidrólise das emulsões de gorduras ou das soluções oleosas da 
vitamina. Os tocoferóis (vitamina E) protegem a vitamina A e os carotenóides contra processos oxidativos. Após a absorção, a vitamina é distribuída no organismo, sendo grande parte armazenada no fígado sob a forma de palmitato (Silva, 1994).

Perturbações que afetam o sistema biliar, como hepatite infecciosa e cirrose hepática, retardam a absorção de vitamina A. Carência de vitamina E, diabetes, fibrose cística do pâncreas, uso prolongado de antibióticos, gastroenterites, colites ulcerativas e constipação intestinal também prejudicam a absorção de vitamina A (Silva, 1994).

A vitamina A é melhor absorvida na forma de éster de retinol em solução oleosa. Dessa maneira, o éster passa intacto através da boca e estômago, sendo hidrolizado em retinol no intestino superior e é absorvido como micela na mucosa intestinal. A seguir, o retinol é transformado em éster, com cadeia de ácidos graxos, particularmente o palmítico, é incorporado e secretado na linfa. No fígado, o retinol é estocado para ser usado posteriormente. Sob condições dietéticas normais, a vitamina A é absorvida e armazenada eficientemente (Ross, $1999^{1}$, citado por Olson, 1999).

O uso a longo prazo de grandes doses dos derivados de vitamina A pode causar manifestações tóxicas, tais como lesões hepáticas, anomalias ósseas, alopécia, diplopia, náuseas, vômitos, diarréia, tonturas e cefaléia. Em mulheres grávidas, o tratamento a longo prazo com retinóides sintéticos induziu um aumento da incidência de defeitos congênitos nos embriões (Cotran et al., 1996).

\subsubsection{Equivalência}

O Conselho Nacional de Pesquisa dos Estados Unidos (NRC, 1980), recomenda as seguintes inter-relações para converter os teores de provitamina A em valores de vitamina A:

1 equivalente de retinol $=1 \mathrm{mcg}$ de retinol

$=6 \mathrm{mcg}$ de beta-caroteno

$=12 \mathrm{mcg}$ de outros carotenóides precursores de vitamina A

\footnotetext{
${ }^{1}$ ROSS, A.C. Vitamin A and retinoids. In: SHILS, M.E.; OLSON, J.A.; SHIKE, M.; ROSS, A.C. Modern nutrition in health and disease. Baltimore: Williams \& Wilkins, 1999. p.305-327.
} 
= 3,33 UI de atividade vitamínica A proveniente de retinol

$=10 \mathrm{UI}$ de atividade vitamínica A proveniente de

beta-caroteno

\subsubsection{Carotenóides}

No Brasil, diversos alimentos regionais são ricos em provitamina A, tais como o buriti, o azeite de dendê, a manga entre outros. O aumento do consumo desses alimentos poderia suprir as necessidade de vitamina A da população vulnerável. Da mesma forma, a fortificação de alimentos industrializados com forma sintética ou natural de provitamina A poderia contribuir para a adequação da quantidade de vitamina ingerida pela população de certas regiões carentes do Brasil ( Fávaro \& Dutra de Oliveira, 1999).

O beta-caroteno é a provitamina A mais abundante nos alimentos. Cerca de 10 a $50 \%$ do beta-caroteno total consumido é absorvido no trato gastrointestinal, e é parcialmente convertido em vitamina A dentro da parede intestinal. A eficiência da absorção do beta-caroteno diminui com o aumento da ingestão, e a conversão em vitamina A é regulada pelo "status" de vitamina A do indivíduo. Portanto, somente são convertidos em vitamina $\mathrm{A}$, quando requisitados pelo organismo, evitando uma possível toxidez (Wang, 1994², citado por Layrisse et al., 2000).

Quanto à biodisponibilidade dos carotenóides da dieta, conclui-se que o caroteno purificado em soluções oleosas é mais biodisponível do que o de folhas escuras e vegetais, e que a trituração e homogeneização dos alimentos aumentam a sua biodisponibilidade (Pee \& West, 1996). Inúmeros fatores influem na absorção e utilização das provitaminas pelo organismo, dentre eles: o tipo e a forma do carotenóide da dieta, consumo de gorduras, vitamina E, fibras, proteínas, zinco, bem como doenças e parasitoses (Rodriguez-Amaya, 1996).

Outros fatores que influenciam a biodisponibilidade dos carotenóides são: espécie do caroteno, ligação molecular, quantidade ingerida na refeição, matriz na qual o carotenóide é incorporado, modificações na absorção e interações (Pee \& West, 1996).

\footnotetext{
${ }^{2}$ WANG, L.D. Absorption and metabolism of $\beta$-caroteno. Journal of the American College of Nutrition, v.13, p.314-325, 1994.
} 
Deve-se salientar que nem todos os carotenóides atuam como precursores de vitamina A, ou seja, dos mais de 400 carotenóides conhecidos, apenas 50 a 60 podem ser convertidos teoricamente em vitamina A (Rodrigues-Amaya, 1985).

Devido ao alto custo dos alimentos de origem animal, e/ou costumes de certas regiões, cerca de $80 \%$ da vitamina A consumida na dieta da população é proveniente de fontes de provitamina A (Booth et al., 1992).

Dentre os carotenóides, beta-caroteno e beta-criptoxantinas são os principais. As frutas podem ser divididas em dois grandes grupos, aquelas onde o beta-caroteno é a provitamina em maior quantidade (buriti, goiaba, nêspera, abricó, manga, maracujá e acerola), e aquelas cuja beta-criptoxantina é predominante (cajá, nectarina, papaia, pêssego, pequi e pitanga). As beta-criptoxantinas possuem somente a metade da atividade do beta-caroteno. Outros carotenóides como gama-caroteno, alfa-caroteno e beta-zeacaroteno também estão presentes em algumas frutas, porém em baixas concentrações (Rodriguez-Amaya, 1996).

Heinonen et al. (1989) avaliaram frutas e vegetais quanto ao seu conteúdo em carotenóides pela técnica de cromatografia líquida de alta eficiência (HPLC) e verificaram que a cenoura $(7600 \mathrm{mcg} / 100 \mathrm{~g})$, o espinafre $(3300 \mathrm{mcg} / 100 \mathrm{~g})$ e o brócolis (1000 mcg/100 g) são ricos em beta-caroteno. Já o alfa-caroteno foi encontrado em cenoura (530 mcg/100 g), feijão (39 mcg/100 g), laranja (19 mcg/100 g), banana (12 $\mathrm{mcg} / 100 \mathrm{~g})$ e abacate $(19 \mathrm{mcg} / 100 \mathrm{~g})$. O gama-caroteno foi encontrado apenas em tomate. O licopeno foi predominante tanto em tomates $(3100 \mathrm{mcg} / 100 \mathrm{~g})$ quanto em ketchup (9900 mcg/100 g). Bureau \& Bushway (1986) determinaram por HPLC o conteúdo de carotenóides de frutas e vegetais nos Estados Unidos e encontraram para a cenoura 3789,67 mcg/100 g de alfa-caroteno e 7602,78 mcg/100 g de beta-caroteno nas amostras.

Heinonen (1990), avaliando o conteúdo de carotenóides e provitamina A de 19 cultivares de cenoura por HPLC, verificou que a quantidade de carotenóides encontrada foi de 4600 a $10300 \mathrm{mcg} / 100 \mathrm{~g}$.

De acordo com Franco (1992), a cenoura crua apresenta cerca de $1.100 \mathrm{mcg}$ de retinol, havendo pequena redução na cenoura cozida, ficando em torno de $900 \mathrm{mcg}$ de 
retinol/100 g. Vora et al. (1998) avaliaram a composição de 4 variedades de cenouras na Austrália e verificaram diferenças quanto ao conteúdo de beta-caroteno que vão de 4790 a $7240 \mathrm{mcg} / 100 \mathrm{~g}$. Já McCance \& Widdowson (1994) apresentaram diferenças entre os valores para raiz velha $(8115 \mathrm{mcg}$ de caroteno/100g) e nova $(5330 \mathrm{mcg}$ de caroteno/100g).

O estágio de maturidade, diferenças de cultivares e climáticas têm influência sobre a concentração de carotenóides. Em amostras de mamão papaia do Rio de Janeiro, a fruta madura apresentou uma média $(82 \mathrm{RE} / 100 \mathrm{~g})$ três vezes maior do que a fruta imatura $(26 \mathrm{RE} / 100 \mathrm{~g})$. Pequenas diferenças foram constatadas entre as variedades cultivadas em São Paulo (média de 99-110 RE/100 g) e na Bahia (120-190 RE/100 g). Essas diferenças também podem ser observadas entre duas variedades de cenoura provenientes de São Paulo (739 e $800 \mathrm{RE} / 100$ g). Influências climáticas foram claramente demonstradas em mamão formosa. Mamões do nordeste da Bahia apresentaram maior conteúdo de beta-caroteno e beta-criptoxantinas, conseqüentemente maior conteúdo de vitamina A (190 RE/100 g), do que aqueles provenientes de São Paulo (99 RE/100 g) (Rodriguez-Amaya, 1996).

\subsection{Interação entre Ferro e Vitamina A}

Em revisão realizada por Mejia et al. (1979), foi concluído que a deficiência de vitamina A pode levar à hematopoiese defeituosa, resultando em anemia com algumas das características de anemia ferropriva. Entretanto, esse tipo de anemia não responde à intervenção medicamentosa, podendo ocorrer, apesar de uma dieta com níveis adequados de ferro. Essa anemia só é revertida após a suplementação de vitamina A (Layrisse et al., 1997).

Em revisão realizada por Lynch (1997), foram encontrados estudos sugerindo que a deficiência de vitamina A prejudica a mobilização de ferro armazenado, resultando em concentrações disponíveis insuficientes para a medula óssea, tendo pouca influência na absorção de ferro.

Garcia-Casal et al. (1998) estudaram os efeitos da vitamina A e beta-caroteno sobre a absorção de ferro a partir de cereais enriquecidos. Esses autores verificaram um 
aumento significativo da absorção de ferro dos cereais, especialmente daqueles que apresentaram componentes inibidores como os fitatos. Segundo Layrisse et al. (1997), estudos espectrofotométricos e com cromatografia líquida de alta eficiência indicaram que a vitamina A se liga ao ferro liberado durante o processo digestivo e forma um complexo que atua como agente quelante, mantendo o ferro solúvel no lúmen intestinal e prevenindo o efeito inibitório dos fitatos e polifenóis sobre a absorção do ferro nãoheme. Em regiões mais pobres, onde se consome muitos cereais, leguminosas e tubérculos, a fortificação com vitamina A não somente previne a deficiência desta, como também potencializa a fortificação do ferro.

Alguns autores têm demonstrado a importância da suplementação conjunta de ferro e vitamina A sobre a melhora no "status" de ferro e condições hematológicas no organismo.

De acordo com Roodenburg et al. (1994), durante o desenvolvimento da deficiência de vitamina A, 4 estágios de mudanças no metabolismo do ferro podem ser observados: o primeiro estágio é caracterizado por leve queda na concentração de hemoglobina e volume de células compactadas. Durante o segundo e terceiro estágio, a absorção de ferro é aparentemente aumentada, e então, a concentração no fígado e baço é aumentada. Durante o quarto estágio, há aumento de ferro no rim e fêmur e há diminuição na capacidade de ligação do ferro total no plasma.

Mejia et al. (1979) estudaram os efeitos da deficiência de vitamina A sobre a absorção, retenção e distribuição de ${ }^{59} \mathrm{Fe}$ em ratos suplementados (6500 UI de palmitato de retinol por kg de dieta) e defícientes (ausência de vitamina A). Nenhuma diferença significativa na absorção de ${ }^{59} \mathrm{Fe}$ foi observada entre os dois grupos, porém a incorporação de ${ }^{59} \mathrm{Fe}$ nas células vermelhas foi significativamente reduzida em animais com deficiência em vitamina $\mathrm{A}$, havendo também significativa redução nos volumes de sangue e plasma. Com respeito à distribuição de ferro, os autores concluíram que em ratos deficientes, o ferro fica retido no fígado e baço e não é efetivamente liberado na circulação para ser utilizado pela medula.

Bloem et al. (1990) avaliaram um grupo de 134 crianças entre 3 a 9 anos de idade com sinais de xeroftalmia, em uma área da Tailândia, onde a deficiência de vitamina A e 
anemia são endêmicas. Sessenta e cinco crianças receberam vitamina A em cápsulas e 69 crianças serviram de controle. Cada cápsula continha $110 \mathrm{mg}$ de vitamina A. Após 2 semanas de suplementação, as crianças foram reexaminadas. Os exames mostraram que houve aumento nos níveis de retinol, hemoglobina, hematócrito, ferro no soro e saturação de transferrina, no grupo que recebeu suplementação vitamínica em comparação com o grupo controle. A concentração de ferritina não teve aumento significativo. Isso confirma que a melhora do metabolismo do ferro não foi resultado de melhora da absorção, mas provavelmente da mobilização de ferro disponível dos estoques e melhor utilização para formação de hemoglobina.

Os níveis de retinol e o "status" de ferro no plasma de 148 crianças entre 6 a 12 anos de idade foram avaliados por Stuijvenberg et al. (1997). Essas crianças receberam suplementação de ferro e vitamina $\mathrm{C}$ através da sopa distribuída na escola. Cada porção (160 ml) de sopa fortificada continha $60 \mathrm{mg}$ de fumarato ferroso e $100 \mathrm{mg}$ de vitamina C para promover melhor absorção do ferro. Os resultados mostraram que crianças em condições marginais de vitamina A $(<20 \mathrm{mcg} / \mathrm{dl})$ apresentaram níveis de ferro no soro, saturação de transferrina e hemoglobina, significativamente menores do que crianças com estado ótimo de vitamina $\mathrm{A}$ ( $\geq 40 \mathrm{mcg} / \mathrm{dl}$ ), ambos verificados antes e após as 15 semanas do programa de fortificação. No grupo deficiente em vitamina A, a ferritina do soro (que é um indicador do estoque de ferro) melhorou significativamente, enquanto os níveis de ferro no soro e saturação de transferrina continuaram baixos, o que indica que a absorção de ferro não é prejudicada pela deficiência de vitamina $\mathrm{A}$, mas sim, pela mobilização do ferro dos depósitos de armazenamento.

Mejía \& Chew (1988) dividiram em 4 grupos de tratamentos 99 crianças anêmicas com idades entre $1-8$ anos. Cada grupo recebeu durante 2 meses o seguinte tratamento: grupo I: suplementação com $10000 \mathrm{UI}(3,0 \mathrm{mg})$ de vitamina A ao dia em forma de gotas (Arovit ${ }^{\circledR}$, Hoffman- La Roche); grupo II: sulfato ferroso na forma de gotas, a níveis de $3 \mathrm{mg}$ de Fe/kg de peso corpóreo ao dia (Fer-In-Sol ${ }^{\circledR}$, Med Johnson); grupo III: receberam a associação de vitamina A e ferro como indicado no grupo I e II e, finalmente, grupo IV: que foi o grupo controle, no qual as crianças receberam placebo, simulando uma preparação contendo ferro. A suplementação vitamínica produziu 
significativa elevação dos níveis de retinol, hemoglobina, hematócrito, eritrócitos, ferro e porcentagem de saturação de transferrina no soro e não teve efeito sobre a capacidade de ligação total de ferro (TIBC) e ferritina sérica. A suplementação com ferro não alterou o retinol sérico. Entretanto, houve melhora hematológica e dos indicadores nutricionais de ferro, incluindo TIBC e ferritina sérica. De acordo com os autores, a administração simultânea de ferro e vitamina $\mathrm{A}$ apresentou níveis de ferro no soro maiores do que o grupo que recebeu ferro sozinho e, com isso, concluíram que a suplementação de vitamina $\mathrm{A}$ em crianças anêmicas e de baixo nível sócio-econômico pode aumentar os níveis de transferrina e favorecer a elevação dos níveis de ferro no plasma, suprindo diferentes tecidos do corpo.

Segundo Northrop-Clewes et al. (1996), o aumento na concentração de retinol sérico poderia conter os efeitos tóxicos do ferro em crianças que receberam suplementação à base de ferro $(15 \mathrm{mg} /$ dia $)$ durante 3 meses. A administração de ferro pode aumentar os riscos de infecções ou realçar as já existentes e, neste caso, as propriedades antiinfecciosas da vitamina A poderiam reduzir os riscos.

Shatrugna et al. (1997) avaliaram as condições de vitamina A no soro de mulheres grávidas entre 17 e 24 semanas de gestação, após suplementação com ferro e vitamina A e ácido fólico. Três grupos de suplementação foram avaliados, sendo que 60 mulheres receberam $60 \mathrm{mg}$ de sulfato ferroso, 60 receberam $120 \mathrm{mg}$ de sulfato ferroso, e 25 receberam $60 \mathrm{mg}$ de sulfato ferroso mais $6000 \mathrm{UI}$ de vitamina A. Essas doses foram administradas diariamente por um período de 12 a 16 semanas, e, em adição, todos os grupos receberam $500 \mathrm{mcg}$ de ácido fólico/dia. Os resultado demonstraram que $60 \mathrm{mg}$ de ferro sozinho poderia impedir a diminuição dos níveis vitamina $A$, entretanto, com o aumento da dose para $120 \mathrm{mg}$ de ferro, houve melhora das condições de vitamina A, quase similar à obtida através da suplementação de vitamina $\mathrm{A}$. De acordo com os autores, a suplementação de ferro para mulheres grávidas resulta não somente em melhora das condições de ferro, mas também do estado nutricional de vitamina $\mathrm{A}$, mesmo na ausência de suplementação dessa vitamina. As condições de vitamina A da mãe têm grande importância sobre as reservas de vitamina A do feto e, subseqüentemente, durante a lactação. 


\subsection{Leguminosas}

As leguminosas constituem importante fonte de proteína, energia e minerais para grande parte da população mundial, especialmente em países ou regiões onde, por vários motivos, a população tem pouco acesso à proteína de origem animal (Sales et al., 1980).

Em alguns países da América Latina, particularmente o Brasil, o feijão comum (Phaseolus vulgaris) é a leguminosa de maior importância nutricional, consumida diretamente como alimento humano (Sgarbieri et al., 1979). Outras leguminosas, como o grão de bico e a lentilha, com valor nutritivo semelhante ao feijão, não são totalmente aceitas, enquanto a soja, apesar de ser mais nutritiva, tem seu uso limitado na forma de grãos na alimentação humana, porém é adicionada em produtos industrializados sob a forma de concentrados, farinhas e outros produtos derivados (Haytowitz \& Matthews, 1989).

Em revisão realizada por Reyes-Moreno \& Paredes-López (1993), mostrou-se que os grãos de leguminosas são ricos em proteínas, carboidratos, vitaminas (especialmente do complexo B) e minerais. Mas também apresentam componentes antinutricionais, como os taninos e ácido fítico, os quais se ligam às proteínas e alguns minerais, como por exemplo o ferro, inibindo sua absorção e biodisponibilidade.

Martínez et al. (1998) avaliaram o feijão verde (Phaseolus vulgaris) de acordo com o tamanho das vagens e verificaram que a composição química e os fatores antinutricionais dependiam do tamanho do grão, e que o conteúdo de ácido fítico aumentava com o desenvolvimento do grão. Sammán et al. (1999) observaram diferenças significativas entre variedades de feijões quanto à composição centesimal e de minerais, de acordo com a região analisada.

De acordo com Antunes \& Sgarbieri (1980), o feijão comum apresenta os mesmos fatores antinutricionais que a soja, dentre eles, o fator antitripsina, fitohemaglutinas ou lectinas, agentes bocigênicos e de flatulência, variando apenas em quantidades. Esses autores também ressaltaram a necessidade do tratamento térmico para eliminar os agentes antinutricionais e da adição de um ou mais aminoácidos essenciais, tais como os sulfurados, para melhorar a qualidade protéica. Paredes-Lopez 
\& Harry (1989), avaliando as mudanças nos teores de antinutricionais do feijão comum durante o preparo do tempeh, verificaram que a maceração e a cocção dos grãos reduziu significativamente a quantidade dos antinutricionais. Já para Candela et al. (1997), o cozimento do feijão levou à diminuição do conteúdo de carboidratos e aumento do conteúdo de proteínas, levando também à perda em aminoácidos.

Oliveira et al. (2001) constataram que o processamento doméstico do feijão comum, ou seja, maceração prévia à cocção com descarte da água de maceração, ocasionou redução de $85 \%$ do conteúdo de fitatos e $88 \%$ de taninos.

Apesar da deficiência em aminoácidos sulfurados, o feijão possui alto teor de lisina, que é o aminoácido essencial limitante dos cereais. Em adição, as proteínas dos cereais, como o arroz, complementam as do feijão contribuindo com metionina e cisteína, formando portanto uma fonte de proteína vegetal de boa qualidade (Sgarbieri et al., 1979).

Elpo et al. (1998) avaliaram o teor de ferro de alguns alimentos da cesta básica do estado do Paraná e verificaram valores de 59,84 a 78,75 mg/kg de ferro para o feijão. Já Fonseca et al. (1974) encontraram em 14 variedades de feijão, dentre elas o preto, valores que variaram de 167,9 a $598,6 \mathrm{mg} / \mathrm{kg}$ do alimento.

Koehler et al. (1987) analisaram 36 cultivares representando 8 tipos de feijão seco (Phaseolus vulgaris) quanto ao conteúdo de ferro, e encontraram média de 6,89 mg de ferro/100g. Guzmán-Maldonado et al. (2000) compararam espécies de feijões comuns e selvagens e verificaram que o conteúdo de ferro foi de $100 \mathrm{mg} / \mathrm{kg}$ para o feijão comum, variando de 71 a $280 \mathrm{mg} / \mathrm{kg}$ para as espécies selvagens.

Sgarbieri et al. (1979) avaliaram o conteúdo e a biodisponibilidade do ferro de quatro variedades brasileiras de feijão: Rico 23, Rosinha-G2, Carioca e Piratã-1 e verificaram que o conteúdo de ferro foi de $9,93,7,93,8,70$ e $5,79 \mathrm{mg} / 100 \mathrm{~g}$ de feijão respectivamente. A disponibilidade absoluta do ferro foi determinada por um experimento de absorção de ferro conduzido com uma dieta de caseína contendo sulfato ferroso como única fonte de ferro. Verificou-se que a biodisponibilidade de ferro nos feijões ficou entre 4,05 e $5 \%$, dentro da faixa esperada para alimentos vegetais. 
De acordo com Canniatti-Brazaca \& Silva (1999), há uma variação no teor de ferro das leguminosas que vai de 68,33 (feijão guandu) a 153,4 mg/kg (soja).

O feijão guandu (Cajanus cajan L) é considerado uma importante leguminosa para nutrição humana em muitos países tropicais com deficiência em proteínas. Sua semente tem moderado conteúdo de proteínas, cerca de 19,34\%, sendo limitante para metionina e triptofano, impedindo que a leguminosa sozinha preencha os aminoácidos requeridos para nutrição humana (Nwokolo, 1987). Singh et al. (1984) avaliaram o conteúdo de minerais e elementos traços de sementes verdes e maduras do feijão guandu e verificaram que as sementes, quando consumidas verdes, são melhor fonte de ferro $(4,58 \mathrm{mg} / 100 \mathrm{~g})$ do que quando maduras $(3,87 \mathrm{mg} / 100 \mathrm{~g})$. Canniatti-Brazaca et al. (1996) avaliaram 6 cultivares de feijão guandu, que apresentaram concentrações de ferro entre 34 a $57 \mathrm{mg} / \mathrm{kg}$.

Devido ao baixo custo e à grande disponibilidade, os produtos de soja são empregados em muitas fórmulas infantis, na elaboração de produtos cárneos, panificação e indústria láctea. No entanto, a absorção de ferro não-heme, a partir da proteína de soja, é bastante limitada. O elevado teor de ácido fítico torna-se um dos principais fatores da baixa absorção do ferro da soja. A absorção de ferro da farinha de soja livre de fitato é duas vezes maior, quando comparada à que apresenta esse antinutricional (Martinez et al., 1999).

Haytowitz \& Matthews (1989) descreveram diferentes valores de ferro para farinha de soja integral $(6,4 \mathrm{mg} / 100 \mathrm{~g})$ e desengordurada $(9,2 \mathrm{mg} / 100 \mathrm{~g})$. O conteúdo de ferro nos concentrados e isolados de soja foram 10,8 e 14,5 mg/100 g, respectivamente.

A biodisponibilidade do ferro nos alimentos depende da forma química em que o elemento se encontra e das possíveis interações com outros constituintes dos alimentos (Antunes \& Sgarbieri, 1980). Canniatti-Brazaca \& Silva (1999) observaram que o tipo de leguminosa, bem como a presença de alimentos promotores, influenciou na disponibilidade do ferro. De acordo com os autores, o grão de bico e o feijão comum apresentaram as melhores disponibilidades de ferro. 


\subsection{Carnes}

Dentre as formas ferro heme e ferro não-heme, sabe-se que o ferro presente em carnes (heme) é mais disponível biologicamente, podendo ser assimilado na proporção de aproximadamente $25 \%$ do total do alimento (Cotran et al., 1996), diferentemente dos alimentos vegetais que contêm ferro não-heme, e a porcentagem de biodisponibilidade vai de 1 a 5\% (Cook, 1983). A absorção de ferro proveniente de alimentos em que o ferro radioativo foi incorporado biologicamente, demonstrou que as carnes apresentaram maior absorção de ferro (8 a $16 \%$ ), em relação aos alimentos de origem vegetal (3 a 8 \%) (Antunes \& Sgarbieri, 1980).

As principais fontes de ferro de origem animal são as carnes vermelhas, as vísceras, em especial o fígado e os moluscos bivalves que acumulam ferro em seus tecidos (Martínez et al., 1999).

Duhaiman (1988) avaliou espectrofotometricamente o conteúdo total de ferro de fígado e carne de diferentes animais e observou que o fígado $(11,52 \mathrm{mg} / 100 \mathrm{~g})$ e carne de boi $(6,72 \mathrm{mg} / 100 \mathrm{~g})$ mostraram concentrações de ferro significativamente maior do que a encontrada em fígado $(8,32 \mathrm{mg} / 100 \mathrm{~g})$ e carne de frango $(3,84 \mathrm{mg} / 100 \mathrm{~g})$ e ovelha $(9,44 \mathrm{e}$ $5,68 \mathrm{mg} / 100 \mathrm{~g})$. Franco (1992) apresentou valores de ferro para carne de boi como sendo 2,39 mg/100g; frango $1,90 \mathrm{mg} / 100 \mathrm{~g}$; e de fígado de boi e frango como sendo $12,10 \mathrm{e}$ $7,40 \mathrm{mg} / 100 \mathrm{~g}$, respectivamente.

\subsection{Compostos de Ferro}

Deficiência em ferro ainda constitui um dos problemas nutricionais mais comuns em saúde pública. Os números são alarmantes, cerca de 4 a 5 bilhões de pessoas, ou seja, 66 a $80 \%$ da população mundial apresentam deficiência em ferro, sendo que 2 bilhões de pessoas, cerca de $30 \%$ da população mundial são anêmicos, principalmente por deficiência em ferro (World Health Organization, 2002).

A suplementação com ferro tem sido a principal estratégia usada no controle da deficiência temporária em ferro e anemia ferropriva. Isso requer o acompanhamento médico, o que acaba se tornando problema em regiões onde o acesso médico é limitado,

principalmente em países em desenvolvimento. Outros fatores, como pouca aderência ao 
tratamento, dose inadequada e tempo de suplementação insuficiente têm contribuído para a ineficácia da suplementação (Viteri, 1997).

A disponibilidade do ferro usado em suplementos ou compostos para enriquecer alimentos varia de acordo com a composição química. O principal tratamento para anemia ferropriva consiste na administração oral de ferro inorgânico na forma ferrosa (Mahan \& Arlin, 1995). Sulfato ferroso é o sal mais freqüentemente usado, devido ao seu baixo custo e boa disponibilidade de ferro, em relação a outros sais de ferro inorgânico (Gibson, 1997).

Em uma dose de $30 \mathrm{mg}$, a absorção de ferro ferroso é três vezes maior do que se a mesma quantidade fosse dada na forma férrica. O preparo mais amplamente usado é o sulfato ferroso, e a dose é calculada em termos da quantidade de ferro elementar fornecido. Outros sais de absorção similar são as formas ferrosas de lactato, fumarato, sulfato de glicina, glutamato e gluconato (Mahan \& Arlin, 1995).

O ferro é melhor absorvido quando o estômago está vazio, entretanto, nessas condições, ele tende a provocar distúrbios gastrointestinais, tais como diarréia, náusea e vômitos (Mahan \& Arlin, 1995), o que acaba levando à não-aderência ao tratamento, principalmente por crianças e gestantes.

Pesquisas vêm sendo conduzidas no sentido de desenvolver preparações que reduzam os efeitos colaterais e aumentem a absorção, dentre elas estão as preparações de liberação controlada. Esses sistemas asseguram uma liberação gástrica sustentada de sulfato ferroso por algumas horas em doses equivalentes a 2 ou 3 comprimidos de 60 $\mathrm{mg}$, reduzindo os efeitos gastrointestinais (Gibson, 1997).

Pineda et al. (1994) citam alguns estudos relativos à importância da forma química do ferro sobre a sua absorção. Comparados ao ferro heme, os sais inorgânicos, que se comportam como ferro não-heme, são pobremente absorvidos, e, quando solúveis, a absorção sofre uma influência negativa de outros componentes, tais como os inibidores da dieta. Ao contrário, o ferro heme, que é uma porfirina quelato, é prontamente absorvido pela mucosa intestinal com subseqüente liberação do ferro elemental dentro das células da mucosa pela ação de uma enzima nesse caso, os inibidores parecem ter pouca ou nenhuma influência sobre a absorção. Dessa maneira, o 
suplemento ideal seria aquele que tivesse absorção eficiente, estivesse biodisponível após a absorção e não produzisse efeitos gástricos indesejáveis. Nesse caso, além do ferro heme, outros tipos de ferro quelato possuem as características que atendem a essas exigências.

Comparando a biodisponibilidade de complexos de ferro com o sulfato ferroso em ratos, Oliveira et al. (1995) verificaram que a biodisponibilidade do ferro sódio EDTA e do ferro aminoquelato produziu resultados similares ao do sulfato ferroso, e que o ferro dessas preparações é de alto valor biológico para ratos. Ortofosfato férrico teve baixo valor biológico, quando comparado com sulfato ferroso e outros complexos estudados.

Singh et al. (1998) realizaram estudo comparando a eficácia terapêutica entre o complexo intravenoso ferro polimaltose (Ferrum Hausmann) e fumarato ferroso (oral) no tratamento da anemia em gestantes. Os resultados sugerem que o ferro intravenoso é mais rápido e eficiente em reabastecer os estoques de ferro do organismo do que a terapia oral, e ainda, é uma alternativa segura, pois nenhuma reação adversa foi relatada, ao contrário da terapia oral.

Casparis et al. (1996) conduziram estudo com 40 mulheres anêmicas, durante ou imediatamente após a gravidez. As mulheres foram divididas em 4 grupos de tratamento, que foram os seguintes: grupo A - receberam gluconato ferroso líquido ( $75 \mathrm{mg}$ por dia tomado em 2 vezes); grupo B - gluconato ferroso sólido ( $80 \mathrm{mg}$ por dia em um único comprimido efervescente); grupo C - sulfato ferroso sólido (105 mg por dia em dose única); grupo D - proteína férrica succinalato ( $80 \mathrm{mg}$ por dia em 2 tomadas). Todos os tratamentos foram realizados por 30 dias. Como resultado, o estudo revelou que o gluconato ferroso na forma líquida foi o mais eficiente e o melhor tolerado dentre as outras formas líquidas ou sólidas contendo ferro.

Pineda et al. (1994) compararam a eficiência do ferro aminoquelato $(120 \mathrm{mg}, 60$ $\mathrm{mg}$ e $30 \mathrm{mg})$ em relação ao sulfato ferroso $(120 \mathrm{mg})$ em adolescentes com níveis de hemoglobina abaixo de $12 \mathrm{~g} / \mathrm{dl}$ (indicativo de anemia), sendo que todos os indivíduos receberam adicionalmente $250 \mathrm{mcg}$ de ácido fólico durante o tratamento. Os autores observaram que $30 \mathrm{mg}$ de ferro aminoquelato foram tão eficientes em elevar os níveis de 
hemoglobina quanto $120 \mathrm{mg}$ de sulfato ferroso, além de não produzir os indesejáveis efeitos gástricos. E que, em relação à melhora dos níveis de hemoglobina e ferritina, uma dose de $60 \mathrm{mg}$ de ferro aminoquelato ao dia, durante 4 semanas, oferece melhor relação dose/resposta, o que também pode ser obtido com $30 \mathrm{mg}$ de ferro aminoquelato, aumentando a duração do tratamento para 6 a 8 semanas.

Estudos recentes têm demonstrado a eficácia e as vantagens que o ferro aminoácido quelato apresenta em relação aos sais de ferro inorgânicos, dentre elas: dose efetiva quatro ou mais vezes menor do que o sulfato ferroso, tempo de tratamento menor, baixa toxicidade e absorção regulada por estoques do organismo (Pineda et al., 1994; Szarfarc et al., 2001; Jeppsen, 2001; Ashmead, 2001; Olivares \& Pizarro, 2001).

No entanto, o acesso ao ferro quelato pela população carente e com maior incidência de deficiência em ferro e anemia ferropriva é restrito. Isso se deve ao maior custo dos medicamentos à base de ferro quelato (cerca de 3 vezes maior) em relação ao sulfato ferroso e outros sais ferrosos mais usados na terapêutica. Além disso, o sulfato ferroso é o sal de escolha distribuído pela rede pública de saúde do Brasil e maioria das prescrições médicas.

Sas et al. (1984) verificaram a eficácia da administração oral de ferro em três grupos de pacientes com as seguintes preparações: grupo A recebeu um complexo férrico (III) - dextrina, grupo B Fe (II) - sulfato e grupo C Fe (II) - fumarato com vitaminas. Os objetivos do trabalho foram: normalizar o conteúdo de hemoglobina no sangue, restabelecer o nível sérico de ferro e de armazenamento. De acordo com os autores, os objetivos foram obtidos tanto com a forma trivalente como a divalente. Nas preparações trivalentes não há risco de toxicidade. Nessas preparações, os sais de ferro precipitam durante a passagem no estômago e duodeno como hidróxido férrico, o qual é quase insolúvel e permanece não absorvido. Existem diferenças na absorção de sais de ferro divalente e trivalente, devido à melhor solubilidade do precipitado Fe (II) hidróxido quando comparado com Fe (III) - hidróxido. No pH menor que 3, a biodisponibilidade do $\mathrm{Fe}$ (II) e Fe (III) são semelhantes.

Uma das alternativas para prevenir a deficiência de ferro e anemia seria a fortificação de alimentos para toda população ou para um grupo específico. Como os 
compostos usados na fortificação provêm de ferro não-heme, é importante selecionar os alimentos ou veículos que serão fortificados com o intuito de não reduzir a biodisponibilidade (Boccio et al., 1997).

De acordo com Boccio et al. (1997), os compostos usados na fortificação podem ser divididos em 3 grupos de acordo com a solubilidade: - solúveis em água (sulfato ferroso, gluconato ferroso e lactato ferroso) têm boa biodisponibilidade, mas têm desvantagens de interagir com o alimento alterando suas propriedades sensoriais; pouco solúveis em água ou solúveis em diluente ácido (ferro fumarato e ferro succinato), apesar de boa biodisponibilidade, podem ser usados apenas em alimentos sólidos desidratados, por não serem solúveis em meio líquido, podendo precipitar; - insolúveis em água e pouco solúveis em diluentes ácidos (ortofosfato férrico, pirofosfato férrico e ferro elemental) apresentam biodisponibilidade muito baixa. A escolha do composto depende da sua solubilidade no suco gástrico e na presença de promotores e/ou inibidores na fortificação do alimento.

Fox et al. (1998), comparando a biodisponibilidade de ferro glicina e sulfato ferroso como fortificante de preparações infantis, verificaram que na presença de inibidores da dieta, tais como os fitatos, não houve diferença significativa entre as formas de ferro, indicando que a quelação não melhora a biodisponibilidade em presença de inibidores.

Um novo composto chamado SFE-171 (nome comercial Biofer) é um sulfato ferroso microencapsulado com lecitina, que apresenta a mesma biodisponibilidade do sulfato ferroso, com a vantagem ser coberto com uma membrana fosfolipídica, a qual impede interações indesejáveis que ocorrem quando o sulfato ferroso é usado, e pode ser utilizado em leites e produtos de laticínios (Boccio et al., 1997). 


\section{MATERIAL E MÉTODOS}

Este trabalho foi realizado no laboratório de Bromatologia do Departamento de Agroindústria, Alimentos e Nutrição, da Escola Superior de Agricultura "Luiz de Queiroz", da Universidade de São Paulo (ESALQ/USP).

\subsection{Matéria prima}

As matérias primas utilizadas foram: feijão comum (Phaseolus vulgaris L.), fígado bovino e cenoura (Daucus carota L.). Os medicamentos utilizados foram: sulfato ferroso na forma de solução (Fer-In-Sol ${ }^{\circledR}$, Mead Johnson); acetato de retinol na forma de drágeas (Arovit ${ }^{\circledR}$, Roche) e ferro quelato glicinato em comprimidos (Neutrofer ${ }^{\circledR}$, Sigma Farma). Todo material foi adquirido no comércio local da cidade de Piracicaba - São Paulo, Brasil.

\subsection{Preparo das amostras}

\subsubsection{Feijão}

O feijão comum foi lavado e deixado sob maceração em água deionizada à temperatura ambiente por 16 horas na proporção de 1:3 - leguminosa: água. Após esse período, desprezou-se a água, e a leguminosa foi colocada novamente sob maceração na proporção de 1:2 e, em seguida, autoclavada à temperatura de $121{ }^{\circ} \mathrm{C}$ por 10 minutos (Molina et al.,1975). Após a autoclavagem, os grãos, juntamente com a água adicionada, foram colocados em liqüidificador e moídos. 


\subsubsection{Fígado}

O fígado bovino foi cozido, em panela de inox aberta, em fogo médio por aproximadamente 15 minutos, sem adição de nenhum outro ingrediente.

\subsubsection{Cenoura}

As cenouras foram lavadas, e após a remoção da película, foram trituradas em processador doméstico (modelo MegaMaster Super Walita).

\subsection{Elaboração das misturas experimentais}

As análises de diálise de ferro, vitamina A e beta-caroteno, foram realizadas antes das amostras serem submetidas à secagem. Para as demais análises, as amostras foram submetidas à secagem em estufa a $55-60^{\circ} \mathrm{C}$ e, a seguir, moídas em processador doméstico e colocadas em embalagens constituídas de sacos plásticos fechados, os quais foram armazenados em refrigerador. Todas as análises foram realizadas em triplicata.

Após o preparo das amostras individualmente, as mesmas foram misturadas entre si e com os medicamentos (Quadro 1). A quantidade de medicamentos adicionada aos alimentos foi calculada em função de uma prévia análise da composição em minerais e beta-caroteno dos alimentos previamente secos, conforme tratamento descrito anteriormente.

As quantidades de ferro sulfato (Fer1) e ferro aminoquelato (N1) correspondem à quantidade de ferro encontrada na amostra de feijão $(78,67 \mathrm{mg} / \mathrm{kg})$. As quantidades de ferro sulfato (Fer2) e ferro aminoquelato (N2) correspondem à concentração de ferro encontrada na amostra de fígado $(211,17 \mathrm{mg} / \mathrm{kg})$. A quantidade vitamina A (A1) foi calculada através da conversão em beta-caroteno encontrado na cenoura $(15 \mathrm{mg} / 100 \mathrm{~g}$ peso fresco).

Cada drágea de Arovit contém 50.000UI, o que corresponde a cerca de $17 \mathrm{mg}$ de acetato de retinol. Cada $\mathrm{ml}$ da solução de Fer-In-Sol contém $25 \mathrm{mg}$ de ferro. Cada comprimido de Neutrofer (300 mg) equivale a $60 \mathrm{mg}$ de ferro elementar. 


\begin{tabular}{|c|c|}
\hline ALIMENTOS & AMOSTRAS \\
\hline CENOURA & $\begin{array}{l}100 \mathrm{~g} \text { de Cenoura }(\mathrm{C}) \\
100 \mathrm{~g} \text { de Cenoura }+731,0 \mathrm{mg} \text { de Arovit }(\mathrm{C}+\mathrm{A} 1) \\
100 \mathrm{~g} \text { de Cenoura }+39,3 \mathrm{mg} \text { de Neutrofer }(\mathrm{C}+\mathrm{N} 1) \\
100 \mathrm{~g} \text { de Cenoura }+105,58 \mathrm{mg} \text { de Neutrofer }(\mathrm{C}+\mathrm{N} 2) \\
100 \mathrm{~g} \text { de Cenoura }+0,32 \mathrm{ml} \text { de Fer-In-Sol }(\mathrm{C}+\mathrm{Fer} 1) \\
100 \mathrm{~g} \text { de Cenoura }+0,84 \mathrm{ml} \text { de Fer-In-Sol }(\mathrm{C}+\mathrm{Fer} 2) \\
100 \mathrm{~g} \text { de cenoura }+100 \mathrm{~g} \text { de Feijão }(\mathrm{C}+\mathrm{F})\end{array}$ \\
\hline FEIJÃO & $\begin{array}{l}100 \mathrm{~g} \text { de Feijão (F) } \\
100 \mathrm{~g} \text { de Feijã }+731,0 \mathrm{mg} \text { de Arovit }(\mathrm{F}+\mathrm{A} 1) \\
100 \mathrm{~g} \text { de Feijão }+0,84 \mathrm{ml} \text { de Fer-In-Sol }(\mathrm{F}+\mathrm{Fer} 2) \\
100 \mathrm{~g} \text { de Feijão }+105,58 \mathrm{mg} \text { de Neutrofer }(\mathrm{F}+\mathrm{N} 2) \\
100 \mathrm{~g} \text { de Feijão }+100 \mathrm{~g} \text { de figado }(\mathrm{F}+\mathrm{Fi})\end{array}$ \\
\hline FÍGADO & $\begin{array}{l}100 \mathrm{~g} \text { de Fígado }(\mathrm{Fi}) \\
100 \mathrm{~g} \text { de Fígado }+402,23 \mathrm{mg} \text { de Arovit }(\mathrm{Fi}+\mathrm{A} 1) \\
100 \mathrm{~g} \text { de Fígado }+0,17 \mathrm{ml} \text { de Fer-In-Sol }(\mathrm{Fi}+\mathrm{Fer} 1) \\
100 \mathrm{~g} \text { de Fígado }+21,63 \mathrm{mg} \text { de Neutrofer }(\mathrm{Fi}+\mathrm{N} 1) \\
100 \mathrm{~g} \text { de fígado }+100 \mathrm{~g} \text { de Cenoura }(\mathrm{Fi}+\mathrm{C})\end{array}$ \\
\hline
\end{tabular}

Quadro 1 - Amostras experimentais

\subsection{Composição centesimal}

As análises químicas da matéria seca, cinza, extrato etéreo e proteína foram realizadas de acordo com a metodologia descrita pela Associação Ofícial de Química Analítica - AOAC (1995):

- para obtenção da matéria seca, as amostras foram secas em estufa, por aproximadamente 14 horas, a $105{ }^{\circ} \mathrm{C}$, até peso constante, sendo a umidade obtida por diferença;

- a fração cinza foi obtida, incinerando-se a amostra em mufla a $600{ }^{\circ} \mathrm{C}$ por 2 horas;

- para determinação do extrato etéreo, foi utilizado o extrator de Soxhlet. Na extração, o éter etílico foi utilizado como solvente à temperatura de $45-50{ }^{\circ} \mathrm{C}$ em refluxo contínuo da amostra por 6 horas. Após a recuperação do éter etílico, os tubos foram retirados e colocados em estufa a $100{ }^{\circ} \mathrm{C}$ durante 20 minutos. A seguir, os tubos foram 
colocados para esfriar em um dissecador e, logo após pesados, obtendo-se a quantidade de extrato etéreo por diferença de peso do tubo;

- o teor de proteínas foi determinado pelo método Microkjeldahl. Nesta metodologia, o teor protéico foi determinado multiplicando-se o conteúdo de nitrogênio pelo fator 6,25 .

A fração fibra dietética foi determinada pelo método enzimático, segundo Asp et al. (1983). Foi realizada extração com éter etílico para as amostras que apresentaram porcentagem de gordura acima de $8 \%$.

Os carboidratos digeríveis foram obtidos por diferença entre o total 100 e a somatória dos demais componentes da fração centesimal.

\subsection{Minerais}

A determinação dos minerais foi realizada de acordo com o método descrito por Sarruge \& Haag (1974). Adicionou-se ácido nítrico concentrado nas amostras, as quais ficaram em repouso por 1 a 2 horas, em seguida, os tubos contendo as amostras foram colocados em um bloco digestor, onde a temperatura atingiu $160{ }^{\circ} \mathrm{C}$ (aproximadamente 15 minutos). Após a obtenção da temperatura desejada, foi acrescentado o ácido

perclórico concentrado, e a temperatura elevada para $210{ }^{\circ} \mathrm{C}$ (aproximadamente 15 minutos). Após o resfriamento, o material foi diluído com água deionizada, para que se procedesse à leitura em espectrofotômetro de absorção atômica. As respectivas leituras foram realizadas no Laboratório de Nutrição Mineral de Plantas do Departamento de Solos e Nutrição de Plantas da ESALQ/USP. Os comprimentos de onda utilizados para o cálcio, cobre, ferro, magnésio, manganês e zinco foram: 422,7 nm, 324,0 nm, 249,3 nm, $285,2 \mathrm{~nm}, 279,5 \mathrm{~nm}$ e $213,9 \mathrm{~nm}$, respectivamente. Os valores do potássio e do fósforo foram obtidos em espectrofotômetro colorimétrico.

\subsection{Componentes antinutricionais}

As análises dos componentes antinutricionais foram realizadas somente nas amostras contendo feijão e suas respectivas misturas. 


\subsubsection{Taninos}

Foram analisados segundo a metodologia descrita por Price et al. (1980), através da extração com metanol e reação colorimétrica com solução de vanilina a 1 \% em metanol, $8 \%$ de $\mathrm{HCl}$ em metanol, na proporção de $1: 1$ de metanol, deixados a $30{ }^{\circ} \mathrm{C}$ por 20 minutos e posterior leitura em espectrofotômetro Beckman modelo DU 640, a 500 nm. A concentração de taninos foi obtida a partir de uma curva padrão de catequina, com resultados expressos em \% de taninos.

\subsection{2 Ácido fítico}

A quantidade de ácido fítico foi determinada conforme o método de Grynspan \& Cheryan (1989). As amostras foram colocadas em solução digestora e a seguir centrifugadas. O sobrenadante foi diluído em água destilada e passado por resina, algodão e cloreto de sódio. Ao eluído adicionou-se o reativo de Wande, e a leitura foi realizada em espectrofotômetro Beckman modelo DU 640 a 500 nm. Após a leitura, obteve-se a curva padrão de ácido fítico com resultados expressos em mg ácido fítico/ $\mathrm{g}$ de amostra.

\subsection{Vitamina A}

Foram determinadas as quantidades de retinol e beta-caroteno e feita a conversão em Unidades Internacionais de vitamina A (UI), utilizando-se os seguintes fatores de conversão: 1,8 para o beta-caroteno e 0,3 mcg de retinol para 1 UI (NRC, 1980).

\subsubsection{Retinol}

As amostras foram analisadas no Instituto de Tecnologia de Alimentos (ITAL Campinas), de acordo com adaptações feitas à metodologia descrita por Manz \& Philipp (1988), utilizando cromatografia líquida de alta eficiência. 


\subsubsection{Beta-caroteno}

A análise de carotenóides foi realizada no Instituto de Tecnologia de Alimentos (ITAL - Campinas), de acordo com adaptações feitas à metodologia descrita Carvalho et al. (1992), empregando análise por cromatografia líquida de alta eficiência.

\subsection{Ferro heme e ferro não-heme}

Empregou-se a metodologia descrita por Carpenter \& Clark (1995), a qual determina o conteúdo de ferro heme e não-heme de carnes, através do método colorimétrico, utilizando o reagente Ferrozine (adaptação do método descrito por Carter (1971) e Stookey (1970)).

\subsubsection{Determinação do ferro heme}

A determinação do ferro heme foi realizada utilizando o método descrito por Hornsey (1956), com algumas adaptações, o qual se baseia na extração por acetona acidificada. As amostras contendo fígado e suas misturas foram colocadas em tubos de centrífuga e adicionadas de $20 \mathrm{ml}$ de acetona mais $0,5 \mathrm{ml}$ de $\mathrm{HCl}$. A seguir, adicionou-se água até que o volume total de água e carne fossem equivalentes a 4,5 g. As amostras foram então misturadas por 15 segundos e filtradas. Mediu-se a absorbância do filtrado a $640 \mathrm{~nm}$, e em seguida, calculou-se o conteúdo de ferro heme. O conteúdo de água das amostras de carne foi determinado por secagem a $105^{\circ} \mathrm{C}$ por 16 horas, de acordo com a metodologia descrita pela AOAC (1990).

\subsubsection{Determinação do ferro não-heme}

As amostras contendo fígado e suas misturas foram pesadas e adicionadas de 15 $\mathrm{ml}$ de solução extratora composta pela mistura de 1:1 de ácido tricloroacético a $40 \%$ e $\mathrm{HCl}$ 6N, (Torrence \& Bothwell, 1968³, citado por Schricker et al., 1982). Adicionou-se

\footnotetext{
${ }^{3}$ TORRENCE, J.D.; BOTHWELL, T.H. A simple technique for measuring storage iron concentrations in formalinised liver samples. South African Medical Journal, v.33, p.9-11, 1968.
} 
nitrito de sódio a $1 \%$ e, então, as amostras foram colocadas em banho de água quente por 18 horas, resfriadas e centrifugadas por 10 minutos, para posterior análise do sobrenadante e determinação do ferro não-heme pelo método Ferrozine.

No método Ferrozine, as amostras receberam um agente redutor a $1 \%$ (ácido ascórbico) e precipitante de proteínas e a seguir foram centrifugadas. Ao sobrenadante foi adicionado acetato de amônio 20 \% seguido de reagente Ferrozine $1 \mathrm{mM}$. Essa mistura resultou no desenvolvimento de complexo colorido magenta que foi determinado por absorbância a $562 \mathrm{~nm}$.

\subsection{Diálise de ferro "in vitro"}

A análise da diálise de ferro foi realizada segundo o método proposto por Whittaker et al. (1989). As amostras foram homogeneizadas em água deionizada e adicionadas de $\mathrm{HCl} 6 \mathrm{~N}$ até que o $\mathrm{pH}$ atingisse valor 2, em seguida, adicionou-se $\mathrm{HCl}$ 0,01 $\mathrm{N}$ até que se completasse o volume de $100 \mathrm{ml}$. A digestão foi realizada adicionando-se $\mathrm{HCl}$-pepsina com incubação a $37^{\circ} \mathrm{C}$ e agitação a $200 \mathrm{rpm}$ por 2 horas. A acidez titulável foi realizada adicionando-se solução de pancreatina-bile seguida de titulação com $\mathrm{KOH}$ 0,5 N até pH 7,5. A partir do volume de $\mathrm{KOH}$ titulável, fez-se uma diluição de mesmo volume de $\mathrm{NaHCO}_{3} 0,5 \mathrm{~N}$.

A diálise foi realizada colocando-se o digerido em 'sacos de diálise' acrescentando-se três vezes o volume de $\mathrm{NaHCO}_{3} 0,5 \mathrm{~N}$ de modo que o digerido ficasse

submerso. Os frascos foram cobertos e agitados durante 30 minutos a $37^{\circ} \mathrm{C}$. Adicionouse suspensão de bile pancreatina, com incubação por mais 2 horas. O conteúdo dialisável foi completado a $25 \mathrm{ml}$, com água deionizada. Em seguida, foram pipetados $5 \mathrm{ml}$ do dialisado para o tubo de centrífuga com adição de solução precipitante de proteínas. Adicionou-se solução cromogênica ao sobrenadante. Após 10 minutos, foi realizada a leitura a $533 \mathrm{~nm}$ em espectrofotômetro Beckman modelo DU 640. Obteve-se a quantidade de ferro dialisado através de uma curva padrão previamente preparada. Os resultados foram expressos em porcentagem. 


\subsection{Concentração de ferro dialisável}

A concentração de ferro dialisável foi calculada a partir da porcentagem de ferro dialisável, com o objetivo de comparação entre as amostras.

Para as amostras contendo fígado, que possuem ferro heme e não-heme, foi necessário somar a quantidade de ferro heme e de não-heme, considerando-se apenas 25 $\%$ da quantidade de ferro heme, conforme sugerido pela literatura (Cotran et al. 1996), como sendo a quantidade real absorvida.

\subsection{Análise estatística}

O delineamento experimental empregado foi o inteiramente ao acaso, com três repetições por tratamento (amostra). Os resultados foram submetidos à análise de variância, com teste F. O teste de Tukey foi realizado para as amostras que obtiveram significância no teste $\mathrm{F}$ ao nível $5 \%$. As análises foram realizadas pelo programa estatístico SAS (Statistical Analysis System, 1996). 


\section{RESULTADOS E DISCUSSÃO}

Os resultados obtidos nas análises estão apresentados na forma de figuras e foram comparados aos resultados descritos na literatura.

\subsection{Composição Centesimal}

A composição centesimal das amostras foi determinada com o objetivo de comparação entre as diferentes composições das amostras de alimentos utilizados na pesquisa.

\subsubsection{Umidade}

A porcentagem de umidade entre as amostras apresentou variação de 53,59 \% (Fi) a 88,17\% (C+Fer2). As amostras contendo cenoura apresentaram elevado teor de umidade, seguidas das amostras contendo feijão e fígado. Não houve diferença significativa entre os alimentos e suas respectivas misturas com medicamentos. Houve diferenças quando os alimentos foram misturados entre si, tendo a mistura $\mathrm{C}+\mathrm{F}$, a maior porcentagem de umidade $(82,57 \%)$.

A porcentagem de umidade encontrada na amostra de feijão cozido foi semelhante à citada pela Universidade de São Paulo (2001) que foi de 77,20 \%, sendo que esse valor pode variar de acordo com a forma de preparo empregada.

A Universidade de São Paulo (2001) descreve como sendo 91,89 \% a porcentagem de umidade da cenoura. Vora et al. (1998) encontraram uma variação no teor de umidade que vai de 87,7 a $89,1 \%$, semelhante ao encontrado neste trabalho $(88,12$ \%). Em relação ao fígado, a Universidade de São Paulo (2001) apresenta a 
porcentagem de umidade para o fígado bovino cru como sendo $71,24 \%$, superior ao encontrado neste trabalho que foi para o fígado bovino cozido.

A figura 1 representa a porcentagem de umidade, em base úmida, das amostras analisadas.

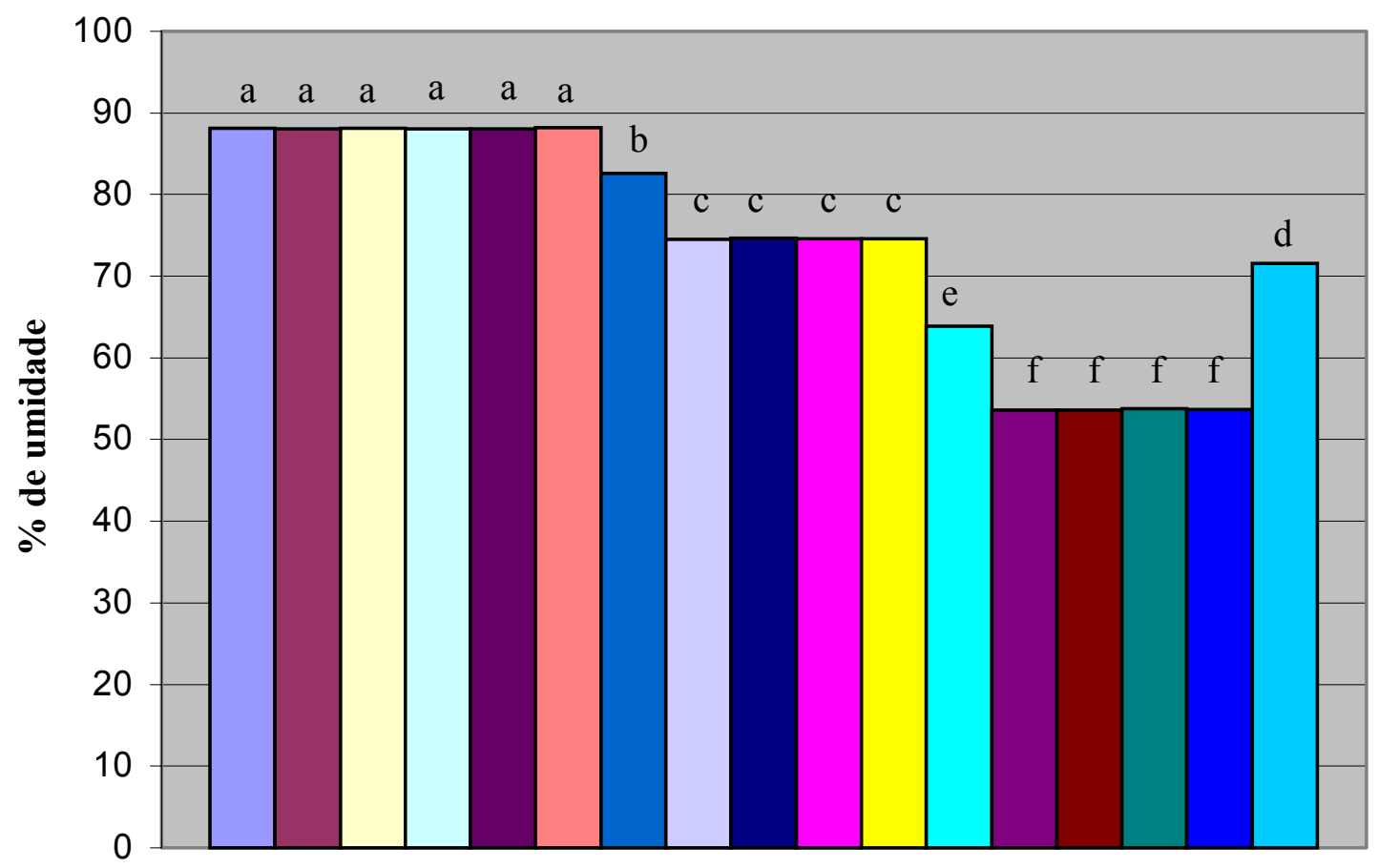

Amostras

\begin{tabular}{|llllll|}
\hline$\square \mathrm{C}$ & $\square \mathrm{C}+\mathrm{A} 1$ & $\square \mathrm{C}+\mathrm{N} 1$ & $\square \mathrm{C}+\mathrm{N} 2$ & $\square \mathrm{C}+\mathrm{Fer} 1$ & $\square \mathrm{C}+\mathrm{Fer} 2$ \\
$\square \mathrm{C}+\mathrm{F}$ & $\square \mathrm{F}$ & $\square \mathrm{F}+\mathrm{A} 1$ & $\square \mathrm{F}+\mathrm{Fer} 2$ & $\square \mathrm{F}+\mathrm{N} 2$ & $\square \mathrm{F}+\mathrm{Fi}$ \\
$\square \mathrm{Fi}$ & $\square \mathrm{Fi}+\mathrm{A} 1$ & $\square \mathrm{Fi}+\mathrm{Fer} 1$ & $\square \mathrm{Fi}+\mathrm{N} 1$ & $\square \mathrm{Fi}+\mathrm{C}$ & \\
\hline
\end{tabular}

$\mathbf{C}=$ cenoura; $\mathbf{F}=$ feijão; $\mathbf{F i}=$ figado; $\mathbf{A} \mathbf{1}=$ Arovit $(15 \mathrm{mg}) ; \mathbf{F e r} \mathbf{1}=$ Fer-In-Sol $(78,67 \mathrm{mg}) ; \mathbf{F e r} \mathbf{2}=$ Fer-InSol (211,17mg); $\mathbf{N 1}=$ Neutrofer $(78,67 \mathrm{mg})$; $\mathbf{N} \mathbf{2}$ = Neutrofer $(211,17 \mathrm{mg})$; valores representam média de 3 repetições; letras diferentes indicam diferença significativa $(\mathrm{p} \leq 0,05)$

Figura 1 - Porcentagem de umidade, em base úmida. 


\subsubsection{Cinza}

A figura 2 representa a porcentagem da fração cinza, em base úmida, das amostras analisadas.

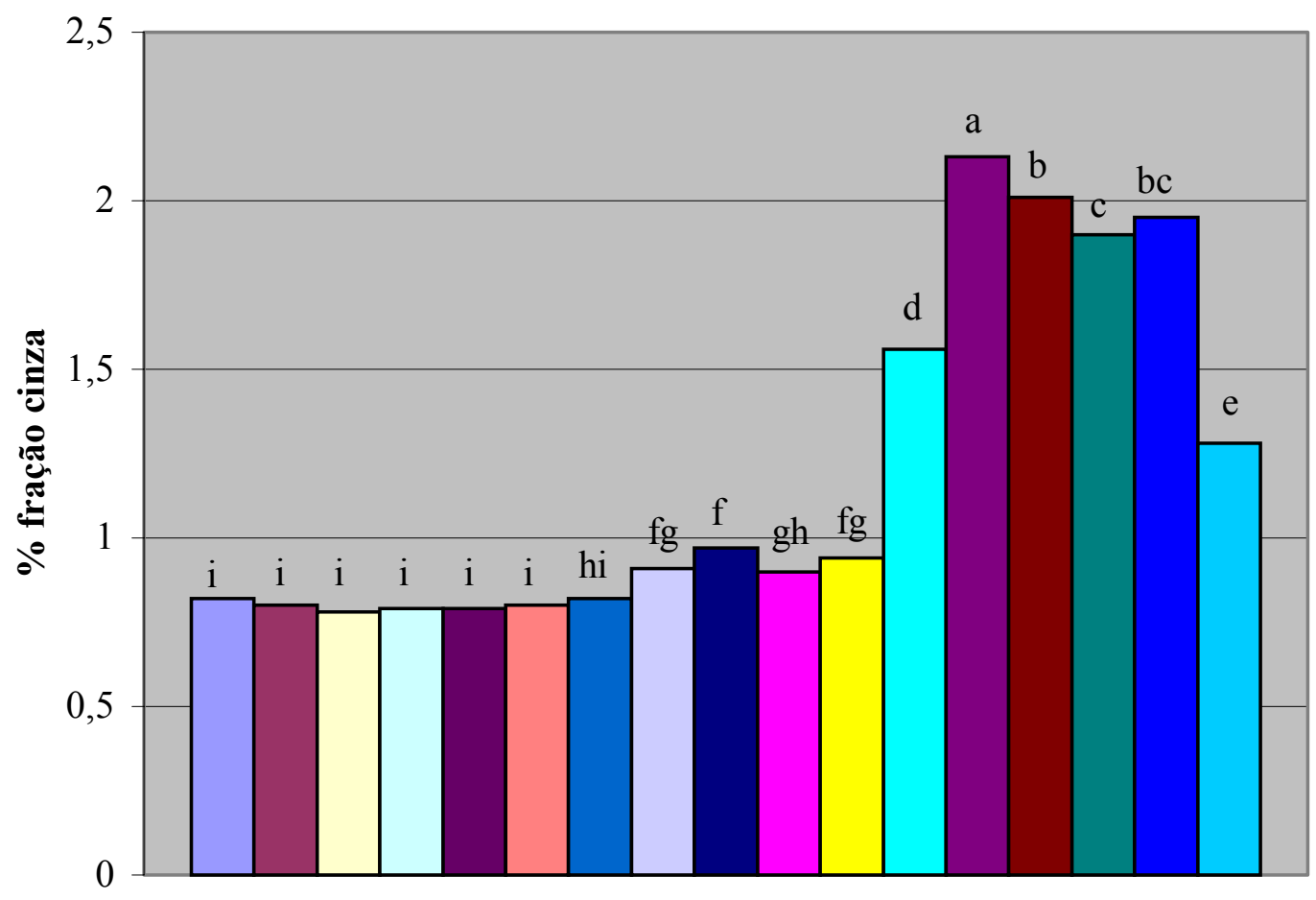

Amostras

\begin{tabular}{|llllll|}
\hline$\square \mathrm{C}$ & $\square \mathrm{C}+\mathrm{A} 1$ & $\square \mathrm{C}+\mathrm{N} 1$ & $\square \mathrm{C}+\mathrm{N} 2$ & $\square \mathrm{C}+\mathrm{Fer} 1$ & $\square \mathrm{C}+\mathrm{Fer} 2$ \\
$\square \mathrm{C}+\mathrm{F}$ & $\square \mathrm{F}$ & $\square \mathrm{F}+\mathrm{A} 1$ & $\square \mathrm{F}+\mathrm{Fer} 2$ & $\square \mathrm{F}+\mathrm{N} 2$ & $\square \mathrm{F}+\mathrm{Fi}$ \\
$\square \mathrm{Fi}$ & $\square \mathrm{Fi}+\mathrm{A} 1$ & $\square \mathrm{Fi}+\mathrm{Fer} 1$ & $\square \mathrm{Fi}+\mathrm{N} 1$ & $\square \mathrm{Fi}+\mathrm{C}$ & \\
\hline
\end{tabular}

$\mathbf{C}=$ cenoura; $\mathbf{F}=$ feijão; $\mathbf{F i}=$ fígado $\mathbf{A 1}=$ Arovit $(15 \mathrm{mg}) ;$ Fer1 $=$ Fer-In-Sol $(78,67 \mathrm{mg}) ;$ Fer2 $=$ Fer-InSol (211,17mg); N1= Neutrofer (78,67 mg); N2 = Neutrofer (211,17mg); valores representam média de 3 repetições; letras diferentes indicam diferença significativa $(\mathrm{p} \leq 0,05)$

Figura 2 - Porcentagem da fração cinza, em base úmida. 
A porcentagem da fração cinza das amostras, em base úmida, como apresentado na figura 2, mostra que as amostras contendo fígado apresentaram maior porcentagem da fração cinza, em relação às amostras contendo cenoura e feijão, devido às características desse alimento.

A porcentagem da fração cinza nas amostras variou de $0,78 \%(\mathrm{C}+\mathrm{N} 1)$ a $2,13 \%$ (Fi). O valor encontrado na amostra de feijão foi de $0,91 \%$ na base úmida, o que corresponde a 3,57 \% na base seca. Esse valor foi superior ao descrito pela Universidade de São Paulo (2001), que foi de 0,59 \%, e semelhante aos valores descritos por Sammán et al. (1999), 3,81 a 5,89 \%, Maldonado \& Sammán (2000), 3,95 a 6,13 \% e Augustin \& Klein (1989), 3,63 a 4,51\%, ambos para base seca.

A porcentagem da fração cinza encontrada na amostra de cenoura foi de $0,82 \%$. Valor semelhante foi descrito pela Universidade de São Paulo (2001), 0,81 \%.

A porcentagem de cinza encontrada na amostra de fígado foi superior à descrita pela Universidade de São Paulo (2001), que foi de 1,37 \% para o fígado cru. 


\subsubsection{Extrato Etéreo}

A figura 3 representa a porcentagem de extrato etéreo em base úmida das amostras analisadas.

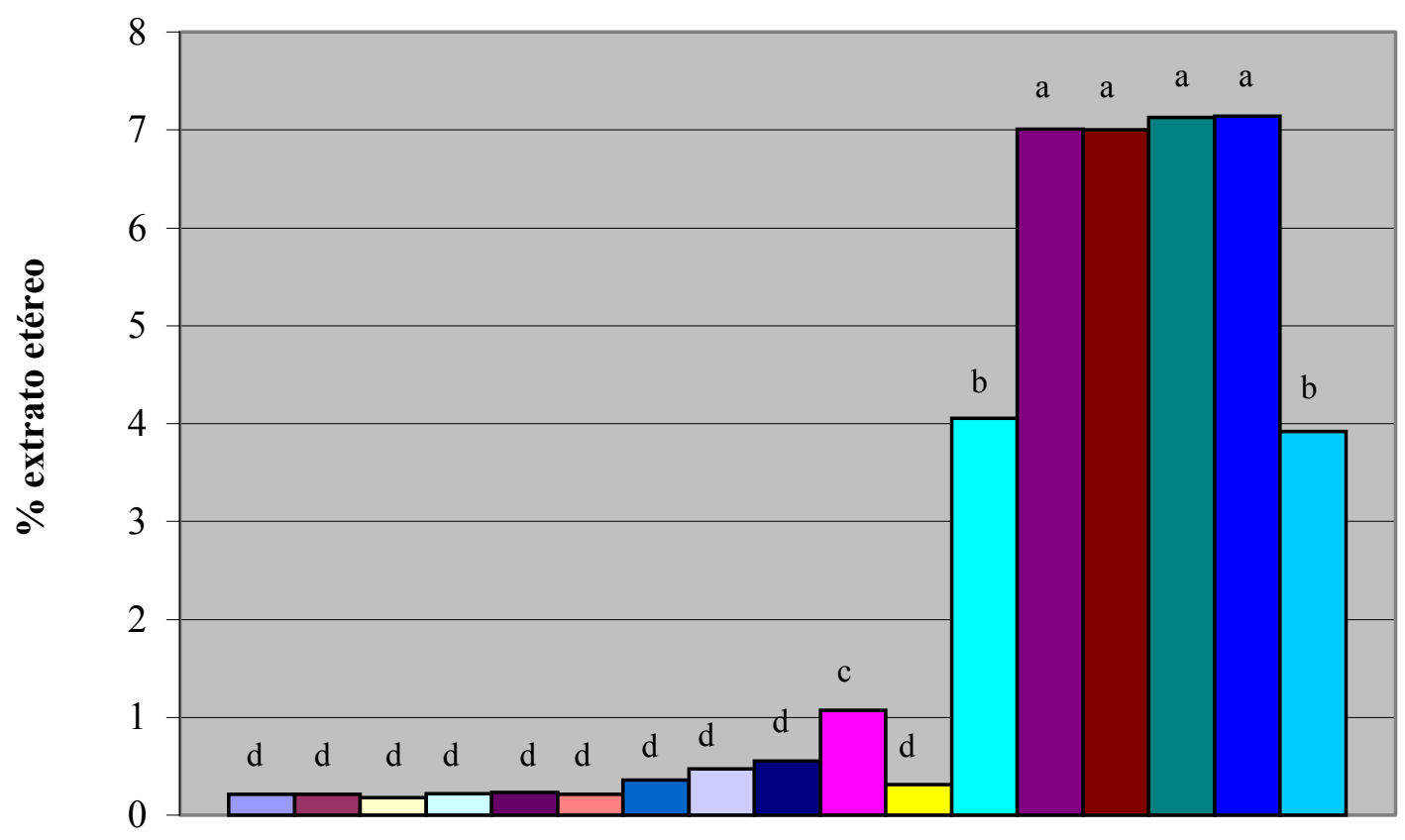

Amostras

\begin{tabular}{|llllll|}
\hline$\square \mathrm{C}$ & $\square \mathrm{C}+\mathrm{A} 1$ & $\square \mathrm{C}+\mathrm{N} 1$ & $\square \mathrm{C}+\mathrm{N} 2$ & $\square \mathrm{C}+\mathrm{Fer} 1$ & $\square \mathrm{C}+\mathrm{Fer} 2$ \\
$\square \mathrm{C}+\mathrm{F}$ & $\square \mathrm{F}$ & $\square \mathrm{F}+\mathrm{A} 1$ & $\square \mathrm{F}+\mathrm{Fer} 2$ & $\square \mathrm{F}+\mathrm{N} 2$ & $\square \mathrm{F}+\mathrm{Fi}$ \\
$\square \mathrm{Fi}$ & $\square \mathrm{Fi}+\mathrm{A} 1$ & $\square \mathrm{Fi}+\mathrm{Fer} 1$ & $\square \mathrm{Fi}+\mathrm{N} 1$ & $\square \mathrm{Fi}+\mathrm{C}$ & \\
\hline
\end{tabular}

$\mathbf{C}=$ cenoura; $\mathbf{F}=$ feijão; $\mathbf{F i}=$ fígado; $\mathbf{A 1}=$ Arovit $(15 \mathrm{mg}) ; \mathbf{F e r} \mathbf{1}=$ Fer-In-Sol $(78,67 \mathrm{mg}) ; \mathbf{F e r 2}=$ Fer-InSol (211,17mg); N1= Neutrofer (78,67 mg); N2 = Neutrofer (211,17mg); valores representam média de 3 repetições; letras diferentes indicam diferença significativa $(\mathrm{p} \leq 0,05)$

Figura 3 - Porcentagem de extrato etéreo, em base úmida. 
De acordo com a figura 3, a amostra contendo fígado e suas misturas apresentou a maior concentração de extrato etéreo, variando entre 3,91 \% (Fi+C) a 7,14 \% (Fi+N1), não diferindo quando adicionados os medicamentos, porém, diferindo com a adição dos alimentos. Não houve diferença entre as amostras contendo cenoura, com exceção da mistura Fi+C. Dentre as amostras contendo feijão, somente F+Fi e F+Fer2 diferiram das demais.

A porcentagem de extrato etéreo encontrada na amostra de feijão foi de $0,47 \%$ na base úmida, correspondendo a 1,86 \% na base seca. Esse valor foi semelhante ao encontrado por Canniatti-Brazaca \& Silva (1999), que foi de $1,85 \%$ para o feijão carioca cozido. Outros autores apresentam valores para feijões crus e na base seca. Martínez et al. (1998) apresentam valores na faixa de 1,55 a 1,82\%, Paredes-Lopez \& Harry (1989), 1,31 \%, Maldonado \& Sámman (2000), 0,62 a 1,42 \%.

A porcentagem de extrato etéreo na amostra de cenoura foi de 0,21 \%, semelhante aos valores descritos pela Universidade de São Paulo (2001) e por Philippi (2001), 0,20\% e 0,19\%, respectivamente.

Para o fígado, o valor de extrato etéreo encontrado nas amostras foi inferior ao descrito por Franco (1992) 9,87 \% e por Philippi (2001) 7,71 \%. 


\subsubsection{Proteína}

A figura 4 representa a porcentagem de proteína, em base úmida, das amostras analisadas.

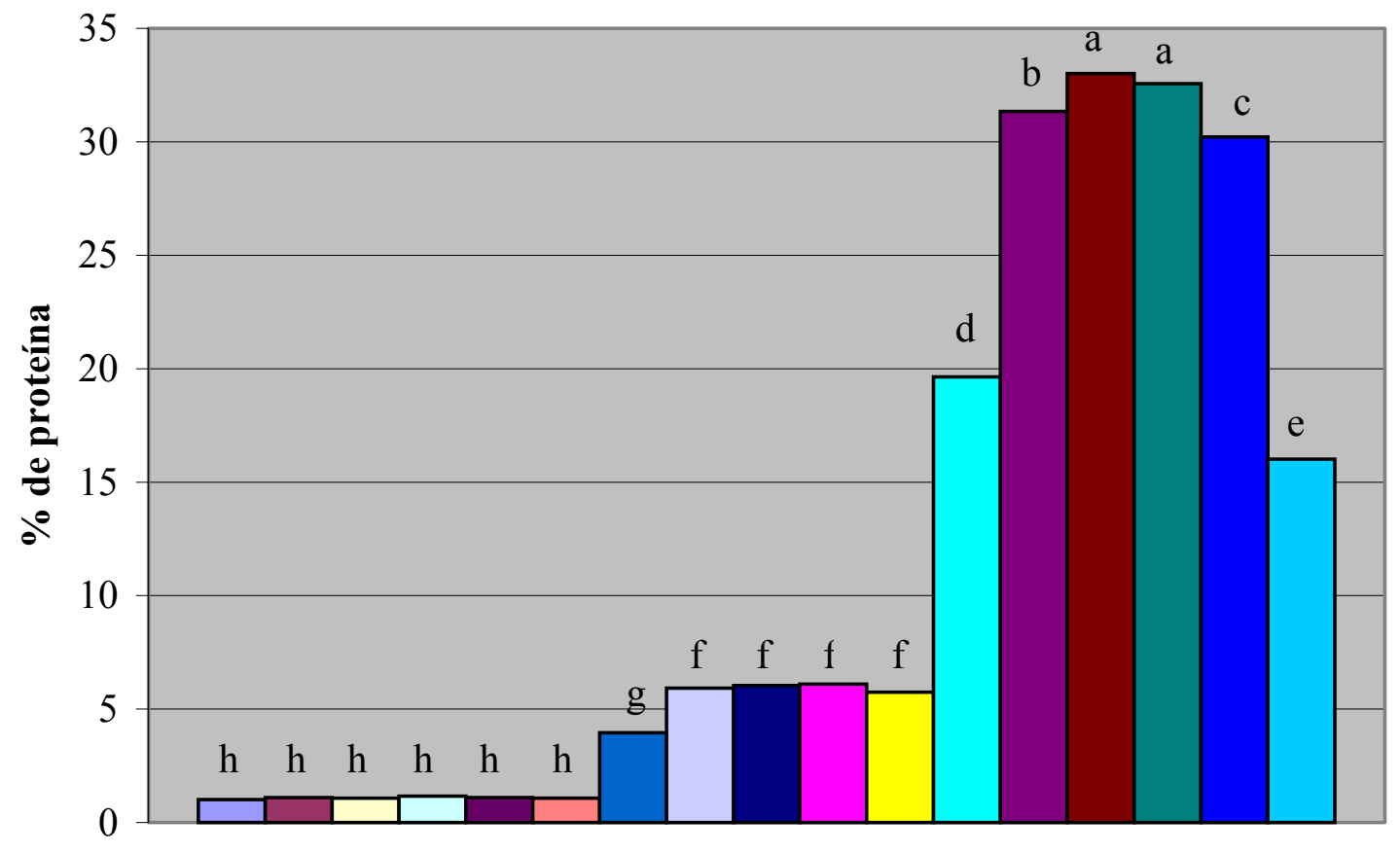

Amostras

\begin{tabular}{|llllll|}
\hline $\mathrm{C}$ & $\square \mathrm{C}+\mathrm{A} 1$ & $\square \mathrm{C}+\mathrm{N} 1$ & $\square \mathrm{C}+\mathrm{N} 2$ & $\square \mathrm{C}+\mathrm{Fer} 1$ & $\square \mathrm{C}+\mathrm{Fer} 2$ \\
$\square \mathrm{C}+\mathrm{F}$ & $\square \mathrm{F}$ & $\square \mathrm{F}+\mathrm{A} 1$ & $\square \mathrm{F}+\mathrm{Fer} 2$ & $\square \mathrm{F}+\mathrm{N} 2$ & $\square \mathrm{F}+\mathrm{Fi}$ \\
$\square \mathrm{Fi}$ & $\square \mathrm{Fi}+\mathrm{A} 1$ & $\square \mathrm{Fi}+\mathrm{Fer} 1$ & $\square \mathrm{Fi}+\mathrm{N} 1$ & $\square \mathrm{Fi}+\mathrm{C}$ & \\
\hline
\end{tabular}

$\mathbf{C}=$ cenoura; $\mathbf{F}=$ feijão; $\mathbf{F i}=$ fígado; $\mathbf{A 1}=$ Arovit $(15 \mathrm{mg}) ; \mathbf{F e r 1}=$ Fer-In-Sol $(78,67 \mathrm{mg}) ; \mathbf{F e r} \mathbf{2}=$ Fer-InSol (211,17mg); N1= Neutrofer (78,67 mg); N2 = Neutrofer $(211,17 \mathrm{mg})$; valores representam média de 3 repetições; letras diferentes indicam diferença significativa $(\mathrm{p} \leq 0,05)$

Figura 4 - Porcentagem de proteína, em base úmida. 
As proteínas e aminoácidos interagem na biodisponibilidade do ferro, fazendo com que seja aumentada a absorção do ferro não-heme. $\mathrm{E}$ em relação à vitamina $\mathrm{A}$, a qualidade protéica afeta o ritmo da depleção das reservas hepáticas de vitamina A. (Caballero, 1988).

A porcentagem de proteína entre as amostras analisadas variou de 1,02\% (C) a $33,02 \%(F I+A)$. Quando os alimentos foram misturados entre si, a amostra F+Fí $(19,64$ \%) apresentou a maior porcentagem de proteína, seguido por $\mathrm{Fi}+\mathrm{C}(16,01 \%)$ e $\mathrm{C}+\mathrm{F}$ $(3,96 \%)$. De modo semelhante ao ocorrido no extrato etéreo, as amostras contendo fígado e suas misturas obtiveram maior concentração de proteína, em relação ao feijão, cenoura e suas respectivas misturas.

A porcentagem de proteína encontrada na amostra de feijão foi de 5,91 \% na base úmida, correspondendo a $23,24 \%$ na base seca. Valores semelhantes foram descritos na literatura. Universidade de São Paulo (2001), 4,77 \%, Canniatti-Brazaca \& Silva (1999), $19,95 \%$ para o feijão carioca na base seca, Sgarbieri et al (1979), 24,5 \% base seca. Augustin \& Klein (1989), 21,34 a 26,75 \% base seca.

A porcentagem de proteínas para a cenoura, encontrada no presente trabalho, está de acordo com a Universidade de São Paulo (2001) que descreve como sendo 1,01 \%. Valores semelhantes também são descritos por Philippi (2001), 1,04 \% e Vora et al. (1998), 1,1 a $1,2 \%$.

A amostra de fígado apresentou concentração de proteína (31,35\%) superior à descrita na literatura por Philippi (2001), 25,79\%. 


\subsubsection{Fibra dietética}

A figura 5 representa a porcentagem de fibra dietética, em base úmida, das amostras analisadas.

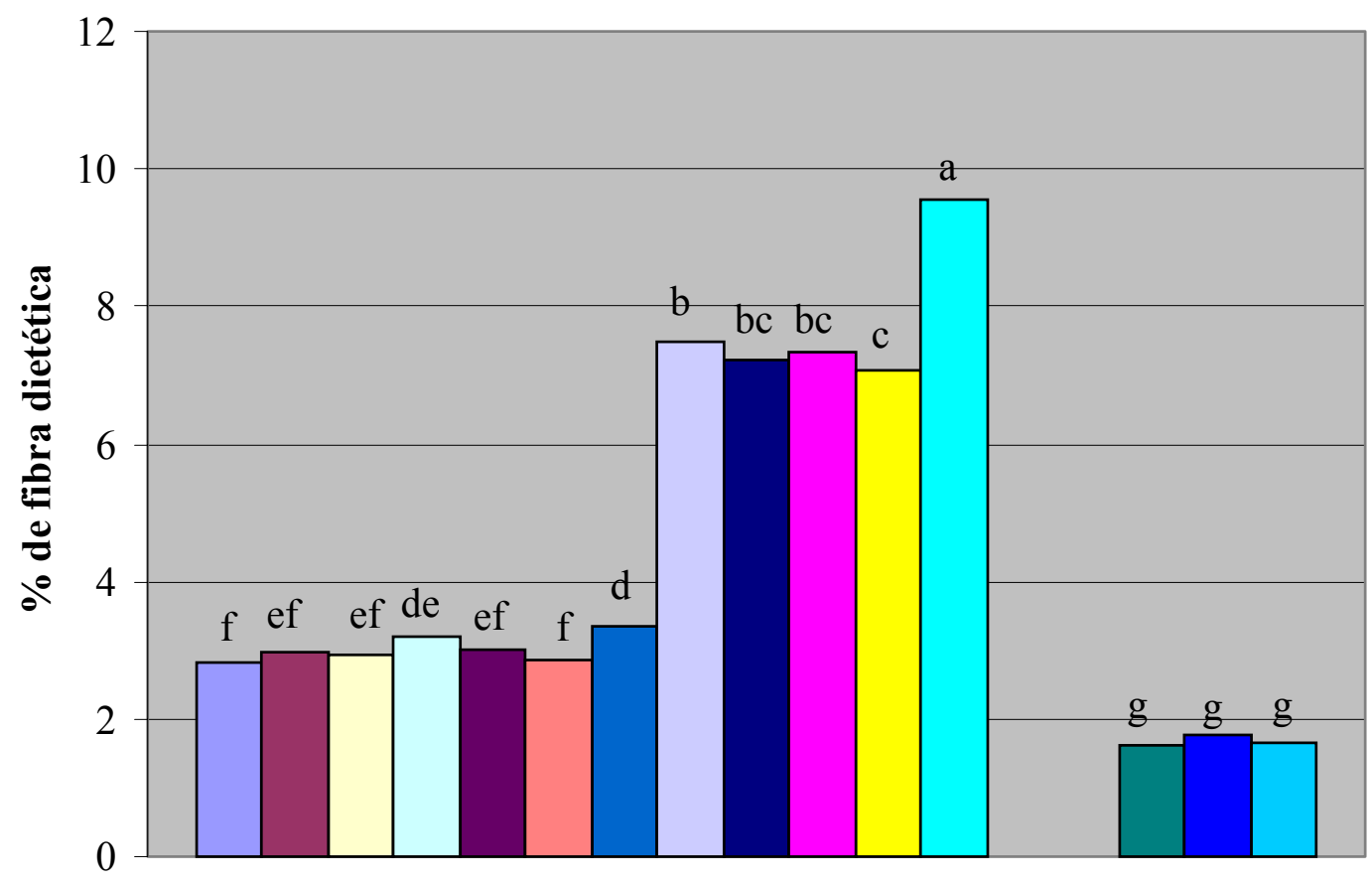

Amostras

\begin{tabular}{|llllll|}
\hline $\mathrm{C}$ & $\square \mathrm{C}+\mathrm{A} 1$ & $\square \mathrm{C}+\mathrm{N} 1$ & $\square \mathrm{C}+\mathrm{N} 2$ & $\square \mathrm{C}+\mathrm{Fer} 1$ & $\square \mathrm{C}+\mathrm{Fer} 2$ \\
$\square \mathrm{C}+\mathrm{F}$ & $\square \mathrm{F}$ & $\square \mathrm{F}+\mathrm{A} 1$ & $\square \mathrm{F}+\mathrm{Fer} 2$ & $\square \mathrm{F}+\mathrm{N} 2$ & $\square \mathrm{F}+\mathrm{Fi}$ \\
$\square \mathrm{Fi}$ & $\square \mathrm{Fi}+\mathrm{A} 1$ & $\square \mathrm{F}+\mathrm{Fer} 1$ & $\square \mathrm{F}+\mathrm{N} 1$ & $\square \mathrm{F}+\mathrm{C}$ & \\
\hline
\end{tabular}

$\mathbf{C}=$ cenoura; $\mathbf{F}=$ feijão; $\mathbf{F i}=$ fígado; $\mathbf{A 1}=$ Arovit $(15 \mathrm{mg}) ; \mathbf{F e r 1}=$ Fer-In-Sol $(78,67 \mathrm{mg}) ;$ Fer2 $=$ Fer-InSol (211,17mg); N1= Neutrofer (78,67 mg); N2 = Neutrofer (211,17mg); valores representam média de 3 repetições; letras diferentes indicam diferença significativa $(\mathrm{p} \leq 0,05)$

Figura 5 - Porcentagem de fibra dietética, em base úmida. 
Fibra dietética consiste na porção da paredes da células das plantas que não podem ser digeridas pelas enzimas do trato digestivo humano. São compostas por carboidratos , celulose, hemicelulose, pectina e compostos fenólicos. Recentemente, médicos e pesquisadores têm dado grande importância ao aumento no consumo de fibras na dieta da população, devido aos benefícios associados ao consumo adequado de fibras, dentre eles: redução do colesterol e risco de doenças do coração, redução dos riscos de câncer de cólon (Reyes-Moreno \& Paredes-López, 1993). O feijão é uma das leguminosas de maior importância no consumo humano, constituindo, também, uma importante fonte de fibras.

As amostras contendo feijão adicionado de alimentos e medicamentos obtiveram a maior quantidade de fibra dietética variando entre 3,33 \% (C+F) a 9,57 \% (F+Fí). Para as amostras de cenoura os valores variaram entre 2,82\%(C) a 3,33\% (C+F). Em relação às amostras contendo fígado, Fi+Fer1 (1,61 \%), Fi+N1 (1,75 \%) e Fi+C (1,66 $\%)$, diferiram estatisticamente, apenas da amostra $\mathrm{F}+\mathrm{Fi}(9,57 \%)$, que, devido à presença do feijão, obteve quantidade maior de fibra dietética. Para as amostras Fi e Fi+A, a quantidade de fibra dietética foi inexistente.

Para o feijão, a quantidade de fibra dietética foi de 7,47 \% na base úmida, o que corresponde a 29,37 \% na base seca. Esse valor foi superior ao encontrado pela Universidade de São Paulo (2001), que foi de 5,60 \%. No entanto, esse valor foi inferior aos descritos na literatura. Martinez et al. (1998) encontraram 33,27 \%, Candela et al. (1997), 32,26 \% e Canniatti-Brazacca \& Silva (1999) encontraram 34,94 \%, ambos em base seca.

A porcentagem de fibra dietética encontrada na amostra de cenoura (2,82 \%) está de acordo com a descrita pela Universidade de São Paulo (2001) que foi 2,81 \%, superior ao descrito por Philippi (2001), como sendo 2,60 \%.

A concentração de fibra total na amostra de fígado e fígado adicionado de Arovit, apresentou valor próximo de zero. Philippi (2001) encontrou 0,04 \% de fibra dietética no fígado bovino cozido. 


\subsubsection{Carboidratos disponíveis}

A figura 6 representa a porcentagem de carboidratos disponíveis obtidos por diferença.

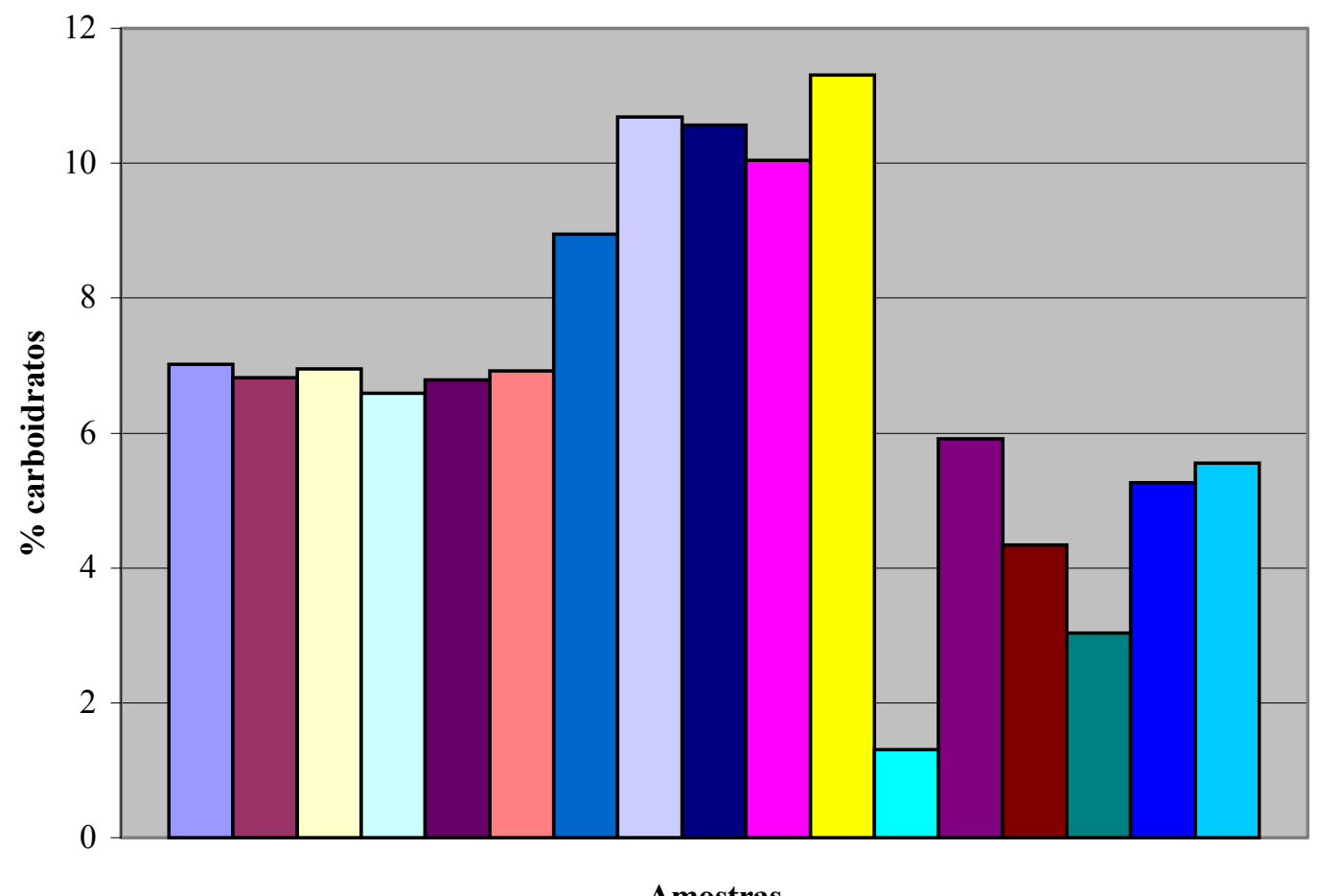

$\begin{array}{llllll}\square \mathrm{C} & \square \mathrm{C}+\mathrm{A} 1 & \square \mathrm{C}+\mathrm{N} 1 & \square \mathrm{C}+\mathrm{N} 2 & \square \mathrm{C}+\mathrm{Fer} 1 & \square \mathrm{C}+\mathrm{Fer} 2 \\ \square \mathrm{C}+\mathrm{F} & \square \mathrm{F} & \square \mathrm{F}+\mathrm{A} 1 & \square \mathrm{F}+\mathrm{Fer} 2 & \square \mathrm{F}+\mathrm{N} 2 & \square \mathrm{F}+\mathrm{Fi} \\ \square \mathrm{Fi} & \square \mathrm{Fi}+\mathrm{A} 1 & \square \mathrm{Fi}+\mathrm{Fer} 1 & \square \mathrm{Fi}+\mathrm{N} 1 & \square \mathrm{Fi}+\mathrm{C} & \end{array}$

$\mathrm{C}=$ cenoura; $\mathbf{F}=$ feijão; $\mathbf{F i}=$ fígado; $\mathbf{A 1}=$ Arovit $(15 \mathrm{mg}) ;$ Fer1 $=$ Fer-In-Sol $(78,67 \mathrm{mg}) ;$ Fer2 $=$ Fer-InSol (211,17mg); N1= Neutrofer (78,67 mg); N2 = Neutrofer $(211,17 \mathrm{mg})$; valores representam média de 3 repetições

Figura 6 - Porcentagem de carboidratos disponíveis obtidos por diferença, em base úmida. 
A quantidade de carboidratos disponíveis obtidos por diferença nas amostras analisadas apresentaram valores menores para o fígado e suas misturas e maiores para o feijão, como era esperado, devido às características de composição desses alimentos.

A quantidade de carboidratos obtidos por diferença encontrado no feijão foi de $10,68 \%$ na base úmida, correspondendo a $41,96 \%$ na base seca. Valor semelhante foi descrito por Martínez et al. (1998) como sendo 40,29 \% na base seca. Canniatti-Brazaca \& Silva (1999) encontraram 38,68 \% e Candela et al. (1997), 37,64 \%, ambos na base seca.

De acordo com a Universidade de São Paulo (2001) a quantidade de carboidratos na cenoura foi de $6,09 \%$. Valor semelhante foi encontrado neste trabalho $(7,02 \%)$. Philippi (2001) obteve valor superior (10,10\%).

A quantidade encontrada no fígado foi semelhante à descrita por Philippi (2001), que foi de $8,16 \%$. 


\subsection{Minerais}

\subsubsection{Cálcio}

A figura 7 apresenta a concentração de cálcio $(\mathrm{g} / \mathrm{kg})$, em base úmida, das amostras analisadas.

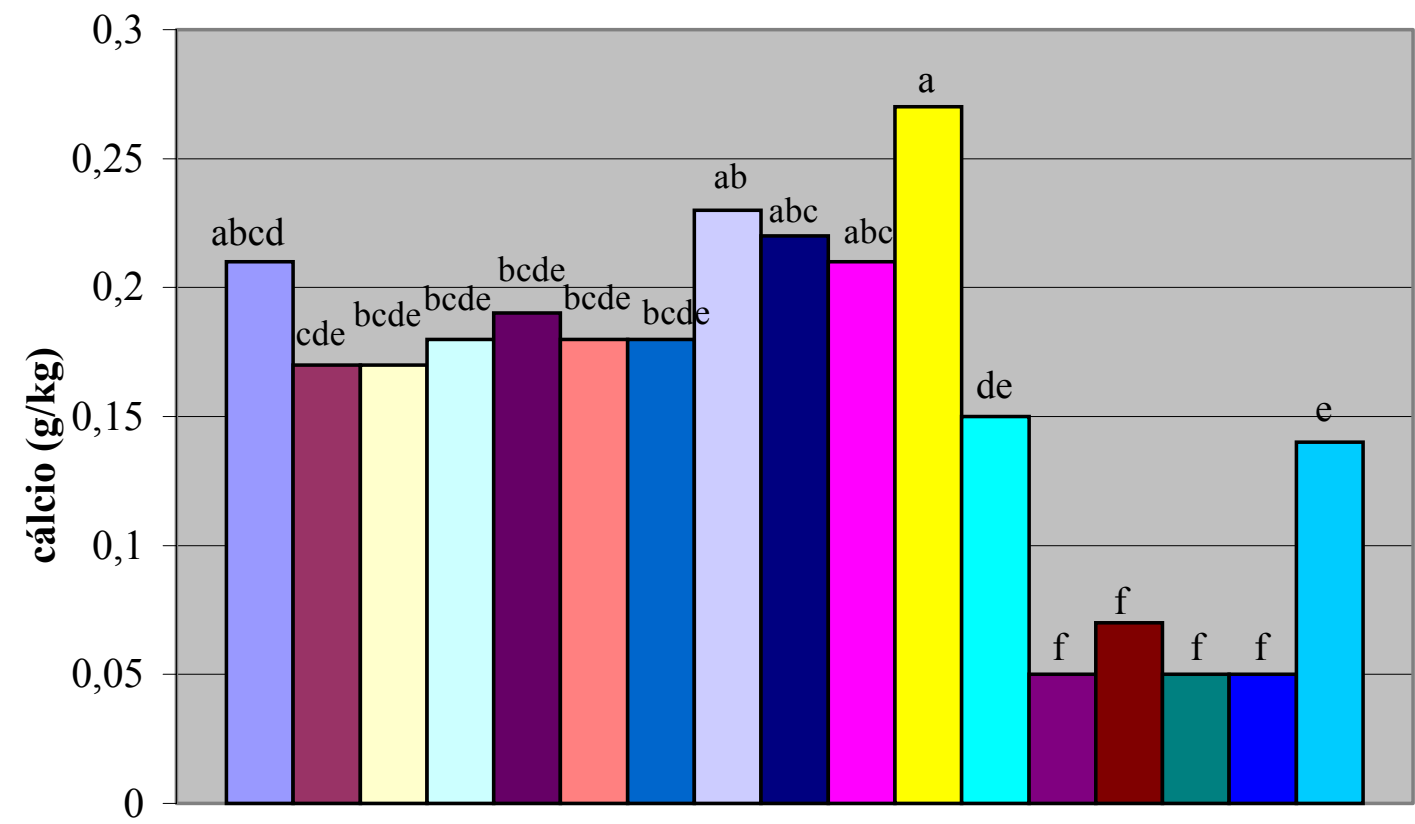

Amostras

\begin{tabular}{|llllll}
\hline$\square \mathrm{C}$ & $\square \mathrm{C}+\mathrm{A} 1$ & $\square \mathrm{C}+\mathrm{N} 1$ & $\square \mathrm{C}+\mathrm{N} 2$ & $\square \mathrm{C}+\mathrm{Fer} 1$ & $\square \mathrm{C}+\mathrm{Fer} 2$ \\
$\square \mathrm{C}+\mathrm{F}$ & $\square \mathrm{F}$ & $\square \mathrm{F}+\mathrm{A} 1$ & $\square \mathrm{F}+\mathrm{Fer} 2$ & $\square \mathrm{F}+\mathrm{N} 2$ & $\square \mathrm{F}+\mathrm{Fi}$ \\
$\square \mathrm{Fi}$ & $\square \mathrm{Fi}+\mathrm{A} 1$ & $\square \mathrm{Fi}+\mathrm{Fer} 1$ & $\square \mathrm{Fi}+\mathrm{N} 1$ & $\square \mathrm{Fi}+\mathrm{C}$ & \\
\hline
\end{tabular}

$\mathbf{C}=$ cenoura; $\mathbf{F}=$ feijão; $\mathbf{F i}=$ fígado $\mathbf{A 1}=$ Arovit $(15 \mathrm{mg}) ;$ Fer1 $=$ Fer-In-Sol $(78,67 \mathrm{mg}) ; \mathbf{F e r} \mathbf{2}=$ Fer-InSol (211,17mg); N1= Neutrofer (78,67 mg); N2 = Neutrofer $(211,17 \mathrm{mg})$; valores representam média de 3 repetições; letras diferentes indicam diferença significativa $(\mathrm{p} \leq 0,05)$

Figura 7 - Concentração de cálcio $(\mathrm{g} / \mathrm{kg})$, em base úmida. 
A adição de cálcio, seja na forma de leite ou sal inorgânico a um alimento, reduz a porcentagem de absorção de ferro não-heme da dieta ou de medicamentos à base de sulfato ferroso, quando ingerido em quantidades maiores do que $500 \mathrm{mg}$. (Lynch, 1997; Cook et al., 1991).

A concentração de cálcio nas amostras variou de $0,05 \mathrm{~g} / \mathrm{kg}$ (Fi) a $0,27 \mathrm{~g} / \mathrm{kg}$ $(\mathrm{F}+\mathrm{N} 2)$, portanto, não houve interferência do cálcio sobre a disponibilidade de ferro. As amostras de feijão (F) e feijão adicionado de medicamentos apresentaram a maior concentração de cálcio. Dentre as misturas entre alimentos, a mistura $\mathrm{C}+\mathrm{F}(0,18 \mathrm{~g} / \mathrm{kg})$ obteve a maior quantidade de cálcio seguida por F+Fí $(0,15 \mathrm{~g} / \mathrm{kg})$ e Fi $+\mathrm{C}(0,14 \mathrm{~g} / \mathrm{kg})$. As amostras contendo fígado e suas misturas apresentaram a menor concentração de cálcio, sendo que não houve diferença entre as amostras de fígado adicionado de medicamentos $(\mathrm{Fi}+\mathrm{A}, \mathrm{Fi}+\mathrm{Fer} 1$ e Fi+N).

A concentração de cálcio encontrada na amostra de cenoura (C) foi semelhante à descrita por Philippi (2001), que foi de $0,27 \mathrm{~g} / \mathrm{kg}$ e um pouco inferior à descrita por Vora et al. (1998), que variou de 0,3 a $0,41 \mathrm{mg} / \mathrm{kg}$. A concentração de cálcio na amostra de feijão (F) foi semelhante à encontrada por Philippi (2001), que foi de $0,33 \mathrm{~g} / \mathrm{kg}$. A amostra de fígado (Fi) apresentou concentração inferior à descrita por Philippi (2001), $1,18 \mathrm{~g} / \mathrm{kg}$. 


\subsubsection{Potássio}

A figura 8 representa a concentração de potássio $(\mathrm{g} / \mathrm{kg})$, em base úmida, das amostras analisadas.

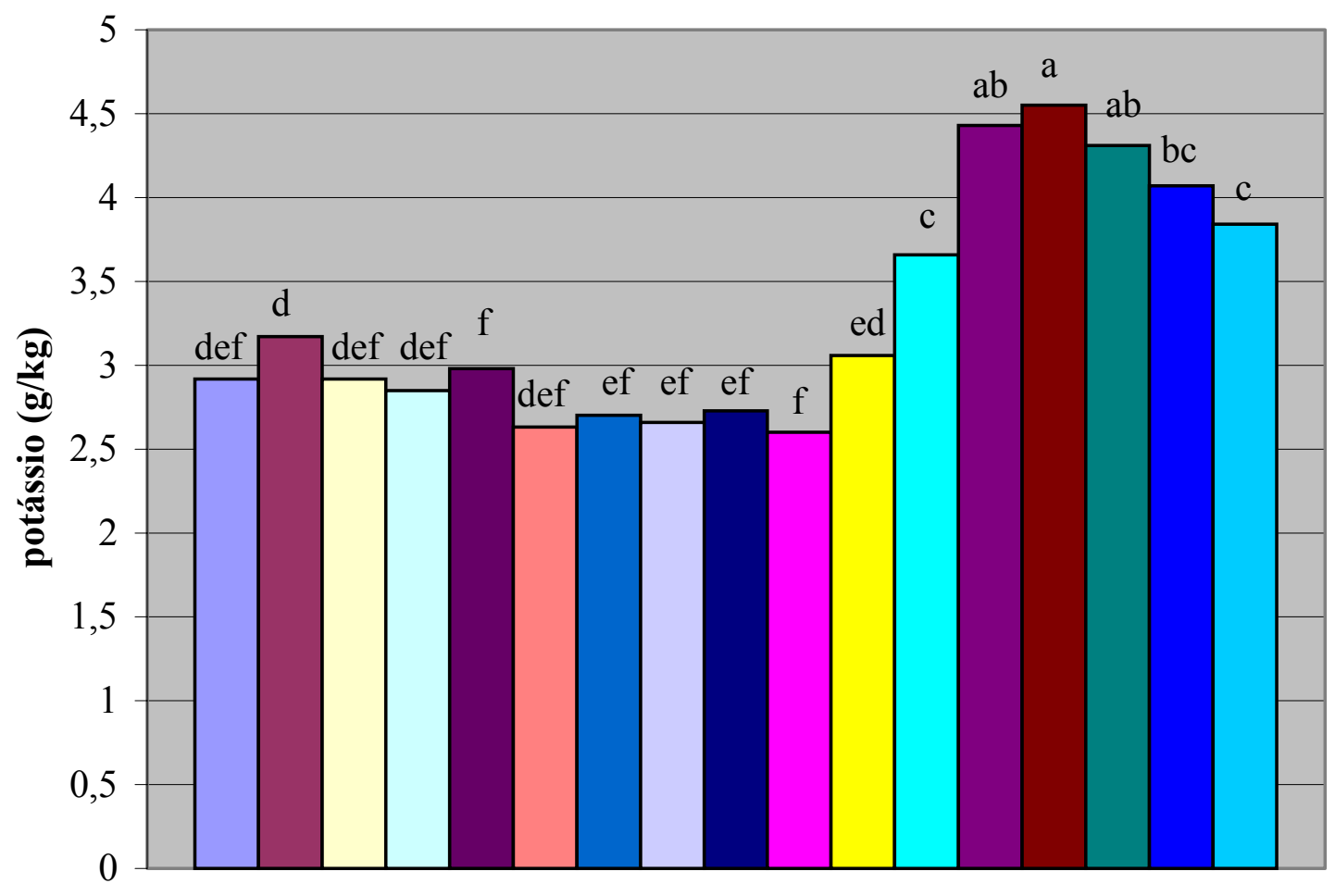

Amostras

\begin{tabular}{|llllll|}
\hline $\mathrm{C}$ & $\square \mathrm{C}+\mathrm{A} 1$ & $\square \mathrm{C}+\mathrm{N} 1$ & $\square \mathrm{C}+\mathrm{N} 2$ & $\square \mathrm{C}+\mathrm{Fer} 1$ & $\square \mathrm{C}+\mathrm{Fer} 2$ \\
$\square \mathrm{C}+\mathrm{F}$ & $\square \mathrm{F}$ & $\square \mathrm{F}+\mathrm{A} 1$ & $\square \mathrm{F}+\mathrm{Fer} 2$ & $\square \mathrm{F}+\mathrm{N} 2$ & $\square \mathrm{F}+\mathrm{Fi}$ \\
$\square \mathrm{Fi}$ & $\square \mathrm{Fi}+\mathrm{A} 1$ & $\square \mathrm{Fi}+\mathrm{Fer} 1$ & $\square \mathrm{Fi}+\mathrm{N} 1$ & $\square \mathrm{Fi}+\mathrm{C}$ & \\
\hline
\end{tabular}

$\mathbf{C}=$ cenoura; $\mathbf{F}=$ feijão; $\mathbf{F i}=$ fígado; $\mathbf{A 1}=$ Arovit $(15 \mathrm{mg}) ; \mathbf{F e r 1}=$ Fer-In-Sol $(78,67 \mathrm{mg}) ;$ Fer2 $=$ Fer-InSol (211,17mg); N1= Neutrofer (78,67 mg); N2 = Neutrofer $(211,17 \mathrm{mg})$; valores representam média de 3 repetições; letras diferentes indicam diferença significativa $(\mathrm{p} \leq 0,05)$

Figura 8 - Concentração de potássio $(\mathrm{g} / \mathrm{kg})$, em base úmida. 
A concentração de potássio variou de $2,60 \mathrm{~g} / \mathrm{kg}$ ( $\mathrm{F}+\mathrm{Fer} 2)$ a $4,55 \mathrm{~g} / \mathrm{kg}(\mathrm{Fi}+\mathrm{A} 1)$.

As amostras contendo fígado e suas misturas com alimentos e medicamentos obtiveram as maiores concentrações de potássio. Dentre as misturas entre alimentos, a amostra $\mathrm{Fi}+\mathrm{C}(3,84 \mathrm{~g} / \mathrm{kg})$ apresentou maior concentração de potássio, seguida por $\mathrm{F}+\mathrm{Fi}$ $(3,66 \mathrm{~g} / \mathrm{kg})$ e $\mathrm{C}+\mathrm{F}(2,70 \mathrm{~g} / \mathrm{kg})$. A concentração de potássio da cenoura está de acordo com a encontrada por Vora et al. (1998), que observaram uma variação entre 2,94 a 3,53 $\mathrm{g} / \mathrm{kg}$. A concentração de potássio no feijão $(2,66 \mathrm{~g} / \mathrm{kg})$ foi pouco inferior à encontrada por Philippi (2001), que foi de $3,38 \mathrm{~g} / \mathrm{kg}$. Já o fígado apresentou teor ligeiramente superior ao descrito por Philippi (2001), que foi de $3,57 \mathrm{~g} / \mathrm{kg}$.

\subsubsection{Magnésio}

A quantidade de magnésio nas amostras variou de $0,08 \mathrm{~g} / \mathrm{kg}(\mathrm{C}+\mathrm{Fer} 1)$ a 0,53 $\mathrm{g} / \mathrm{kg}$ (Fi+A1). Dentre as misturas de alimentos, a amostra F+Fi apresentou maior concentração de magnésio( $0,3 \mathrm{~g} / \mathrm{kg})$, seguida por $\mathrm{C}+\mathrm{F}(0,20 \mathrm{~g} / \mathrm{kg})$ e Fi+C $(0,08 \mathrm{~g} / \mathrm{kg})$.

As concentrações de magnésio da cenoura $(\mathrm{C})$, feijão $(\mathrm{F})$ e fígado $(\mathrm{Fi})$ estão de acordo com os valores descritos por Philippi (2001), 0,15 g/kg, 0,42 g/kg e 0,23 g/kg, respectivamente.

A figura 9 representa a concentração de magnésio $(\mathrm{g} / \mathrm{kg})$, em base úmida, das amostras analisadas. 


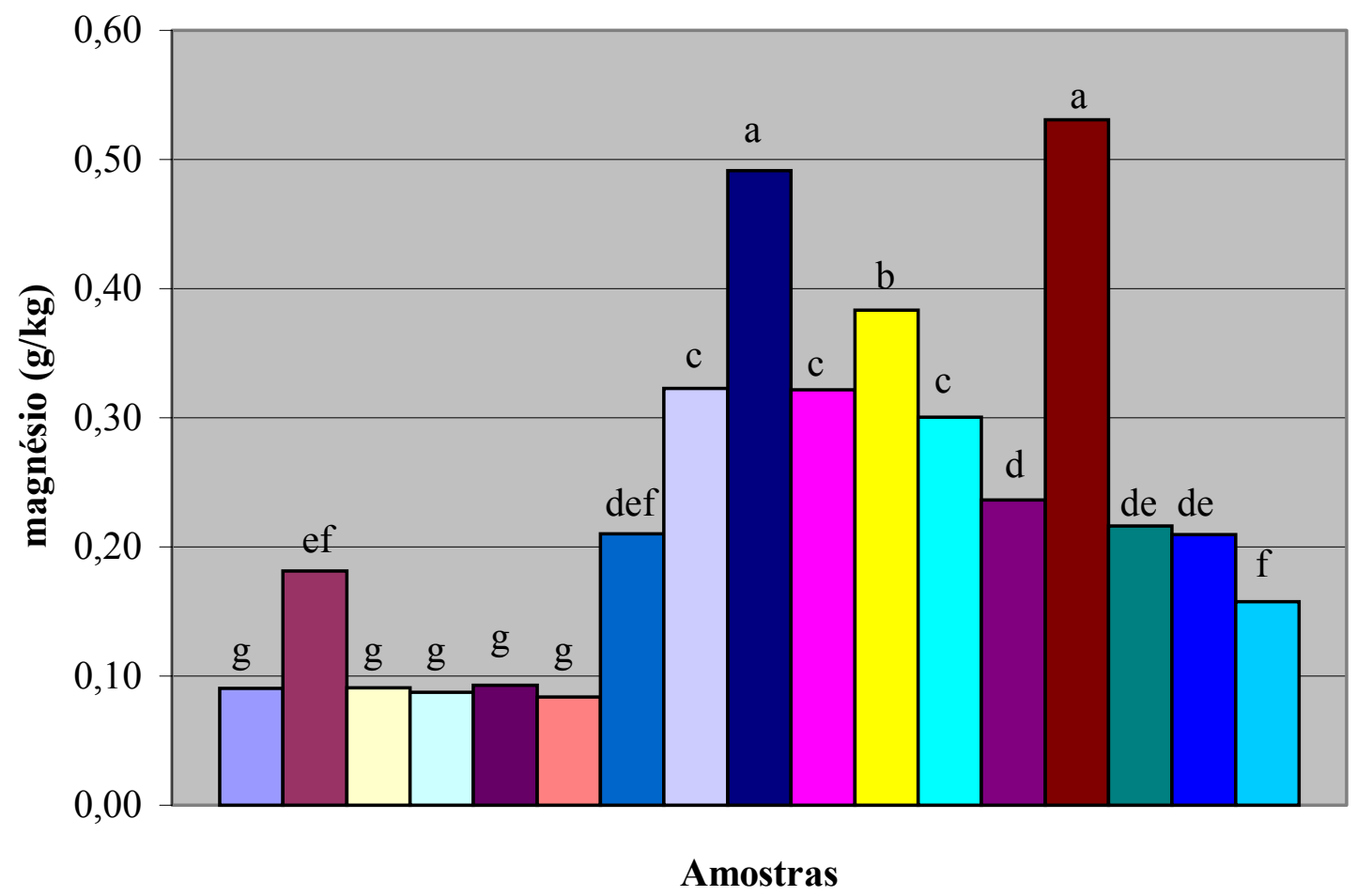

\begin{tabular}{|llllll|}
\hline $\mathrm{C}$ & $\square \mathrm{C}+\mathrm{A} 1$ & $\square \mathrm{C}+\mathrm{N} 1$ & $\square \mathrm{C}+\mathrm{N} 2$ & $\square \mathrm{C}+\mathrm{Fer} 1$ & $\square \mathrm{C}+\mathrm{Fer} 2$ \\
$\square \mathrm{C}+\mathrm{F}$ & $\square \mathrm{F}$ & $\square \mathrm{F}+\mathrm{A} 1$ & $\square \mathrm{F}+\mathrm{Fer} 2$ & $\square \mathrm{F}+\mathrm{N} 2$ & $\square \mathrm{F}+\mathrm{Fi}$ \\
$\square \mathrm{Fi}$ & $\square \mathrm{Fi}+\mathrm{A} 1$ & $\square \mathrm{Fi}+\mathrm{Fer} 1$ & $\square \mathrm{Fi}+\mathrm{N} 1$ & $\square \mathrm{Fi}+\mathrm{C}$ &
\end{tabular}

$\mathbf{C}=$ cenoura $\mathbf{F}=$ feijão; $\mathbf{F i}=$ fígado; $\mathbf{A 1}=$ Arovit $(15 \mathrm{mg}) ; \mathbf{F e r} 1=$ Fer-In-Sol $(78,67 \mathrm{mg}) ; \mathbf{F e r 2}=$ Fer-InSol (211,17mg); N1= Neutrofer (78,67 mg); N2 = Neutrofer (211,17mg); valores representam média de 3 repetições; letras diferentes indicam diferença significativa $(\mathrm{p} \leq 0,05)$

Figura 9 - Concentração de magnésio (g/kg), em base úmida. 


\subsubsection{Fósforo}

A figura 10 representa a quantidade de fósforo $(\mathrm{g} / \mathrm{kg})$, em base úmida, das amostras analisadas.

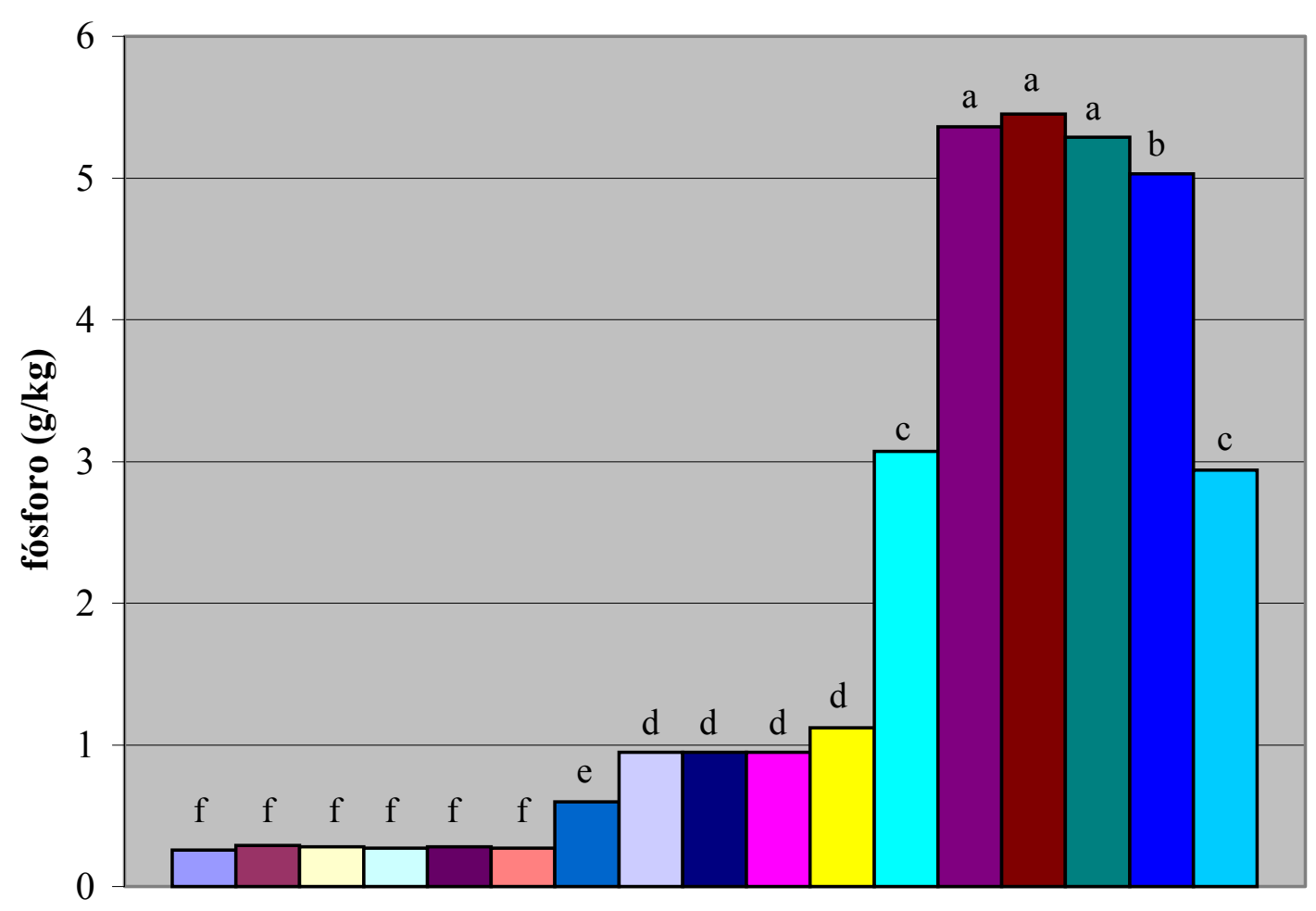

Amostras

\begin{tabular}{|llllll|}
$\square \mathrm{C}$ & $\square \mathrm{C}+\mathrm{A} 1$ & $\square \mathrm{C}+\mathrm{N} 1$ & $\square \mathrm{C}+\mathrm{N} 2$ & $\square \mathrm{C}+\mathrm{Fer} 1$ & $\square \mathrm{C}+\mathrm{Fer} 2$ \\
$\square \mathrm{C}+\mathrm{F}$ & $\square \mathrm{F}$ & $\square \mathrm{F}+\mathrm{A} 1$ & $\square \mathrm{F}+\mathrm{Fer} 2$ & $\square \mathrm{F}+\mathrm{N} 2$ & $\square \mathrm{F}+\mathrm{Fi}$ \\
$\square \mathrm{Fi}$ & $\square \mathrm{Fi}+\mathrm{A} 1$ & $\square \mathrm{Fi}+\mathrm{Fer} 1$ & $\square \mathrm{Fi}+\mathrm{N} 1$ & $\square \mathrm{Fi}+\mathrm{C}$ & \\
\hline
\end{tabular}

$\mathbf{C}=$ cenoura; $\mathbf{F}=$ feijão; $\mathbf{F i}=$ fígado $\mathbf{A} \mathbf{1}=$ Arovit $(15 \mathrm{mg}) ;$ Fer1 $=$ Fer-In-Sol $(78,67 \mathrm{mg}) ; \mathbf{F e r} \mathbf{2}=$ Fer-InSol (211,17mg); N1= Neutrofer (78,67 mg); N2 = Neutrofer $(211,17 \mathrm{mg})$; valores representam média de 3 repetições; letras diferentes indicam diferença significativa $(\mathrm{p} \leq 0,05)$

Figura 10 - Concentração de fósforo $(\mathrm{g} / \mathrm{kg})$, em base úmida. 
A quantidade de fósforo das amostras variou de $0,26 \mathrm{~g} / \mathrm{kg}$ (C) a $5,44 \mathrm{~g} / \mathrm{kg}$ ( $\mathrm{Fi}+\mathrm{A} 1)$. O fígado e suas misturas apresentaram as maiores médias, seguido pelo feijão, pela cenoura e por suas respectivas misturas. Em relação à mistura entre alimentos, a maior concentração de fósforo foi obtida pela amostra $\mathrm{F}+\mathrm{Fi}(3,07 \mathrm{~g} / \mathrm{kg})$, seguida por $\mathrm{Fi}+\mathrm{C}(2,94 \mathrm{~g} / \mathrm{kg})$ e $\mathrm{C}+\mathrm{F}(0,60 \mathrm{~g} / \mathrm{kg})$. Quanto à adição de medicamentos aos alimentos, tanto para a cenoura quanto para o feijão, não houve diferença estatística entre as respectivas misturas.

A concentração de fósforo na amostra de cenoura foi de $0,26 \mathrm{~g} / \mathrm{kg}$, valor abaixo ao descrito na literatura, $0,44 \mathrm{~g} / \mathrm{kg}$ (Philippi, 2001).

A concentração de fósforo do feijão foi de $0,95 \mathrm{~g} / \mathrm{kg}$ o que corresponde a 3,75 $\mathrm{g} / \mathrm{kg}$ na base seca. Canniatti-Brazaca \& Silva (1999) obtiveram valor semelhante $(3,96$ $\mathrm{g} / \mathrm{kg}$ na base seca).

Já o fígado apresentou concentração superior ao descrito por Philippi (2001), que foi de $4,46 \mathrm{~g} / \mathrm{kg}$.

\subsubsection{Enxofre}

O enxofre existe em diversos aminoácidos essenciais e em certas vitaminas (Silva, 1994). A quantidade de enxofre variou de $0,09 \mathrm{~g} / \mathrm{kg}$ (C) a 3,26 g/kg (Fi). As maiores quantidades de enxofre foram encontradas nas amostras contendo fígado e suas misturas.

A figura 11 representa a concentração de enxofre $(\mathrm{g} / \mathrm{kg})$, em base úmida das amostras analisadas. 


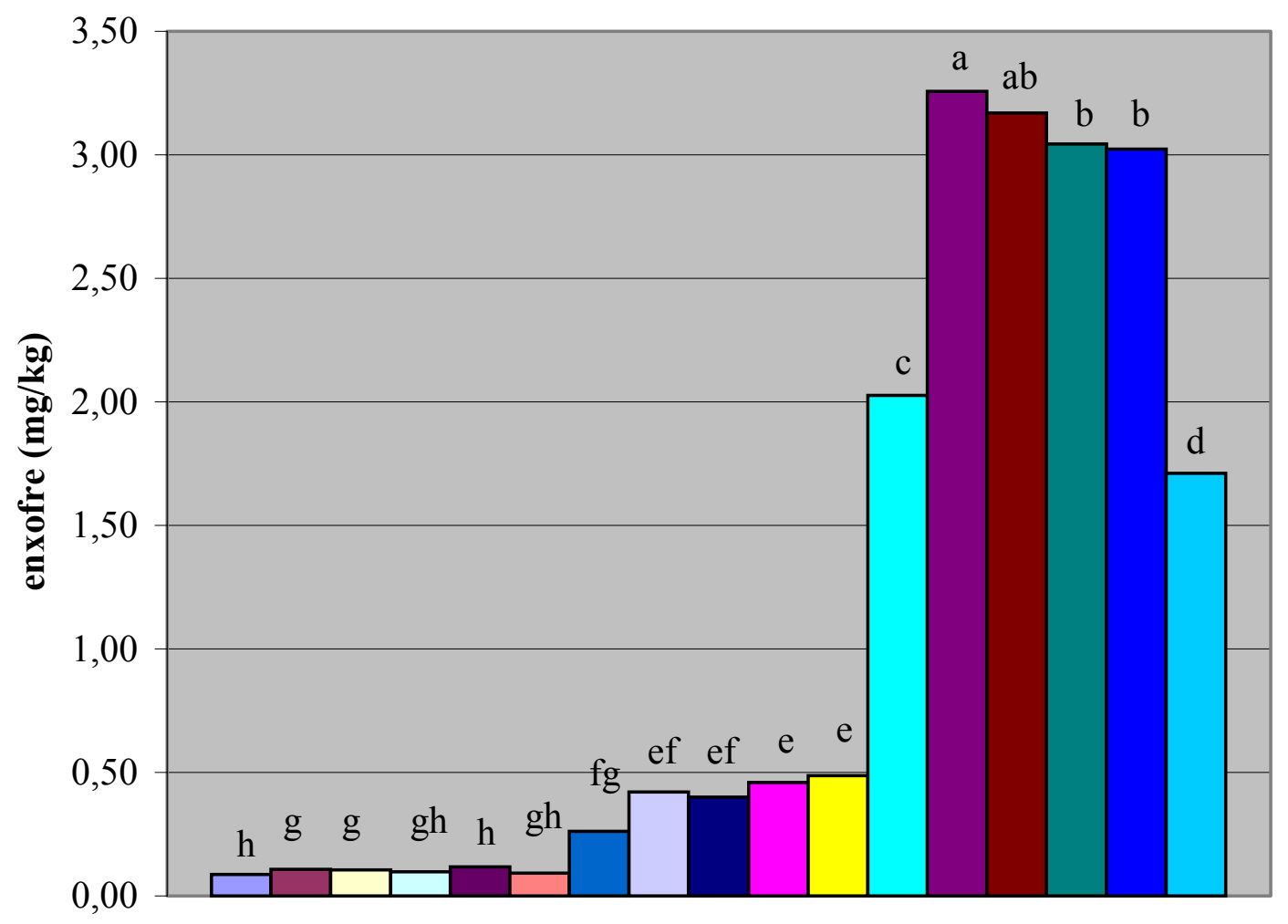

Amostras

\begin{tabular}{|llllll|}
\hline $\mathrm{C}$ & $\square \mathrm{C}+\mathrm{A} 1$ & $\square \mathrm{C}+\mathrm{N} 1$ & $\square \mathrm{C}+\mathrm{N} 2$ & $\square \mathrm{C}+\mathrm{Fer} 1$ & $\square \mathrm{C}+\mathrm{Fer} 2$ \\
$\square \mathrm{C}+\mathrm{F}$ & $\square \mathrm{F}$ & $\square \mathrm{F}+\mathrm{A} 1$ & $\square \mathrm{F}+\mathrm{Fer} 2$ & $\square \mathrm{F}+\mathrm{N} 2$ & $\square \mathrm{F}+\mathrm{Fi}$ \\
$\square \mathrm{Fi}$ & $\square \mathrm{Fi}+\mathrm{A} 1$ & $\square \mathrm{Fi}+\mathrm{Fer} 1$ & $\square \mathrm{Fi}+\mathrm{N} 1$ & $\square \mathrm{Fi}+\mathrm{C}$ & \\
\hline
\end{tabular}

$\mathbf{C}=$ cenoura; $\mathbf{F}=$ feijão; $\mathbf{F i}=$ fígado; $\mathbf{A 1}=$ Arovit $(15 \mathrm{mg}) ; \mathbf{F e r 1}=$ Fer-In-Sol $(78,67 \mathrm{mg}) ;$ Fer2 $=$ Fer-InSol (211,17mg); N1= Neutrofer (78,67 mg); N2 = Neutrofer (211,17mg); valores representam média de 3 repetições; letras diferentes indicam diferença significativa $(\mathrm{p} \leq 0,05)$

Figura 11 - Concentração de enxofre ( $\mathrm{g} / \mathrm{kg})$, em base úmida. 


\subsubsection{Cobre}

A figura 12 representa a concentração de cobre $(\mathrm{mg} / \mathrm{kg})$, em base úmida, das amostras analisadas.

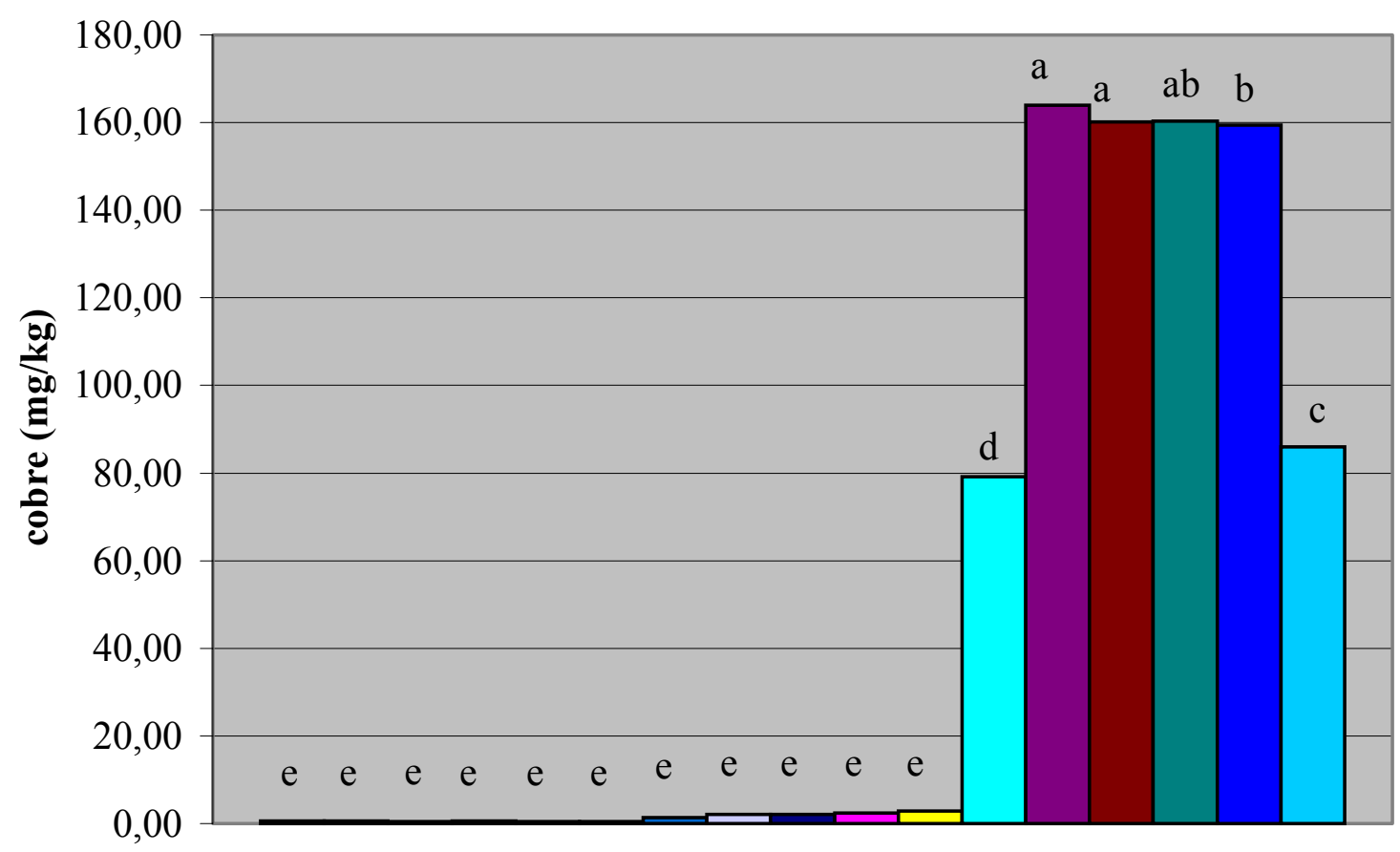

Amostras

\begin{tabular}{|c|c|c|c|c|c|}
\hline$\square \mathrm{C}$ & $\square \mathrm{C}+\mathrm{A} 1$ & $\square \mathrm{C}+\mathrm{N} 1$ & $\square \mathrm{C}+\mathrm{N} 2$ & $\square \mathrm{C}+\mathrm{Fer} 1$ & $\square \mathrm{C}+\mathrm{Fer} 2$ \\
\hline$\square \mathrm{C}+\mathrm{F}$ & $\square \mathrm{F}$ & $\square \mathrm{F}+\mathrm{A} 1$ & $\square \mathrm{F}+\mathrm{Fer} 2$ & $\square \mathrm{F}+\mathrm{N} 2$ & $\square \mathrm{F}+\mathrm{Fi}$ \\
\hline$\square \mathrm{Fi}$ & $\square \mathrm{Fi}+\mathrm{A} 1$ & $\square \mathrm{Fi}+\mathrm{Fer} 1$ & $\square \mathrm{Fi}+\mathrm{N} 1$ & $\square \mathrm{Fi}+\mathrm{C}$ & \\
\hline
\end{tabular}

$\mathbf{C}=$ cenoura; $\mathbf{F}=$ feijão; $\mathbf{F i}=$ fígado $\mathbf{A 1}=$ Arovit $(15 \mathrm{mg}) ;$ Fer1 $=$ Fer-In-Sol $(78,67 \mathrm{mg}) ;$ Fer2 $=$ Fer-InSol (211,17mg); N1= Neutrofer (78,67 mg); N2 = Neutrofer (211,17mg); valores representam média de 3 repetições; letras diferentes indicam diferença significativa $(\mathrm{p} \leq 0,05)$

Figura 12 - Concentração de cobre $(\mathrm{mg} / \mathrm{kg})$, em base úmida. 
A quantidade de cobre variou de $0,44 \mathrm{mg} / \mathrm{kg}(\mathrm{C}+\mathrm{Fer} 2)$ a $163,94 \mathrm{mg} / \mathrm{kg}(\mathrm{F} 1)$. A amostra de cenoura $(\mathrm{C}),(\mathrm{C}+\mathrm{F})$ e cenoura adicionada de medicamentos não diferiram estatisticamente entre si, também não diferindo da amostra de feijão $(\mathrm{F}),(\mathrm{F}+\mathrm{N} 2)$, $(\mathrm{F}+\mathrm{Fer} 2)$ e $(\mathrm{F}+\mathrm{A} 1)$. A concentração de cobre nas amostras contendo fígado e suas misturas foi superior das demais amostras.

A concentração de cobre da amostra de cenoura (C) $(0,57 \mathrm{mg} / \mathrm{kg})$ e de feijão $(\mathrm{F})$, foi semelhante à descrita por Philippi (2001), que foi de $0,50 \mathrm{mg} / \mathrm{kg}$ e 2,09 $\mathrm{mg} / \mathrm{kg}$, respectivamente. Já para a amostra de fígado (Fi), o valor obtido no presente trabalho foi superior ao descrito por Philippi (2001), que foi de 43,04 mg/kg.

\subsubsection{Manganês}

O manganês, quando presente em proporção 300 vezes maior que o ferro, possui efeito inibitório sobre a absorção de ferro não-heme, devido a propriedades físicoquímicas semelhantes (Rossander-Hulten et al., 1991).

A quantidade de manganês variou de $0,54 \mathrm{mg} / \mathrm{kg}(\mathrm{C}+\mathrm{Fer} 1)$ a $5,28 \mathrm{mg} / \mathrm{kg}(\mathrm{Fi})$. A concentração de manganês não teve interferência sobre a disponibilidade de ferro das amostras. Não houve diferença estatística entre a cenoura e suas misturas com medicamentos.

As concentrações de manganês encontradas nas amostras de cenoura (C), feijão (F) e fígado (Fi), foram superiores às descritas por Philippi (2001) que foram de 0,14 $\mathrm{mg} / \mathrm{kg}$, zero e $4,39 \mathrm{mg} / \mathrm{kg}$, respectivamente.

A figura 13 representa a concentração de manganês $(\mathrm{mg} / \mathrm{kg})$, em base úmida, das amostras analisadas. 


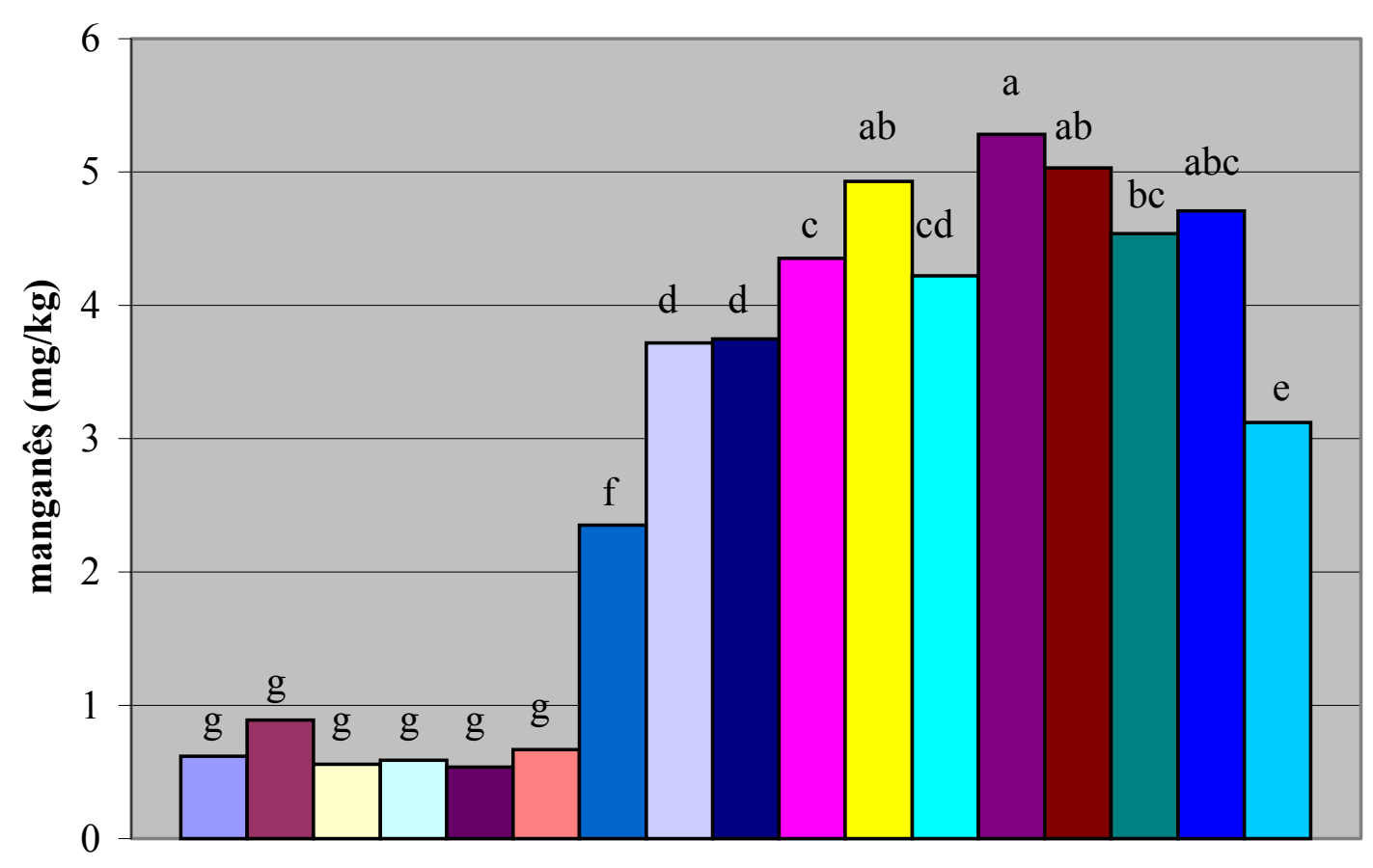

Amostras

\begin{tabular}{|llllll|}
\hline$\square \mathrm{C}$ & $\square \mathrm{C}+\mathrm{A} 1$ & $\square \mathrm{C}+\mathrm{N} 1$ & $\square \mathrm{C}+\mathrm{N} 2$ & $\square \mathrm{C}+\mathrm{Fer} 1$ & $\square \mathrm{C}+\mathrm{Fer} 2$ \\
$\square \mathrm{C}+\mathrm{F}$ & $\square \mathrm{F}$ & $\square \mathrm{F}+\mathrm{A} 1$ & $\square \mathrm{F}+\mathrm{Fer} 2$ & $\square \mathrm{F}+\mathrm{N} 2$ & $\square \mathrm{F}+\mathrm{Fi}$ \\
$\square \mathrm{Fi}$ & $\square \mathrm{Fi}+\mathrm{A} 1$ & $\square \mathrm{Fi}+\mathrm{Fer} 1$ & $\square \mathrm{Fi}+\mathrm{N} 1$ & $\square \mathrm{Fi}+\mathrm{C}$ & \\
\hline
\end{tabular}

$\mathbf{C}=$ cenoura; $\mathbf{F}=$ feijão; $\mathbf{F i}=$ fígado; $\mathbf{A 1}=$ Arovit $(15 \mathrm{mg}) ; \mathbf{F e r 1}=$ Fer-In-Sol $(78,67 \mathrm{mg}) ;$ Fer2 $=$ Fer-InSol (211,17mg); N1= Neutrofer (78,67 mg); N2 = Neutrofer (211,17mg); valores representam média de 3 repetições; letras diferentes indicam diferença significativa $(\mathrm{p} \leq 0,05)$

Figura 13 - Concentração de manganês (mg/kg), em base úmida. 


\subsubsection{Zinco}

A figura 14 representa a concentração de zinco $(\mathrm{mg} / \mathrm{kg})$, em base úmida, das amostras analisadas.

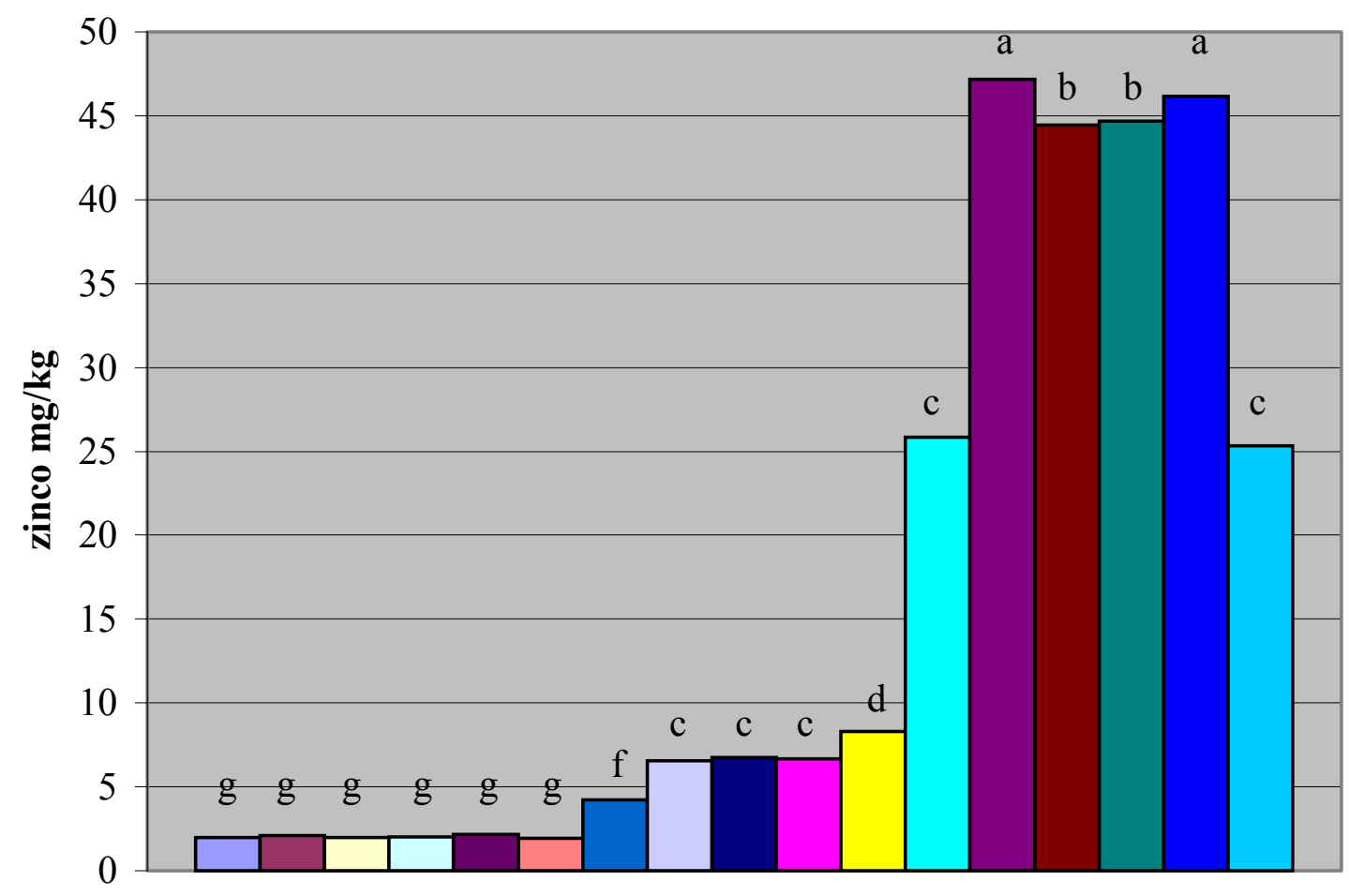

Amostras

\begin{tabular}{|llllll|}
$\square \mathrm{C}$ & $\square \mathrm{C}+\mathrm{A} 1$ & $\square \mathrm{C}+\mathrm{N} 1$ & $\square \mathrm{C}+\mathrm{N} 2$ & $\square \mathrm{C}+\mathrm{Fer} 1$ & $\square \mathrm{C}+\mathrm{Fer} 2$ \\
$\square \mathrm{C}+\mathrm{F}$ & $\square \mathrm{F}$ & $\square \mathrm{F}+\mathrm{A} 1$ & $\square \mathrm{F}+\mathrm{Fer} 2$ & $\square \mathrm{F}+\mathrm{N} 2$ & $\square \mathrm{F}+\mathrm{Fi}$ \\
$\square \mathrm{Fi}$ & $\square \mathrm{Fi}+\mathrm{A} 1$ & $\square \mathrm{Fi}+\mathrm{Fer} 1$ & $\square \mathrm{Fi}+\mathrm{N} 1$ & $\square \mathrm{Fi}+\mathrm{C}$ & \\
\hline
\end{tabular}

$\mathbf{C}=$ cenoura $\mathbf{F}=$ feijão; $\mathbf{F i}=$ fígado $\mathbf{A} 1=$ Arovit $(15 \mathrm{mg}) ; \mathbf{F e r} 1=$ Fer-In-Sol $(78,67 \mathrm{mg}) ; \mathbf{F e r} 2=$ Fer-InSol (211,17mg); N1= Neutrofer (78,67 mg); N2 = Neutrofer (211,17mg); valores representam média de 3 repetições; letras diferentes indicam diferença significativa $(\mathrm{p} \leq 0,05)$

Figura 14 - Concentração de zinco (mg/kg), em base úmida. 
O zinco possui ação inibitória sobre a absorção de ferro não heme, quando o conteúdo é 5 vezes maior que o conteúdo de ferro (Rossander-Hulten et al., 1991).

A quantidade de zinco nas amostras variou de $1,95 \mathrm{mg} / \mathrm{kg}$ (C+Fer1) a 47,17 $\mathrm{mg} / \mathrm{kg}$ (Fi). A quantidade de zinco das amostras não interferiu na quantidade de ferro disponível das mesmas. As maiores quantidades de zinco foram encontradas nas amostras contendo fígado e suas misturas. Dentre as misturas de alimentos, $\mathrm{Fi}+\mathrm{F}$ obteve maior valor $(25,85 \mathrm{mg} / \mathrm{kg})$, seguido por $\mathrm{Fi}+\mathrm{C}(25,33 \mathrm{mg} / \mathrm{kg})$ e C+F. $(4,21 \mathrm{mg} / \mathrm{kg})$.

\subsubsection{Ferro}

A quantidade de ferro nas amostras analisadas variou de $2,77 \mathrm{mg} / \mathrm{kg}(\mathrm{C}+\mathrm{A})$ a $138,58 \mathrm{mg} / \mathrm{kg}$ (Fi+Fer1). A maior quantidade de ferro foi encontrada nas amostras de fígado adicionado de ferro na forma de sulfato e aminoquelato. De maneira geral, os alimentos adicionados de sulfato ferroso obtiveram maior concentração de ferro do que aqueles adicionados de ferro na forma de quelato. Quanto às misturas entre alimentos, o $\mathrm{F}+\mathrm{Fi}(55,18 \mathrm{mg} / \mathrm{kg})$ obteve maior concentração de ferro do que $\mathrm{Fi}+\mathrm{C}(53,30 \mathrm{mg} / \mathrm{kg})$ e $\mathrm{C}+\mathrm{F}(7,92 \mathrm{mg} / \mathrm{kg})$.

A quantidade de ferro encontrada na amostra de cenoura foi de $4,01 \mathrm{mg} / \mathrm{kg}$, valor semelhante ao descrito por Vora et al. (1998), $4 \mathrm{mg} / \mathrm{kg}$ e Philippi (2001), $5 \mathrm{mg} / \mathrm{kg}$. Para o feijão, a quantidade de ferro foi de $14,95 \mathrm{mg} / \mathrm{kg}$ na base úmida, o que corresponde a $58,75 \mathrm{mg} / \mathrm{kg}$ na base seca. Maldonado \& Sammán (2000) verificaram em 10 variedades de feijão cru uma variação de 89,1 a $760,03 \mathrm{mg} / \mathrm{kg}$ de ferro na base seca. Sammán et al. (1999) encontraram também na base seca a concentração de ferro em torno de 53,3 a 200,26 mg/kg. Canniatti-Brazaca \& Silva (1999) encontraram 93,15 mg/kg de ferro em feijão carioca cozido expressos na base seca.

A amostra de fígado obteve quantidade de ferro $(102,56 \mathrm{mg} / \mathrm{kg})$ semelhante à descrita por Rangan et al. (1997), que foi de $100,7 \mathrm{mg} / \mathrm{kg}$ e superior à descrita por Philippi (2001), que foi de 60,82 mg/kg, ambos para fígado bovino cozido. Carpenter \& Clark (1995) encontraram $194 \mathrm{mg} / \mathrm{kg}$ de ferro total em fígado bovino.

A figura 15 representa a concentração de ferro $(\mathrm{mg} / \mathrm{kg})$, em base úmida, das amostras analisadas 


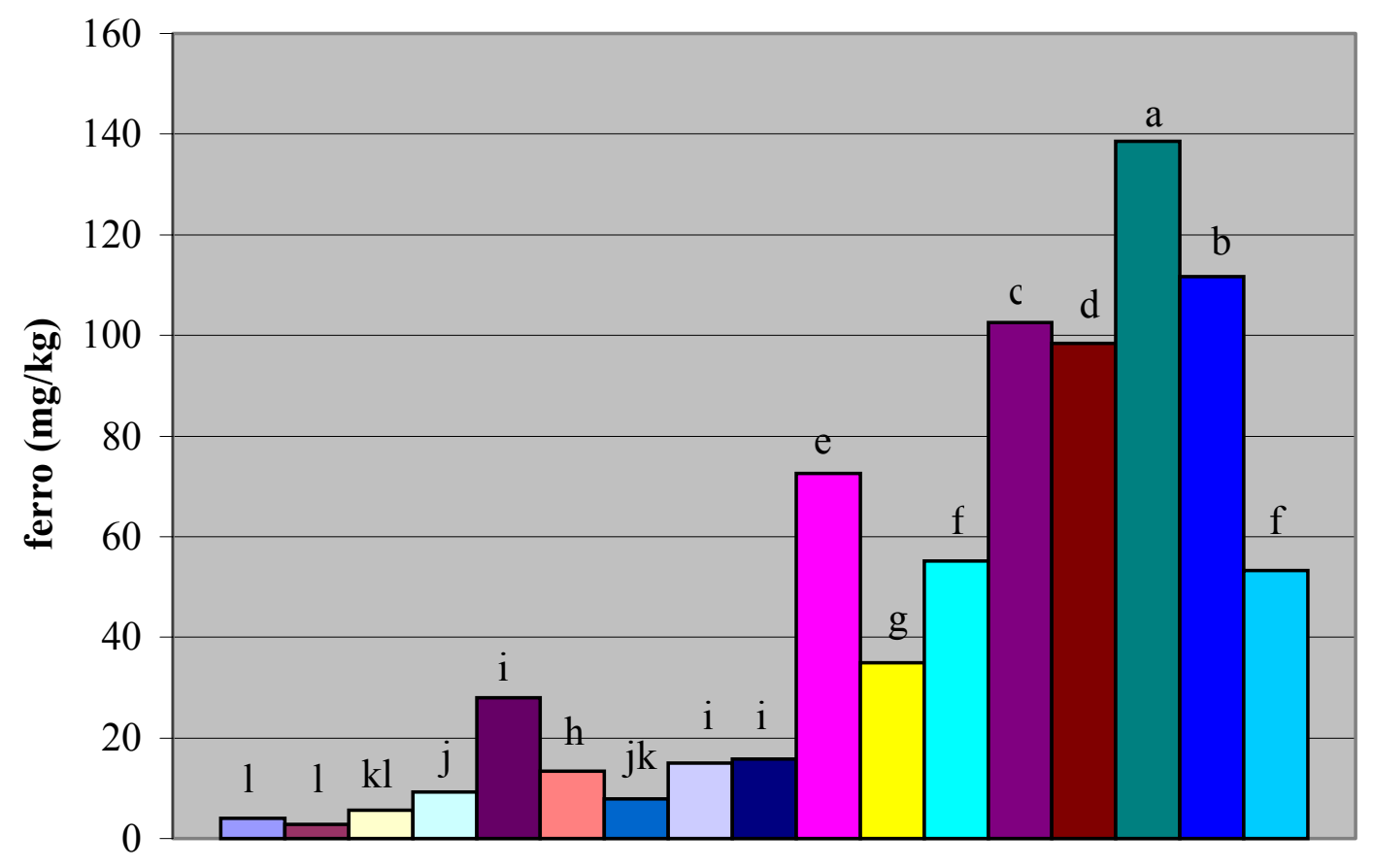

Amostras

\begin{tabular}{|llllll|}
\hline $\mathrm{C}$ & $\square \mathrm{C}+\mathrm{A} 1$ & $\square \mathrm{C}+\mathrm{N} 1$ & $\square \mathrm{C}+\mathrm{N} 2$ & $\square \mathrm{C}+\mathrm{Fer} 1$ & $\square \mathrm{C}+\mathrm{Fer} 2$ \\
$\square \mathrm{C}+\mathrm{F}$ & $\square \mathrm{F}$ & $\square \mathrm{F}+\mathrm{A} 1$ & $\square \mathrm{F}+\mathrm{Fer} 2$ & $\square \mathrm{F}+\mathrm{N} 2$ & $\square \mathrm{F}+\mathrm{Fi}$ \\
$\square \mathrm{Fi}$ & $\square \mathrm{Fi}+\mathrm{A} 1$ & $\square \mathrm{Fi}+\mathrm{Fer} 1$ & $\square \mathrm{Fi}+\mathrm{N} 1$ & $\square \mathrm{Fi}+\mathrm{C}$ & \\
\hline
\end{tabular}

$\mathbf{C}=$ cenoura; $\mathbf{F}=$ feijão; $\mathbf{F i}=$ fígado; $\mathbf{A 1}=$ Arovit $(15 \mathrm{mg}) ; \mathbf{F e r 1}=$ Fer-In-Sol $(78,67 \mathrm{mg}) ;$ Fer2 $=$ Fer-InSol (211,17mg); N1= Neutrofer (78,67 mg); N2 = Neutrofer (211,17mg); valores representam média de 3 repetições; letras diferentes indicam diferença significativa $(\mathrm{p} \leq 0,05)$

Figura 15 - Concentração de ferro $(\mathrm{mg} / \mathrm{kg})$, em base úmida. 


\subsection{Antinutricionais: Taninos e Ácido fítico}

O feijão comum cru apresenta certas substâncias antinutricionais e tóxicas tais como taninos, fitatos, fitohemaglutininas, antitripsinas, agentes bocigênicos e de flatulência. Essas substâncias são geralmente eliminadas através do uso da maceração, seguida do tratamento térmico a elevada temperatura na remoção dessas substâncias tóxicas (Reyes-Moreno \& Paredes López, 1993).

Mosha et al. (1995) verificaram que, após 10 minutos de cozimento doméstico ocorreu redução de $30 \%$ dos teores de ácido fítico e taninos, porém ressaltaram a necessidade de maiores estudos quanto ao tempo de cozimento. Oliveira et al. (2001) verificaram acentuada redução dos teores de fitatos e taninos, após a maceração com descarte da água, seguida de cocção. 


\subsubsection{Taninos}

A figura 16 representa a porcentagem de taninos, em base úmida, das amostras de feijão e suas respectivas misturas.

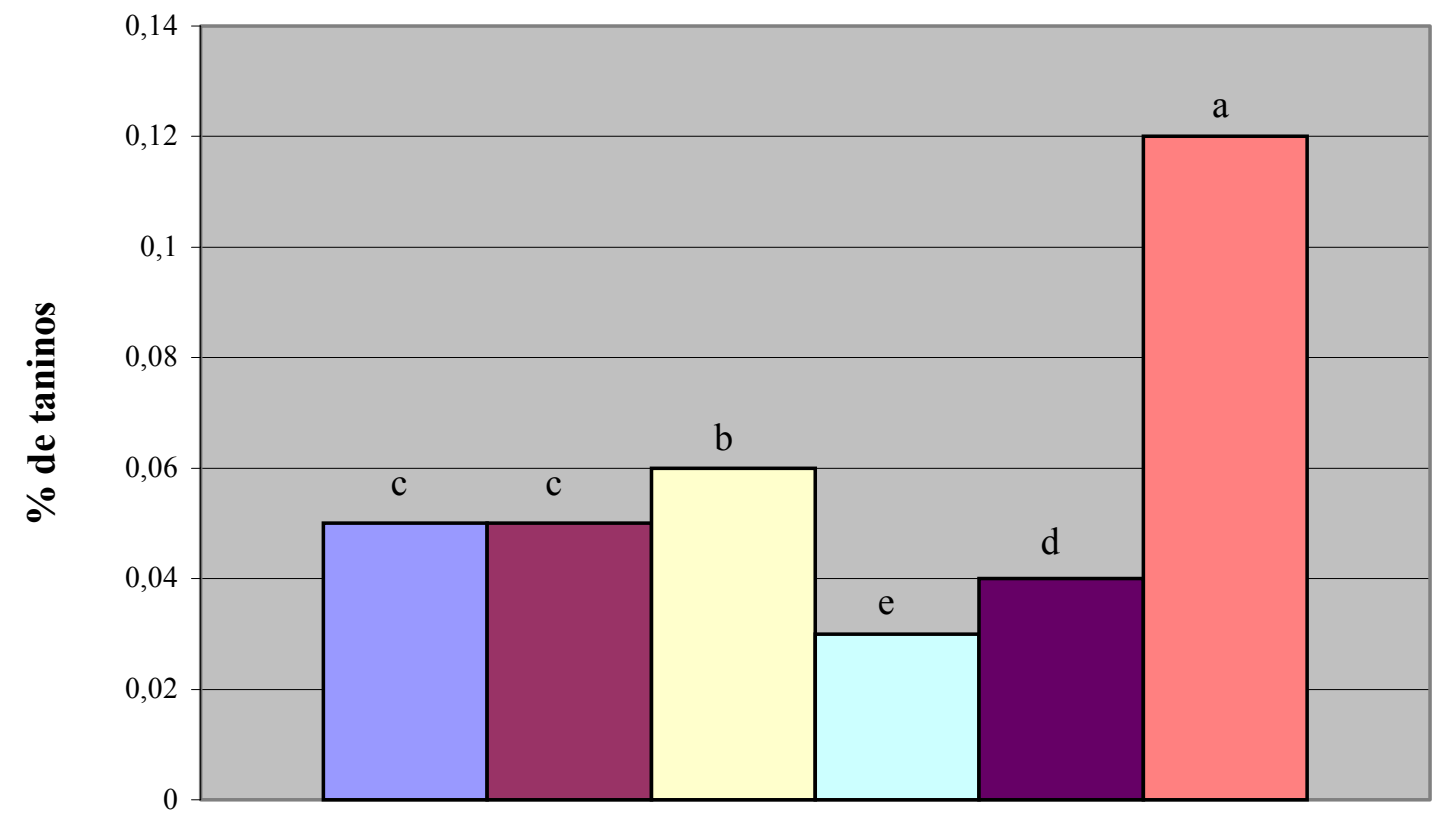

Amostras

$\square \mathrm{C}+\mathrm{F} \quad \square \mathrm{F} \quad \square \mathrm{F}+\mathrm{A} \quad \square \mathrm{F}+\mathrm{Fer} 2 \quad \square \mathrm{F}+\mathrm{N} 2 \quad \square \mathrm{F}+\mathrm{Fi}$

$\mathbf{C}=$ cenoura $; \mathbf{F}=$ feijão; $\mathbf{F i}=$ fígado $\mathbf{A 1}=$ Arovit $(15 \mathrm{mg}) ; \mathbf{F e r} 1=$ Fer-In-Sol $(78,67 \mathrm{mg}) ; \mathbf{F e r} 2=$ Fer-InSol (211,17mg); N1= Neutrofer (78,67 mg); N2 = Neutrofer (211,17mg); valores representam média de 3 repetições; letras diferentes indicam diferença significativa $(\mathrm{p} \leq 0,05)$

Figura 16 - Porcentagem de taninos, em base úmida. 
Os taninos pertencem à classe dos polifenóis e podem ser classificados em 2 grupos baseados no tipo estrutural: condensado e hidrolisado, sendo o condensado o de maior ocorrência na natureza. Os taninos possuem a capacidade de se ligar às proteínas, tornando-as insolúveis (Reyes-Moreno \& Paredes-Lopéz, 1993).

A porcentagem de taninos foi avaliada somente nas amostras contendo feijão, havendo variação entre $0,03 \%(\mathrm{~F}+\mathrm{Fer} 2)$ a $0,12 \%(\mathrm{~F}+\mathrm{Fi})$.

A quantidade de taninos encontrada na amostra de feijão (F) foi de $0,05 \%$ na matéria úmida, o que corresponde a $0,18 \%$ na matéria seca. Weder et al. (1997) encontraram para o grão cru variação de 0,57 \% a 0,73 \%. Paredes-López \& Harry (1989) encontraram $0,95 \%$ de taninos para grãos crus de feijão comum. CanniattiBrazaca \& Silva (1999) encontraram $0,034 \%$ de taninos na matéria seca do feijão cozido. De acordo com Goycoolera et al. (1990), o teor de taninos no feijão cozido é menor do que no cru, sendo também influenciado pelo modo de preparo. Oliveira et al. (2001) observaram que somente o processo de cozimento ocasionou uma redução do conteúdo de taninos e que o melhor tratamento para a remoção de taninos foi a maceração, seguida da cocção sem a água de maceração, em que a redução do teor de taninos chegou a $88 \%$. 


\subsection{2 Ácido fítico}

A figura 17 representa a quantidade de ácido fítico $(\mathrm{mg} / \mathrm{g})$, em base úmida, da amostra de feijão e suas respectivas misturas.

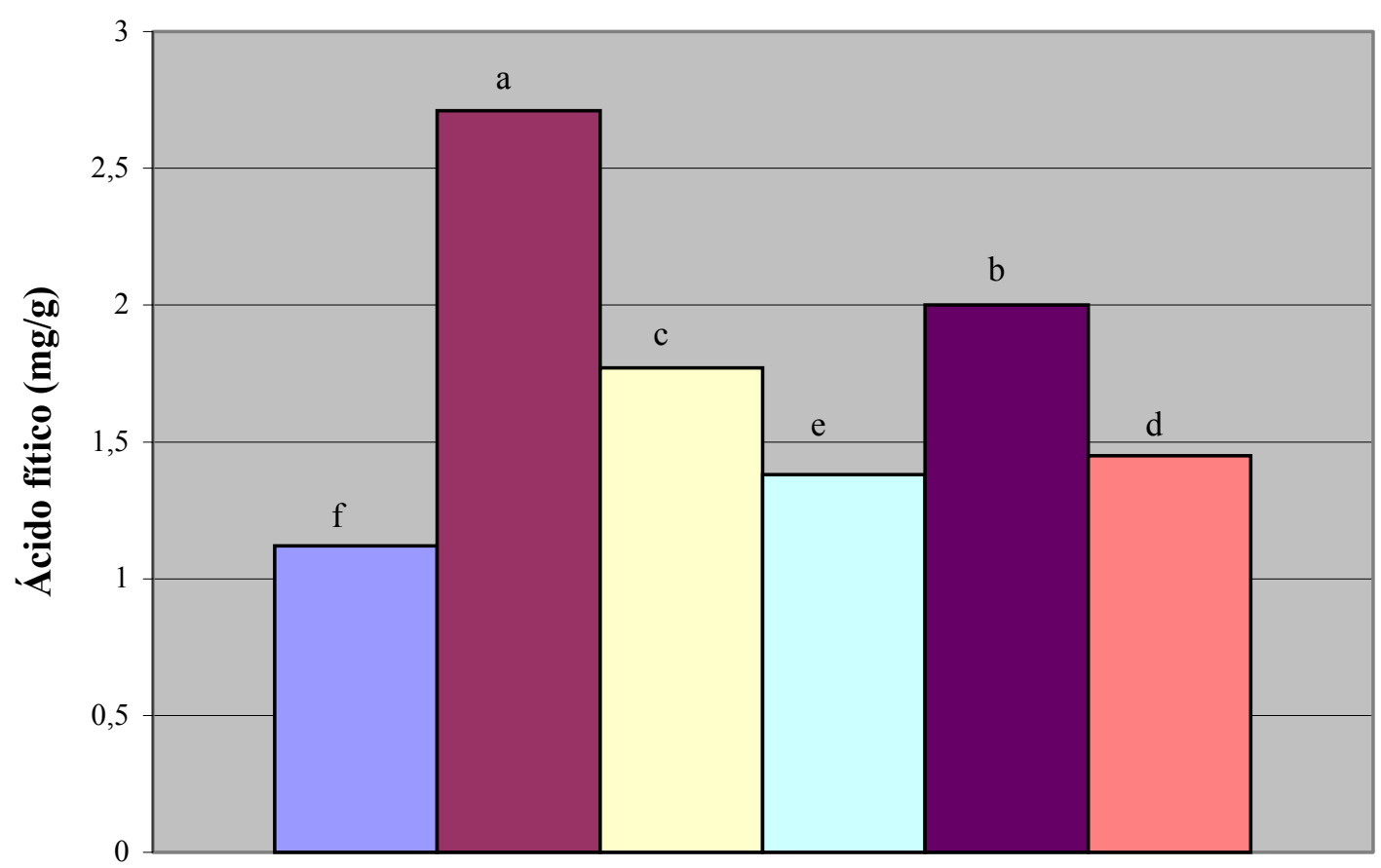

Amostras

\section{$\square \mathrm{C}+\mathrm{F} \quad \square \mathrm{F} \quad \square \mathrm{F}+\mathrm{A} \quad \square \mathrm{F}+\mathrm{Fer} 2 \quad \square \mathrm{F}+\mathrm{N} 2 \quad \square \mathrm{F}+\mathrm{Fi}$}

$\mathbf{C}=$ cenoura; $\mathbf{F}=$ feijão; $\mathbf{F i}=$ fígado; $\mathbf{A 1}=$ Arovit $(15 \mathrm{mg}) ;$ Fer1 $=$ Fer-In-Sol $(78,67 \mathrm{mg}) ;$ Fer2 = Fer-InSol (211,17mg); N1= Neutrofer (78,67 mg); N2 = Neutrofer (211,17mg); valores representam média de 3 repetições; letras diferentes indicam diferença significativa $(\mathrm{p} \leq 0,05)$

Figura 17 - Concentração de ácido fítico (mg/g), em base úmida. 
O ácido fítico é um ácido orgânico com função de metal quelato, que interfere na disponibilidade biológica de minerais presentes na dieta, tais como: cálcio, zinco, ferro e magnésio (Mosha et al. 1995). A interação do ácido fítico com minerais e proteínas é considerado um dos principais fatores limitantes do valor nutritivo das leguminosas (Reyes-Moreno \& Paredes-Lopéz, 1993).

Neste trabalho houve variação de $1,12 \mathrm{mg} / \mathrm{g}(\mathrm{C}+\mathrm{F})$ a $2,71 \mathrm{mg} / \mathrm{g}(\mathrm{F})$ do conteúdo de ácido fítico das amostras. Todas as amostras diferiram estatisticamente.

A quantidade de ácido fítico encontrado no feijão foi de $2,71 \mathrm{mg} / \mathrm{g}$ na base úmida, correspondendo a 10,66 mg/g na base seca. Esse valor foi superior ao encontrado por Canniatti-Brazaca \& Silva (1999), que foi de $6,38 \mathrm{mg} / \mathrm{g}$ para o feijão carioca cozido na base seca. Paredes-López \& Harry (1989) encontraram 21 mg/g. Já GuzmánMaldonado et al. (2000), verificaram para o feijão cozido, uma variação entre 10,0 a $18,3 \mathrm{mg} / \mathrm{g}$ para espécies de feijões selvagens e 7,3 a 10,8 mg/g para os feijões comuns.

Oliveira et al. (2001) observaram que a maceração ocasionou uma redução no teor de ácido fítico e que a maceração prévia à cocção, com descarte da água de maceração, obteve melhores resultados, reduzindo em até $85 \%$ o teor de fitatos. 


\subsection{Vitamina A, Retinol e Beta-caroteno}

\subsubsection{Vitamina A}

A figura 18 representa a concentração de vitamina A (UI/100g), em base úmida.

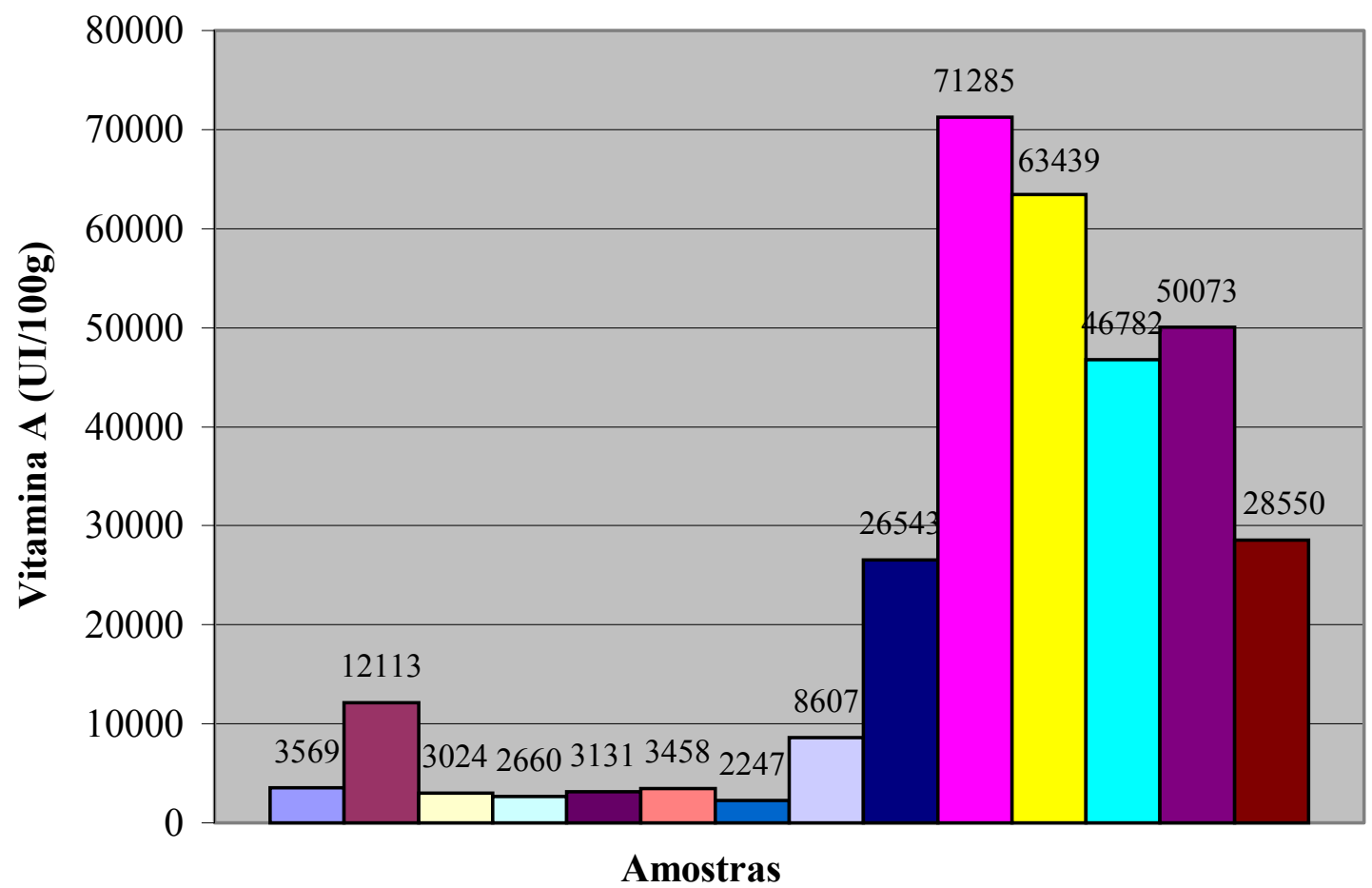

\begin{tabular}{|c|c|c|c|c|}
\hline$\square \mathrm{C}$ & $\square \mathrm{C}+\mathrm{A}$ & $\square \mathrm{C}+\mathrm{N}$ & $\square \mathrm{C}+\mathrm{N} 2$ & $\square \mathrm{C}+\mathrm{Fer} 1 \square \mathrm{C}+\mathrm{Fer} 2 \square \mathrm{C}+\mathrm{F}$ \\
\hline$\square F+A$ & $\mathrm{IF}+\mathrm{F} 1$ & LF1 & $\triangle \mathrm{F} 1+\mathrm{A}$ & $\Delta \mathrm{F} 1+\mathrm{Fer} 1 \mathrm{DF} 1+\mathrm{N}$ \\
\hline
\end{tabular}

$\mathbf{C}=$ cenoura; $\mathbf{F}=$ feijão; Fi $=$ fígado; $\mathbf{A 1}=$ Arovit $(15 \mathrm{mg}) ; \mathbf{F e r} \mathbf{1}=$ Fer-In-Sol $(78,67 \mathrm{mg}) ; \mathbf{F e r} \mathbf{2}=$ Fer-InSol (211,17mg); N1= Neutrofer (78,67 mg); N2 = Neutrofer (211,17mg); valores representam média de 3 repetições;

Figura 18 - Concentração de vitamina A (UI/100g), em base úmida. 
A quantidade de vitamina A nas amostras analisadas variou de $2247 \mathrm{UI} / 100 \mathrm{~g}$ $(\mathrm{C}+\mathrm{F})$ a $71285 \mathrm{UI} / 100 \mathrm{~g}$ (Fi). Para a cenoura, essa quantidade foi de $3569 \mathrm{UI} / 100 \mathrm{~g}$, valor inferior ao descrito por Philippi (2001), que foi de 9376,66 UI/100g. Já o fígado obteve concentração de vitamina A (71285 UI/100g), superior ao encontrado por Philippi (2001), que foi de 34395,9 UI/100g. Normalmente, a quantidade de vitamina A de um alimento é expressa em UI/100g. Por esse motivo, os valores de retinol e beta-caroteno das amostras foram convertidos em vitamina $\mathrm{A}$, e somados quando presentes na mesma amostra.

\subsubsection{Retinol}

A concentração de retinol das amostras analisadas variou de 2,58 mg/100g (F+A1) a 21,39 mg/100g (Fi).

A figura 19 representa a concentração de retinol (mg/100g), em base úmida, das amostras analisadas. 


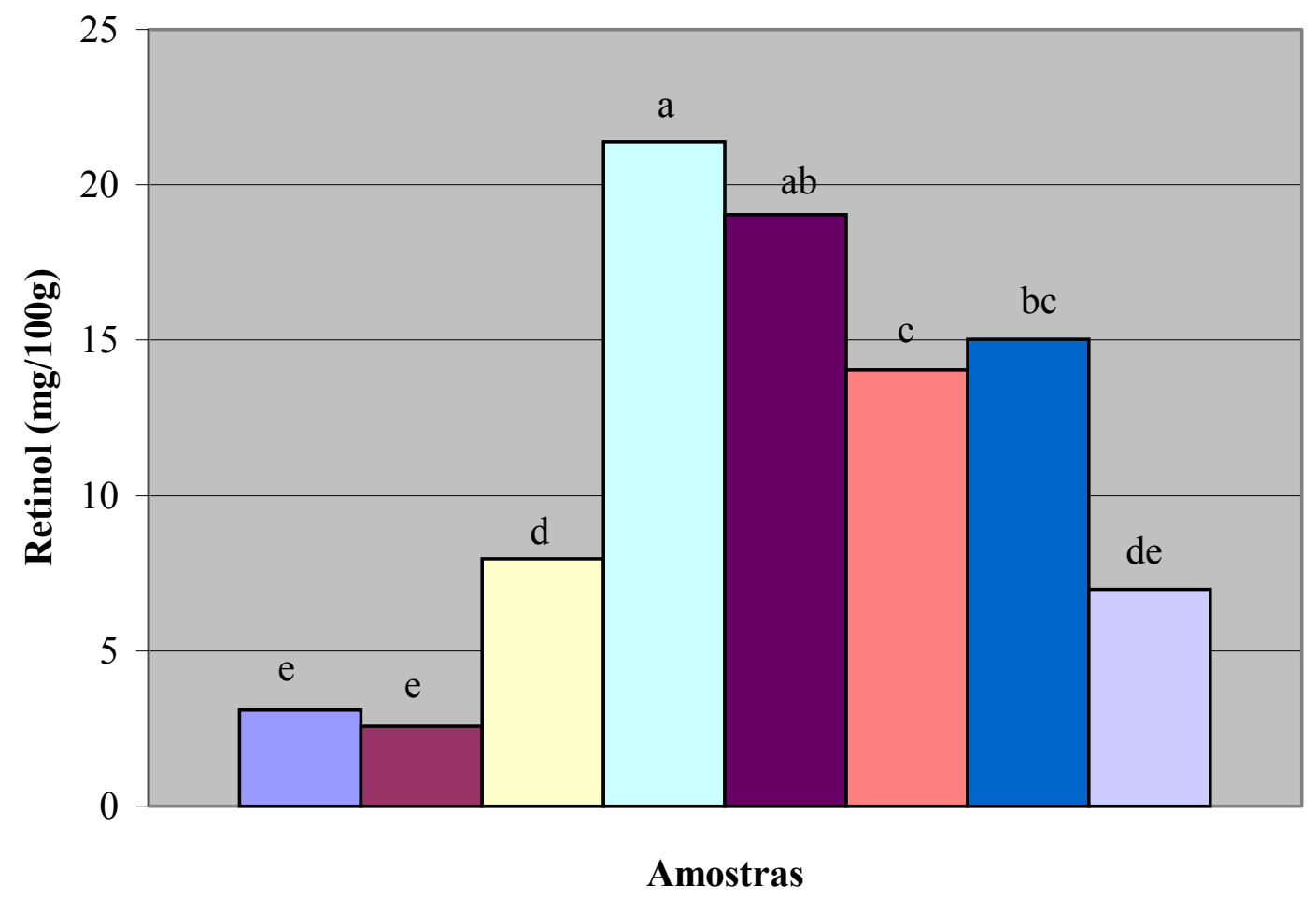

$\square \mathrm{C}+\mathrm{A} \square \mathrm{F}+\mathrm{A} \square \mathrm{F}+\mathrm{Fi} \square \mathrm{Fi} \square \mathrm{Fi}+\mathrm{A} \square \mathrm{Fi}+\mathrm{Fer} 1 \square \mathrm{Fi}+\mathrm{N} \square \mathrm{Fi}+\mathrm{C}$

$\mathbf{C}=$ cenoura; $\mathbf{F}=$ feijão; $\mathbf{F i}=$ fígado; $\mathbf{A 1}=$ Arovit $(15 \mathrm{mg}) ;$ Fer1 $=$ Fer-In-Sol $(78,67 \mathrm{mg}) ;$ Fer2 $=$ Fer-InSol (211,17mg); N1= Neutrofer (78,67 mg); N2 = Neutrofer (211,17mg); valores representam média de 3 repetições; letras diferentes indicam diferença significativa $(\mathrm{p} \leq 0,05)$

Figura 19 - Concentração de retinol (mg/100g), em base úmida. 


\subsubsection{Beta caroteno}

A figura 20 representa a concentração de beta caroteno $(\mathrm{mg} / 100 \mathrm{~g})$, em base úmida, da amostra de cenoura e suas respectivas misturas.

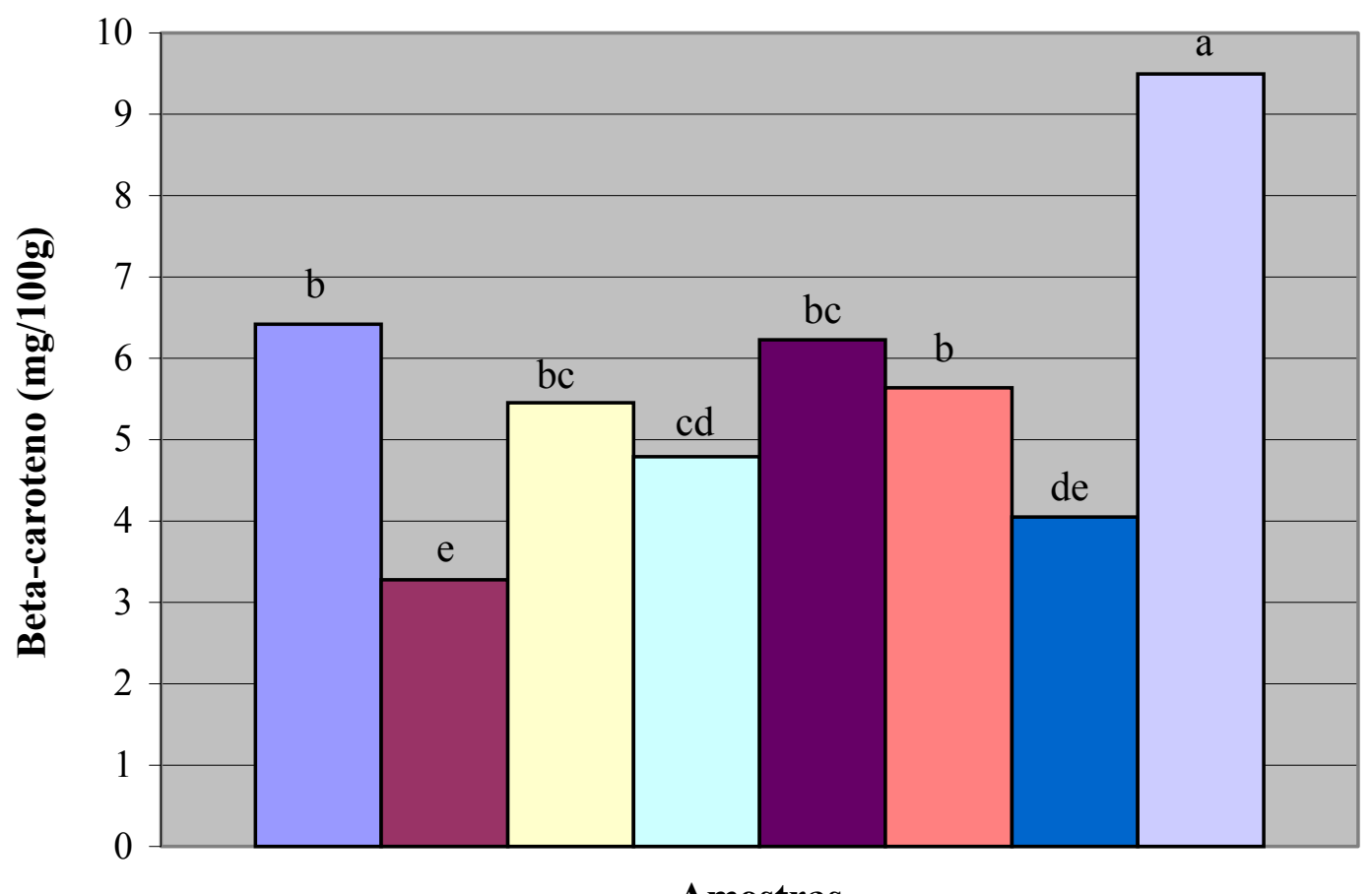

Amostras

\section{$\square \mathrm{C} \square \mathrm{C}+\mathrm{A} \square \mathrm{C}+\mathrm{N} \square \mathrm{C}+\mathrm{N} 2 \square \mathrm{C}+\mathrm{Fer} 1 \square \mathrm{C}+\mathrm{Fer} 2 \square \mathrm{C}+\mathrm{F} \square \mathrm{Fi}+\mathrm{C}$}

$\mathbf{C}=$ cenoura; $\mathbf{F}=$ feijão; $\mathbf{F i}=$ fígado; $\mathbf{A 1}=$ Arovit $(15 \mathrm{mg}) ; \mathbf{F e r 1}=$ Fer-In-Sol (78,67 mg); Fer2 = Fer-InSol (211,17mg); N1= Neutrofer (78,67 mg); N2 = Neutrofer (211,17mg); valores representam média de 3 repetições; letras diferentes indicam diferença significativa $(\mathrm{p} \leq 0,05)$

Figura 20 - Concentração de beta-caroteno (mg/100g), em base úmida. 
A quantidade de beta-caroteno nas amostras analisadas variou de $3,28 \mathrm{mg} / 100 \mathrm{~g}$ $(\mathrm{C}+\mathrm{A})$ a $9,50 \mathrm{mg} / 100 \mathrm{~g}(\mathrm{Fí}+\mathrm{C})$.

A amostra de cenoura apresentou $6,42 \mathrm{mg} / 100 \mathrm{~g}$ de beta-caroteno. Esse valor está de acordo com a literatura. Vora et al. (1998) obtiveram valores entre 4,79 a 7,24 $\mathrm{mg} / 100 \mathrm{~g}$. Já Heinonen (1990) encontraram variações de 4,6 a $10,3 \mathrm{mg} / 100 \mathrm{~g}$ de betacaroteno em cultivares de cenoura. Para Bureau \& Bushway (1986), a concentração de beta-caroteno ficou na média de 7,60 mg/100g. 


\subsection{Ferro heme e não heme}

\subsubsection{Ferro heme}

A figura 21 representa a concentração de ferro heme $(\mathrm{mcg} / \mathrm{g})$, em base úmida, da amostra de fígado e suas respectivas misturas.

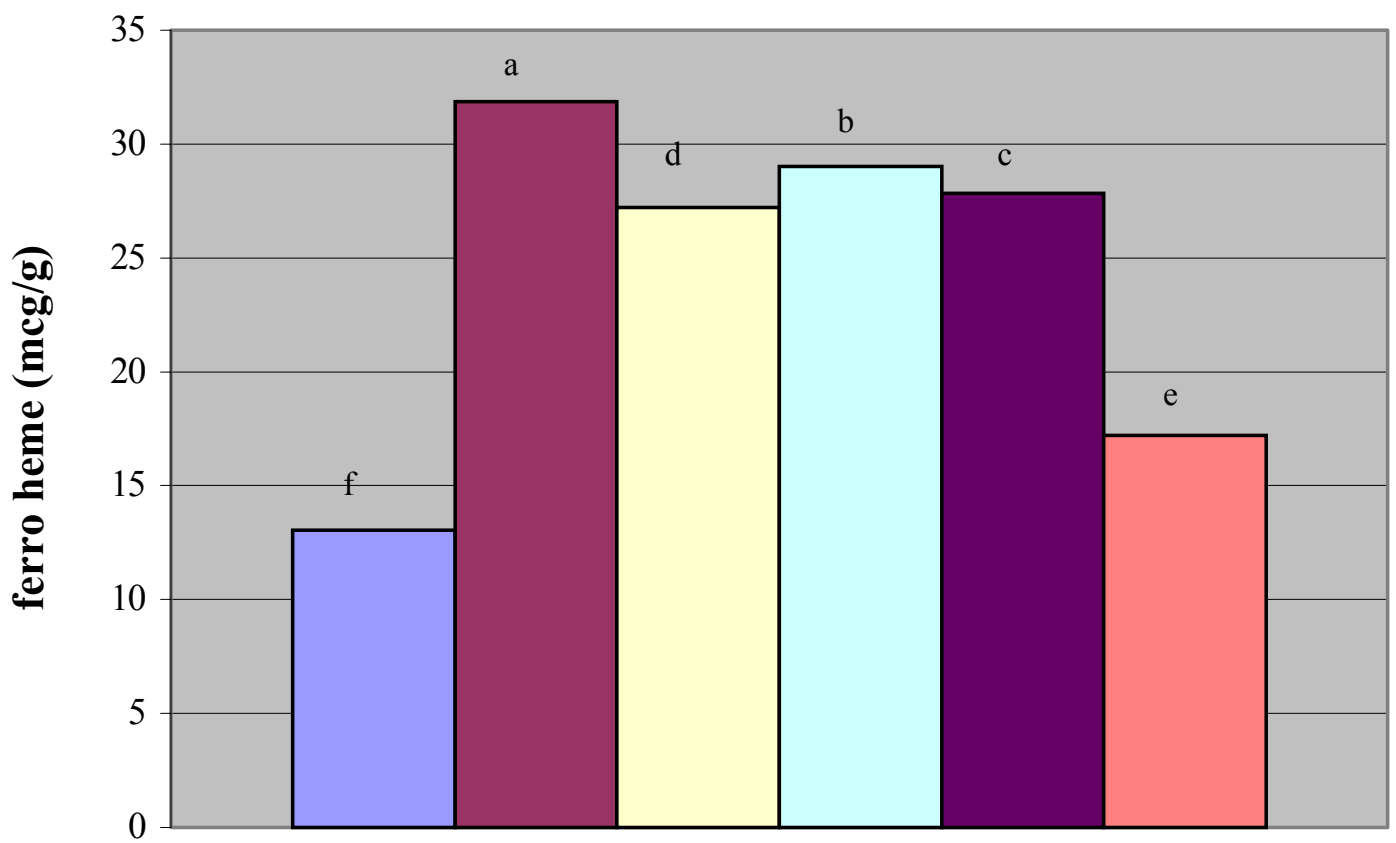

Amostras

\section{$\square \mathrm{F}+\mathrm{Fi} \quad \square \mathrm{Fi} \quad \square \mathrm{Fi}+\mathrm{A} \quad \square \mathrm{Fi}+\mathrm{Ferl} \quad \square \mathrm{Fi}+\mathrm{N} \quad \square \mathrm{Fi}+\mathrm{C}$}

$\mathbf{C}=$ cenoura $; \mathbf{F}=$ feijão; $\mathbf{F i}=$ fígado; $\mathbf{A 1}=$ Arovit $(15 \mathrm{mg}) ; \mathbf{F e r} \mathbf{1}=$ Fer-In-Sol $(78,67 \mathrm{mg}) ;$ Fer2 $=$ Fer-InSol (211,17mg); N1= Neutrofer (78,67 mg); N2 = Neutrofer (211,17mg); valores representam média de 3 repetições; letras diferentes indicam diferença significativa $(\mathrm{p} \leq 0,05)$

Figura 21 - Concentração de ferro heme $(\mathrm{mcg} / \mathrm{g})$, em base úmida. 
A quantidade de ferro heme só foi determinada nas amostras contendo fígado (figura 21). A variação de ferro heme ficou entre $13,06 \mathrm{mcg} / \mathrm{g}$ ( F+Fi) a $31,85 \mathrm{mcg} / \mathrm{g}$ (Fi). Rangan et al. (1997) encontraram 33,60 mcg/g de ferro heme para o fígado frito. Schricker et al. (1982) verificaram a quantidade de ferro total em carne bovina e encontraram uma média de $16,2 \mathrm{mcg} / \mathrm{g}$ de ferro heme.

\subsubsection{Ferro não-heme}

A concentração de ferro-não heme variou de $2,54 \mathrm{mcg} / \mathrm{g}(\mathrm{Fi}+\mathrm{C})$ a $9,48 \mathrm{mcg} / \mathrm{g}$ (FítFer1). A concentração de ferro não heme para o fígado foi de $7,42 \mathrm{mcg} / \mathrm{g}$, muito inferior à encontrada por Rangan et al. (1997), que foi de $67,15 \mathrm{mcg} / \mathrm{g}$, para o fígado bovino frito. Para o ferro não-heme, Schricker et al. (1982) verificaram a média de 9,8 $\mathrm{mcg} / \mathrm{g}$ nas amostras de carne.

A figura 22 representa a concentração de ferro não-heme $(\mathrm{mcg} / \mathrm{g})$, em base úmida, da amostra de fígado e suas respectivas misturas. 


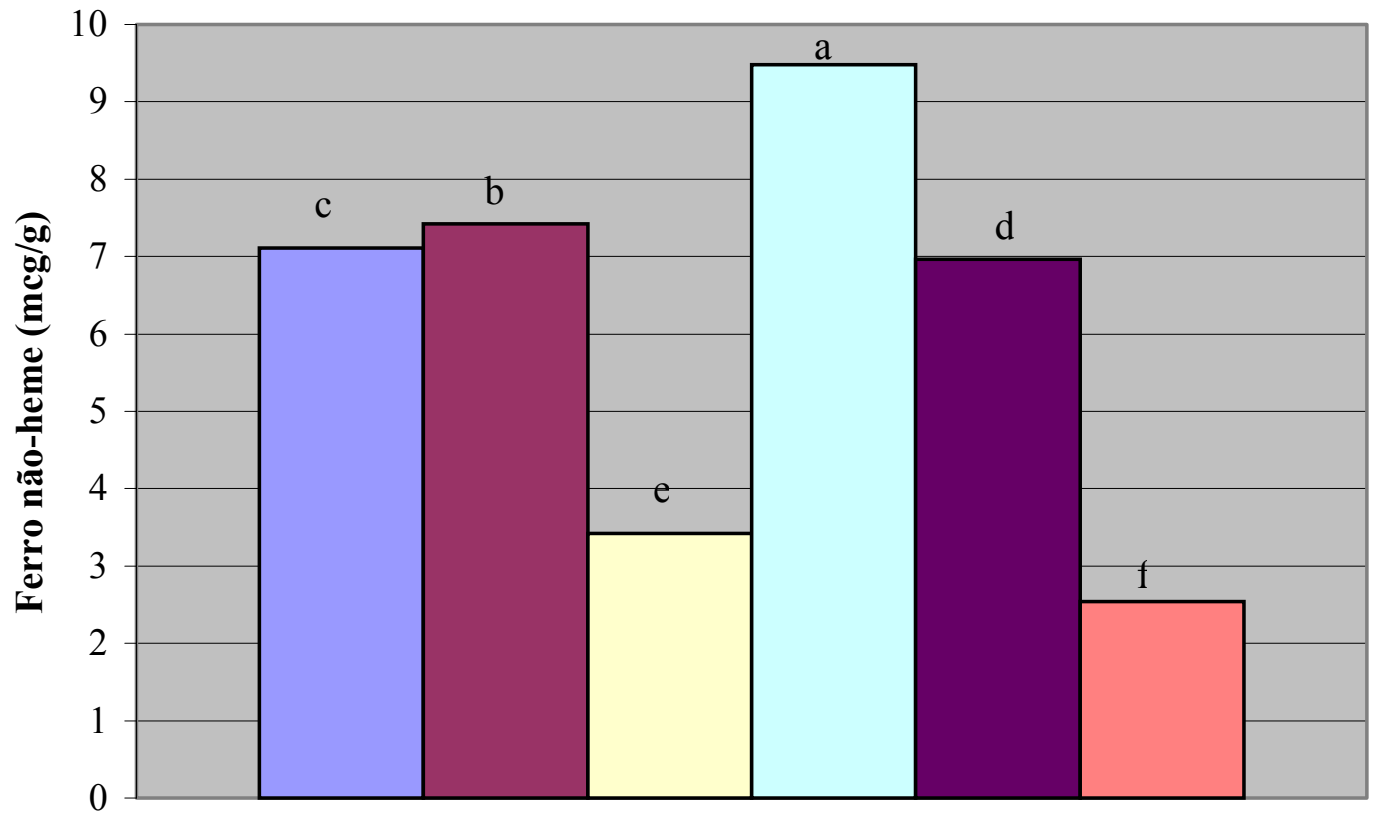

Amostras

\section{$\square \mathrm{F}+\mathrm{Fi} \quad \square \mathrm{Fi} \quad \square \mathrm{Fi}+\mathrm{A} \quad \square \mathrm{Fi}+\mathrm{Ferl} \quad \square \mathrm{Fi}+\mathrm{N} \quad \square \mathrm{Fi}+\mathrm{C}$}

$\mathbf{C}=$ cenoura; $\mathbf{F}=$ feijão; $\mathbf{F i}=$ fígado; $\mathbf{A 1}=$ Arovit $(15 \mathrm{mg}) ; \mathbf{F e r} 1=$ Fer-In-Sol $(78,67 \mathrm{mg}) ; \mathbf{F e r} \mathbf{2}=$ Fer-InSol (211,17mg); N1= Neutrofer (78,67 mg); N2 = Neutrofer $(211,17 \mathrm{mg})$; valores representam média de 3 repetições; letras diferentes indicam diferença significativa $(\mathrm{p} \leq 0,05)$

Figura 22 - Concentração de ferro não-heme (mcg/g), em base úmida. 


\subsection{Diálise de ferro "in vitro"}

A figura 23 representa a porcentagem de ferro dialisável, em base úmida, das amostras analisadas.

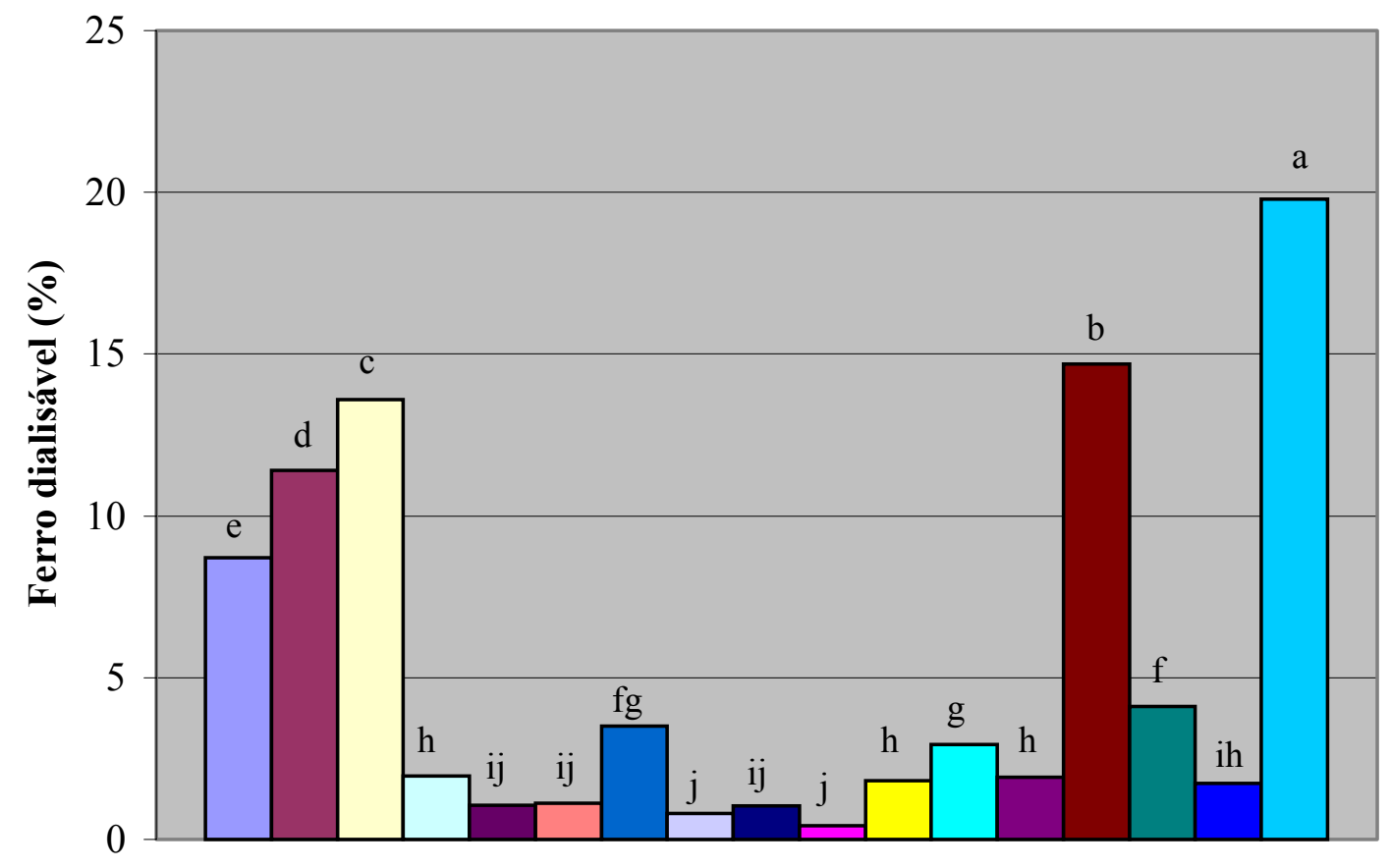

\section{Amostras}

\begin{tabular}{|llllll|}
\hline$\square \mathrm{C}$ & $\square \mathrm{C}+\mathrm{A}$ & $\square \mathrm{C}+\mathrm{N}$ & $\square \mathrm{C}+\mathrm{N} 2$ & $\square \mathrm{C}+\mathrm{Fer} 1$ & $\square \mathrm{C}+\mathrm{Fer} 2$ \\
$\square \mathrm{C}+\mathrm{F}$ & $\square \mathrm{F}$ & $\square \mathrm{F}+\mathrm{A}$ & $\square \mathrm{F}+\mathrm{Fer} 2$ & $\square \mathrm{F}+\mathrm{N} 2$ & $\square \mathrm{F}+\mathrm{Fi}$ \\
$\square \mathrm{Fi}$ & $\square \mathrm{Fi}+\mathrm{A}$ & $\square \mathrm{Fi}+\mathrm{Fer} 1$ & $\square \mathrm{Fi}+\mathrm{N}$ & $\square \mathrm{Fi}+\mathrm{C}$ & \\
\hline
\end{tabular}

$\mathbf{C}=$ cenoura; $\mathbf{F}=$ feijão; $\mathbf{F i}=$ fígado; $\mathbf{A 1}=$ Arovit $(15 \mathrm{mg}) ;$ Fer1 $=$ Fer-In-Sol $(78,67 \mathrm{mg}) ;$ Fer2 $=$ Fer-InSol (211,17mg); N1= Neutrofer (78,67 mg); N2 = Neutrofer $(211,17 \mathrm{mg})$; valores representam média de 3 repetições; letras diferentes indicam diferença significativa $(\mathrm{p} \leq 0,05)$

Figura 23 - Porcentagem de ferro dialisável, em base úmida. 
A porcentagem de ferro dialisável variou de $19,80 \%(\mathrm{Fí}+\mathrm{C})$ a $0,42 \%(\mathrm{~F}+\mathrm{Fer} 2)$, sendo que, nas amostras contendo fígado, deve-se considerar a presença de ferro na forma heme. Considerando-se os alimentos isolados, a cenoura apresentou a maior porcentagem de ferro dialisável, seguida pelo fígado e feijão. Quando foram adicionados medicamentos às amostras de cenoura, observou-se que houve aumento da porcentagem do ferro dialisável com a adição do Arovit e do Neutrofer1. No entanto, aumentando-se a concentração do Neutrofer (N2), essa porcentagem diminui consideravelmente. A menor porcentagem de ferro dialisável, no caso das amostras de cenoura, foi observada para as amostras de $\mathrm{C}+\mathrm{Fer} 1$ e $\mathrm{C}+\mathrm{Fer} 2$, não havendo diferença significativa entre as duas concentrações de Fer-In-Sol (Fer1 e Fer2) estudadas.

Para as amostras de feijão, houve melhora da porcentagem de ferro dialisável com a adição de Neutrofer e Arovit. Em relação ao Fer-In-Sol 2, essa porcentagem reduziu-se pela metade.

$\mathrm{A}$ adição de medicamentos ao fígado obteve melhores resultados para o Fi+A1 $(14,69 \%)$ e Fi+Fer1 (4,12 \%), sendo que a amostra Fi+N1 (1,72 \%) não apresentou melhora da porcentagem de ferro dialisável.

Considerando-se as misturas entre alimentos, a mistura Fi+C (19,80\%) obteve maior porcentagem de ferro dialisável do que $\mathrm{C}+\mathrm{F}(3,50 \%)$ e $\mathrm{F}+\mathrm{Fi}(2,94 \%)$.

Comparando o desempenho dos medicamentos em relação aos alimentos, no caso da cenoura, a adição de Arovit, melhorou a porcentagem de ferro dialisável da cenoura. A porcentagem de ferro dialisável também mostrou melhor resultado para a amostra $\mathrm{C}+\mathrm{N} 1$ do que para $\mathrm{C}+\mathrm{F}$. No caso da mistura $\mathrm{C}+\mathrm{Fer1}$, a amostra $\mathrm{C}+\mathrm{F}$ obteve melhor resultado. Já para a cenoura adicionada de fígado, o resultado foi muito superior ao das respectivas concentrações de ferro nos medicamentos Fer2 e N2.

Para o feijão, a adição da cenoura obteve melhor resultado do que a adição de Arovit. Da mesma forma, a adição do fígado obteve melhor resultado do que os medicamentos $(\mathrm{C}+\mathrm{N} 2$ e $\mathrm{C}+\mathrm{Fer} 2)$. Sendo assim, para o feijão, as adições de cenoura e fígado foram mais eficientes em elevar a porcentagem de ferro dialisável do que o uso dos medicamentos correspondentes. 
Comparando-se a amostra de fígado, a mistura $\mathrm{Fi}+\mathrm{C}$ também foi mais efetiva do que Fi+A. No entanto, a amostra Fi+Ferl apresentou melhor resultado do que Fi+F e $\mathrm{Fi}+\mathrm{N} 1$.

Portanto, a adição de cenoura às amostras de feijão e de fígado foi mais efetiva na melhora da porcentagem de ferro dialisável do que seu medicamento correspondente (Arovit). 


\subsection{Ferro dialisável (mg/kg)}

A figura 24 representa a concentração de ferro dialisável $(\mathrm{mg} / \mathrm{kg})$, em base úmida, das amostras analisadas

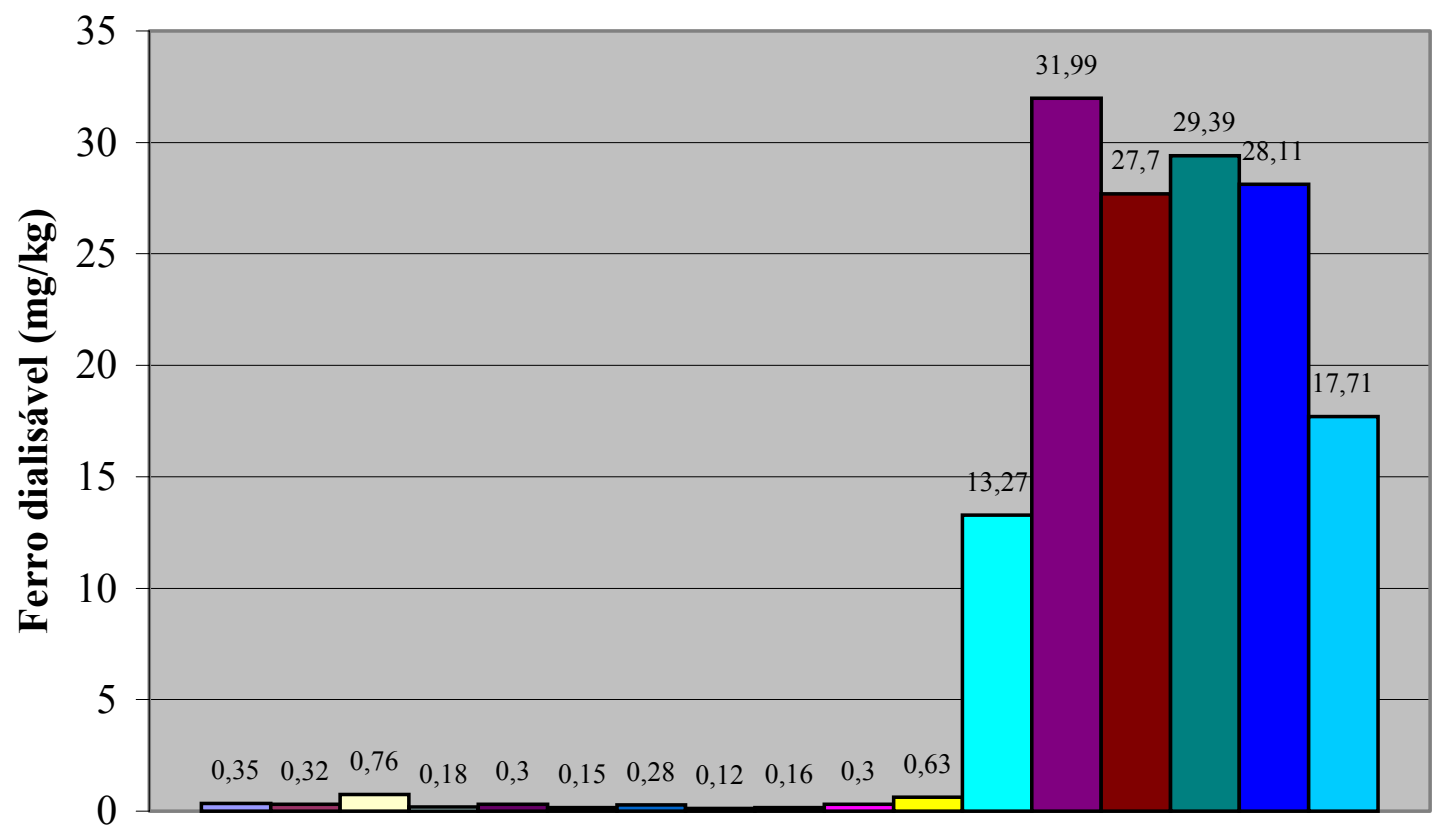

Amostras

\begin{tabular}{|llllll}
$\square \mathrm{C}$ & $\square \mathrm{C}+\mathrm{A}$ & $\square \mathrm{C}+\mathrm{N}$ & $\square \mathrm{C}+\mathrm{N} 2$ & $\square \mathrm{C}+\mathrm{Fer} 1$ & $\square \mathrm{C}+\mathrm{Fer} 2$ \\
$\square \mathrm{C}+\mathrm{F}$ & $\square \mathrm{F}$ & $\square \mathrm{F}+\mathrm{A}$ & $\square \mathrm{F}+\mathrm{Fer} 2$ & $\square \mathrm{F}+\mathrm{N} 2$ & $\square \mathrm{F}+\mathrm{Fi}$ \\
$\square \mathrm{Fi}$ & $\square \mathrm{Fi}+\mathrm{A}$ & $\square \mathrm{Fi}+\mathrm{Fer} 1$ & $\square \mathrm{Fi}+\mathrm{N}$ & $\square \mathrm{Fi}+\mathrm{C}$ &
\end{tabular}

$\mathbf{C}=$ cenoura; $\mathbf{F}=$ feijão; $\mathbf{F i}=$ fígado; $\mathbf{A 1}=$ Arovit $(15 \mathrm{mg}) ; \mathbf{F e r 1}=$ Fer-In-Sol $(78,67 \mathrm{mg}) ; \mathbf{F e r 2}=$ Fer-InSol (211,17mg); N1= Neutrofer (78,67 mg); N2 = Neutrofer (211,17mg); valores representam média de 3 repetições; letras diferentes indicam diferença significativa $(\mathrm{p} \leq 0,05)$

Figura 24 - Concentração de ferro dialisável $(\mathrm{mg} / \mathrm{kg})$, em base úmida. 
A quantidade total do ferro de um alimento ou dieta não indica a quantidade que será biodisponível, isso porque, existem vários fatores que influenciam a absorção e utilização desse mineral. Dessa forma, para garantir um suporte adequado de ferro é necessário conhecer e diferenciar a quantidade total de ferro da quantidade biodisponível (Young \& Janghorbani, 1981).A quantidade de ferro biodisponível está relacionada à medida da fração de ferro alimentar capaz de ser absorvida pelo trato gastrointestinal e, subseqüentemente, armazenada e incorporada ao ferro heme (Consaul \& Lee, 1983).

A concentração de ferro dialisável na amostra de cenoura foi $0,35 \mathrm{mg} / \mathrm{kg}$. A adição de vitamina $\mathrm{A}$ em forma de medicamento $(\mathrm{C}+\mathrm{A} 1)$ não promoveu melhora na concentração de ferro dialisável. O mesmo foi observado para a adição dos medicamentos contendo ferro nas concentrações semelhantes ao feijão e fígado, com exceção da amostra $(\mathrm{C}+\mathrm{N} 1)$, cuja concentração de ferro dialisável dobrou. Em relação à adição de alimentos, a amostra $(\mathrm{C}+\mathrm{F})$ obteve concentração de ferro dialisável $(0,28 \mathrm{mg} / \mathrm{kg})$ inferior à da amostra (Fi+C) cuja concentração foi de 4,80 mg/kg de ferro dialisável.

A amostra de feijão (F) obteve a maior concentração de carboidratos, fibra dietética e antinutricionais. As fibras, assim como os antinutricionais encontrados nas leguminosas, são fatores que interferem negativamente na disponibilidade do ferro nãoheme. A amostra de feijão apresentou pobre disponibilidade de ferro em relação às demais. $\mathrm{A}$ adição de vitamina $\mathrm{A}(\mathrm{F}+\mathrm{A} 1)$ e beta-caroteno $(\mathrm{C}+\mathrm{F})$ melhorou a concentração de ferro dialisável do feijão, sendo que a adição de cenoura foi mais eficiente do que a respectiva concentração em medicamento. A adição de ferro na forma de medicamentos também promoveu um aumento na disponibilidade de ferro do feijão. A amostra F+Fi (3,48 mg/kg) obteve a maior concentração de ferro dialisável dentre as amostras contendo feijão.

De acordo com Garcia-Casal et al. (1998), a vitamina A e o beta-caroteno exerceram efeito promotor sobre a absorção de ferro de cereais, especialmente daqueles que apresentaram componentes inibidores como os fitatos. Segundo Layrisse et al. (1997), a presença de vitamina A forma um complexo com o ferro, mantendo-o solúvel no lúmen intestinal, prevenindo o efeito inibitório dos fitatos e polifenóis sobre a absorção do ferro não-heme. 
A maior concentração de ferro dialisável foi observada na amostra de fígado $(8,10 \mathrm{mg} / \mathrm{kg})$ e suas misturas. Esse resultado era esperado, devido às características inerentes ao fígado, tais como: presença de ferro heme e proteínas. A amostra (Fi) também apresentou as maiores concentrações de fração cinza, extrato etéreo, proteínas, vitamina A e ferro heme. A adição das misturas ao fígado não proporcionou melhora da concentração de ferro dialisável, uma vez que o ferro heme não sofre interferência dos componentes da dieta. No entanto, comparando-se o desempenho dos medicamentos em relação aos alimentos, os medicamentos foram mais eficientes do que os alimentos.

Em relação à combinação entre alimentos, a mistura $\mathrm{Fi}+\mathrm{C}$ ofereceu a maior quantidade de ferro dialisável $(4,80 \mathrm{mg} / \mathrm{kg})$, seguido pelo $\mathrm{Fi}+\mathrm{F}(3,48 \mathrm{mg} / \mathrm{kg})$ e $\mathrm{C}+\mathrm{F}(0,28$ $\mathrm{mg} / \mathrm{kg}$ ). 


\section{CONCLUSÕES}

Com base nos resultados obtidos, pode-se concluir que:

- as amostras contendo cenoura apresentaram as maiores concentrações de umidade e beta-caroteno;

- as maiores concentrações de carboidratos, fibra dietética, taninos e ácido fítico foram encontradas nas amostras contendo feijão;

- as amostras contendo fígado apresentaram as maiores concentrações de fração cinza, extrato etéreo, proteínas, vitamina A, ferro heme e quantidade de ferro disponível;

- não houve influência dos minerais considerados interferentes (Ca, $\mathrm{Zn}$ e $\mathrm{Mn}$ ) sobre a disponibilidade de ferro das amostras analisadas;

- os antinutricionais taninos e ácido fítico exerceram efeito inibitório sobre a disponibilidade de ferro das amostras analisadas, sendo que o ácido fítico exerceu efeito inibitório maior;

- as concentrações de vitamina A e beta-caroteno avaliadas exerceram efeito positivo sobre a porcentagem de diálise do ferro;

- a cenoura e o fígado apresentaram melhor porcentagem de ferro dialisável do que os respectivos medicamentos em concentrações semelhantes.

Portanto, pode-se concluir que houve influência da vitamina A sobre a diálise do ferro, sendo que as misturas contendo fígado foram as que obtiveram melhores concentrações de ferro disponível. 
ANEXOS 
Anexo A. Composição centesimal (\%), em base úmida.

\begin{tabular}{ccccccc}
\hline Amostra & Umidade & Fração cinza & $\begin{array}{c}\text { Extrato } \\
\text { etéreo }\end{array}$ & Proteína & $\begin{array}{c}\text { Fibra } \\
\text { dietética }\end{array}$ & $\begin{array}{c}\text { Carboidratos } \\
\text { disponíveis }\end{array}$ \\
\hline C & $88,12 \pm 0,02^{\text {a }^{\mathrm{a}}}$ & $0,82 \pm 0,03^{\mathrm{i}}$ & $0,21 \pm 0,01^{\mathrm{d}}$ & $1,02 \pm 0,02^{\mathrm{h}}$ & $2,82 \pm 0,02^{\mathrm{f}}$ & 7,02 \\
$\mathrm{C}+\mathrm{A}$ & $88,07 \pm 0,02^{\mathrm{a}}$ & $0,80^{\mathrm{i}}$ & $0,21^{\mathrm{d}}$ & $1,11 \pm 0,01^{\mathrm{h}}$ & $2,99 \pm 0,18^{\text {ef }}$ & 6,82 \\
$\mathrm{C}+\mathrm{N}$ & $88,10 \pm 0,05^{\mathrm{a}}$ & $0,78^{\mathrm{i}}$ & $0,18 \pm 0,01^{\mathrm{d}}$ & $1,07 \pm 0,01^{\mathrm{h}}$ & $2,93 \pm 0,09^{\mathrm{ef}}$ & 6,95 \\
$\mathrm{C}+\mathrm{N} 2$ & $88,04 \pm 0,01^{\mathrm{a}}$ & $0,79 \pm 0,01^{\mathrm{i}}$ & $0,22 \pm 0,01^{\mathrm{d}}$ & $1,15 \pm 0,01^{\mathrm{h}}$ & $3,21 \pm 0,03^{\mathrm{de}}$ & 6,59 \\
$\mathrm{C}+\mathrm{Fer} 1$ & $88,05 \pm 0,01^{\mathrm{a}}$ & $0,79^{\mathrm{i}}$ & $0,23 \pm 0,01^{\mathrm{d}}$ & $1,11 \pm 0,01^{\mathrm{h}}$ & $3,02 \pm 0,12^{\mathrm{ef}}$ & 6,79 \\
$\mathrm{C}+\mathrm{Fer} 2$ & $88,17 \pm 0,03^{\mathrm{a}}$ & $0,80 \pm 0,02^{\mathrm{i}}$ & $0,21 \pm 0,02^{\mathrm{d}}$ & $1,06 \pm 0,02^{\mathrm{h}}$ & $2,85 \pm 0,16^{\mathrm{f}}$ & 6,92 \\
$\mathrm{C}+\mathrm{F}$ & $82,57 \pm 0,01^{\mathrm{b}}$ & $0,82 \pm 0,06^{\mathrm{hi}}$ & $0,36 \pm 0,01^{\mathrm{d}}$ & $3,96 \pm 0,09^{\mathrm{g}}$ & $3,33 \pm 0,15^{\mathrm{d}}$ & 8,95 \\
$\mathrm{~F}$ & $74,55 \pm 0,02^{\mathrm{c}}$ & $0,91 \pm 0,01^{\mathrm{fg}}$ & $0,47 \pm 0,05^{\mathrm{d}}$ & $5,91 \pm 0,04^{\mathrm{f}}$ & $7,47 \pm 0,02^{\mathrm{b}}$ & 10,68 \\
$\mathrm{~F}+\mathrm{A}$ & $74,65 \pm 0,05^{\mathrm{c}}$ & $0,97 \pm 0,01^{\mathrm{f}}$ & $0,55 \pm 0,01^{\mathrm{d}}$ & $6,03 \pm 0,05^{\mathrm{f}}$ & $7,23 \pm 0,03^{\mathrm{bc}}$ & 10,56 \\
$\mathrm{~F}+\mathrm{Fer} 2$ & $74,58 \pm 0,07^{\mathrm{c}}$ & $0,90 \pm 0,03^{\mathrm{gh}}$ & $1,07 \pm 0,13^{\mathrm{c}}$ & $6,10 \pm 0,04^{\mathrm{f}}$ & $7,32 \pm 0,04^{\mathrm{bc}}$ & 10,04 \\
$\mathrm{~F}+\mathrm{N} 2$ & $74,59 \pm 0,04^{\mathrm{c}}$ & $0,94 \pm 0,01^{\mathrm{fg}}$ & $0,31 \pm 0,02^{\mathrm{d}}$ & $5,75 \pm 0,05^{\mathrm{f}}$ & $7,09 \pm 0,02^{\mathrm{c}}$ & 11,31 \\
$\mathrm{~F}+\mathrm{Fi}$ & $63,87 \pm 0,04^{\mathrm{e}}$ & $1,56 \pm 0,03^{\mathrm{d}}$ & $4,05 \pm 0,41^{\mathrm{b}}$ & $19,64 \pm 0,32^{\mathrm{d}}$ & $9,57 \pm 0,04^{\mathrm{a}}$ & 1,31 \\
$\mathrm{Fi}$ & $53,59 \pm 0,11^{\mathrm{f}}$ & $2,13^{\mathrm{a}}$ & $7,01 \pm 0,22^{\mathrm{a}}$ & $31,35 \pm 0,95^{\mathrm{b}}$ & - & 5,91 \\
Fi+A & $53,63 \pm 0,15^{\mathrm{f}}$ & $2,01 \pm 0,01^{\mathrm{b}}$ & $7,00 \pm 0,16^{\mathrm{a}}$ & $33,02 \pm 0,13^{\mathrm{a}}$ & - & 4,34 \\
Fi+Fer1 & $53,77 \pm 0,23^{\mathrm{f}}$ & $1,90 \pm 0,02^{\mathrm{c}}$ & $7,13 \pm 0,16^{\mathrm{a}}$ & $32,56 \pm 0,30^{\mathrm{a}}$ & $1,61 \pm 0,06^{\mathrm{g}}$ & 3,03 \\
$\mathrm{Fi}+\mathrm{N}$ & $53,69 \pm 0,04^{\mathrm{f}}$ & $1,95 \pm 0,01^{\mathrm{bc}}$ & $7,14 \pm 0,07^{\mathrm{a}}$ & $30,20 \pm 0,13^{\mathrm{c}}$ & $1,75 \pm 0,23^{\mathrm{g}}$ & 5,26 \\
Fi+C & $71,59 \pm 0,04^{\mathrm{d}}$ & $1,28 \pm 0,02^{\mathrm{e}}$ & $3,92 \pm 0,15^{\mathrm{b}}$ & $16,01 \pm 0,57^{\mathrm{e}}$ & $1,66 \pm 0,08^{\mathrm{g}}$ & 5,55 \\
\hline
\end{tabular}

* Média \pm desvio padrão de 3 repetições. Valores na mesma coluna, seguidos por letras diferentes indicam diferença significativa $(\mathrm{p} \leq 0,05)$.

$\mathbf{C}=$ cenoura, $\mathbf{F}=$ feijão, $\mathbf{F i}=$ fígado, $\mathbf{A 1}=$ Arovit $(15 \mathrm{mg}), \mathbf{F e r 1}=$ Fer-In-Sol $(78,67 \mathrm{mg})$, Fer2 $=$ Fer-InSol $(211,17 \mathrm{mg}), \mathbf{N 1}=$ Neutrofer $(78,67 \mathrm{mg}), \mathbf{N} 2=$ Neutrofer $(211,17 \mathrm{mg})$ 
Anexo B. Concentração de macrominerais $(\mathrm{g} / \mathrm{kg})$, em base úmida.

\begin{tabular}{|c|c|c|c|c|c|}
\hline Amostra & $\mathrm{Ca}$ & K & $\mathrm{Mg}$ & $\mathrm{P}$ & $\mathrm{S}$ \\
\hline $\mathrm{C}$ & $0,21 \pm 0,02^{* a b c d}$ & $2,92 \pm 0,06^{\mathrm{def}}$ & $0,09^{\mathrm{g}}$ & $0,26 \pm 0,01^{\mathrm{f}}$ & $0,09 \pm 0,01^{\mathrm{h}}$ \\
\hline $\mathrm{C}+\mathrm{A}$ & $0,17 \pm 0,01^{\text {cde }}$ & $3,17 \pm 0,11^{\mathrm{d}}$ & $0,18 \pm 0,02^{\mathrm{ef}}$ & $0,29 \pm 0,01^{\mathrm{f}}$ & $0,11 \pm 0,01^{\mathrm{gh}}$ \\
\hline $\mathrm{C}+\mathrm{N} 1$ & $0,17 \pm 0,03^{\text {bcde }}$ & $2,92 \pm 0,06^{\mathrm{def}}$ & $0,09^{\mathrm{g}}$ & $0,28^{f}$ & $0,11 \pm 0,01^{\mathrm{gh}}$ \\
\hline $\mathrm{C}+\mathrm{N} 2$ & $0,18 \pm 0,01^{\mathrm{bcde}}$ & $2,85 \pm 0,06^{\mathrm{def}}$ & $0,09^{\mathrm{g}}$ & $0,27 \pm 0,01^{\mathrm{f}}$ & $0,10 \pm 0,01^{\mathrm{gh}}$ \\
\hline $\mathrm{C}+\mathrm{Fer} 1$ & $0,18 \pm 0,02^{\text {bcde }}$ & $2,63 \pm 0,06^{\mathrm{f}}$ & $0,08^{\mathrm{g}}$ & $0,27 \pm 0,01^{\mathrm{f}}$ & $0,09 \pm 0,01^{\mathrm{h}}$ \\
\hline $\mathrm{C}+\mathrm{Fer} 2$ & $0,19 \pm 0,02^{\text {bcde }}$ & $2,98^{\mathrm{def}}$ & $0,09 \pm 0,01^{\mathrm{g}}$ & $0,28 \pm 0,01^{\mathrm{f}}$ & $0,12^{\mathrm{gh}}$ \\
\hline $\mathrm{C}+\mathrm{F}$ & $0,18 \pm 0,02^{\text {bcde }}$ & $2,70 \pm 0,08^{\mathrm{ef}}$ & $0,21 \pm 0,01^{\mathrm{def}}$ & $0,60 \pm 0,03^{\mathrm{e}}$ & $0,26 \pm 0,02^{\mathrm{fg}}$ \\
\hline $\mathrm{F}$ & $0,23 \pm 0,01^{\mathrm{ab}}$ & $2,66 \pm 0,11^{\mathrm{ef}}$ & $0,32 \pm 0,01^{\mathrm{c}}$ & $0,95 \pm 0,01^{\mathrm{d}}$ & $0,42 \pm 0,01^{\mathrm{ef}}$ \\
\hline $\mathrm{F}+\mathrm{A}$ & $0,22 \pm 0,01^{\mathrm{abc}}$ & $2,73 \pm 0,11^{\mathrm{ef}}$ & $0,49 \pm 0,01^{\mathrm{a}}$ & $0,95 \pm 0,04^{\mathrm{d}}$ & $0,40 \pm 0,01^{\mathrm{ef}}$ \\
\hline $\mathrm{F}+\mathrm{Fer} 2$ & $0,21 \pm 0,02^{\mathrm{abc}}$ & $2,60 \pm 0,01^{\mathrm{f}}$ & $0,32 \pm 0,02^{\mathrm{c}}$ & $0,95 \pm 0,03^{\mathrm{d}}$ & $0,46 \pm 0,02^{\mathrm{e}}$ \\
\hline $\mathrm{F}+\mathrm{N} 2$ & $0,27 \pm 0,05^{\mathrm{a}}$ & $3,06 \pm 0,11^{\mathrm{ed}}$ & $0,38 \pm 0,03^{\mathrm{b}}$ & $1,12 \pm 0,05^{\mathrm{d}}$ & $0,49 \pm 0,03^{\mathrm{e}}$ \\
\hline $\mathrm{F}+\mathrm{Fi}$ & $0,15 \pm 0,03^{\mathrm{de}}$ & $3,66 \pm 0,28^{\mathrm{c}}$ & $0,30 \pm 0,02^{\mathrm{c}}$ & $3,07 \pm 0,02^{\mathrm{c}}$ & $2,03 \pm 0,06^{\mathrm{c}}$ \\
\hline $\mathrm{Fi}$ & $0,05^{\mathrm{f}}$ & $4,43 \pm 0,21^{\mathrm{ab}}$ & $0,24 \pm 0,02^{\mathrm{d}}$ & $5,36 \pm 0,18^{\mathrm{a}}$ & $3,26 \pm 0,03^{\mathrm{a}}$ \\
\hline $\mathrm{Fi}+\mathrm{A}$ & $0,07^{\mathrm{f}}$ & $4,55 \pm 0,21^{\mathrm{a}}$ & $0,53 \pm 0,06^{\mathrm{a}}$ & $5,45 \pm 0,12^{\mathrm{a}}$ & $3,17 \pm 0,15^{\mathrm{ab}}$ \\
\hline $\mathrm{Fi}+\mathrm{Fer} 1$ & $0,05 \pm 0,01^{\mathrm{f}}$ & $4,31^{a b}$ & $0,22 \pm 0,01^{\mathrm{de}}$ & $5,29 \pm 0,05^{\mathrm{a}}$ & $3,04 \pm 0,04^{b}$ \\
\hline $\mathrm{Fi}+\mathrm{N}$ & $0,05 \pm 0,01^{\mathrm{f}}$ & $4,07 \pm 0,21^{b c}$ & $0,21 \pm 0,01^{\mathrm{def}}$ & $5,03 \pm 0,13^{b}$ & $3,02 \pm 0,10^{\mathrm{b}}$ \\
\hline $\mathrm{Fi}+\mathrm{C}$ & $0,14 \pm 0,01^{\mathrm{e}}$ & $3,84 \pm 0,26^{\mathrm{c}}$ & $0,16^{\mathrm{f}}$ & $2,94 \pm 0,07^{\mathrm{c}}$ & $1,71 \pm 0,09^{\mathrm{d}}$ \\
\hline
\end{tabular}

* Média \pm desvio padrão de 3 repetições. Valores na mesma coluna, seguidos por letras diferentes indicam diferença significativa $(\mathrm{p} \leq 0,05)$.

$\mathbf{C}=$ cenoura, $\mathbf{F}=$ feijão, $\mathbf{F i}=$ fígado, $\mathbf{A 1}=$ Arovit $(15 \mathrm{mg}), \mathbf{F e r} \mathbf{1}=$ Fer-In-Sol $(78,67 \mathrm{mg})$, Fer2 $=$ Fer-InSol $(211,17 \mathrm{mg}), \mathbf{N} 1=$ Neutrofer $(78,67 \mathrm{mg}), \mathbf{N} 2=$ Neutrofer $(211,17 \mathrm{mg})$. 
Anexo C. Concentração de microminerais $(\mathrm{mg} / \mathrm{kg})$, em base úmida.

\begin{tabular}{cccc}
\hline Amostra & $\mathrm{Cu}$ & $\mathrm{Mn}$ & $\mathrm{Zn}$ \\
\hline $\mathrm{C}$ & $0,57 \pm 0,08^{\mathrm{e}}$ & $0,62 \pm 0,03^{\mathrm{g}}$ & $1,99 \pm 0,05^{\mathrm{g}}$ \\
$\mathrm{C}+\mathrm{A}$ & $0,59 \pm 0,09^{\mathrm{e}}$ & $0,89 \pm 0,05^{\mathrm{g}}$ & $2,11 \pm 0,13^{\mathrm{g}}$ \\
$\mathrm{C}+\mathrm{N} 1$ & $0,49 \pm 0,01^{\mathrm{e}}$ & $0,56 \pm 0,04^{\mathrm{g}}$ & $1,99 \pm 0,12^{\mathrm{g}}$ \\
$\mathrm{C}+\mathrm{N} 2$ & $0,57 \pm 0,04^{\mathrm{e}}$ & $0,59 \pm 0,07^{\mathrm{g}}$ & $2,00 \pm 0,05^{\mathrm{g}}$ \\
$\mathrm{C}+\mathrm{Fer} 1$ & $0,44 \pm 0,06^{\mathrm{e}}$ & $0,67 \pm 0,05^{\mathrm{g}}$ & $1,95 \pm 0,10^{\mathrm{g}}$ \\
$\mathrm{C}+\mathrm{Fer} 2$ & $0,52 \pm 0,04^{\mathrm{e}}$ & $0,54 \pm 0,01^{\mathrm{g}}$ & $2,18 \pm 0,15^{\mathrm{g}}$ \\
$\mathrm{C}+\mathrm{F}$ & $1,31 \pm 0,05^{\mathrm{e}}$ & $2,34 \pm 0,18^{\mathrm{f}}$ & $4,21 \pm 0,20^{\mathrm{f}}$ \\
$\mathrm{F}$ & $2,08 \pm 0,13^{\mathrm{e}}$ & $3,72 \pm 0,12^{\mathrm{d}}$ & $6,54 \pm 0,16^{\mathrm{e}}$ \\
$\mathrm{F}+\mathrm{A}$ & $2,07 \pm 0,21^{\mathrm{e}}$ & $3,75 \pm 0,13^{\mathrm{d}}$ & $6,74 \pm 0,16^{\mathrm{e}}$ \\
$\mathrm{F}+\mathrm{Fer} 2$ & $2,35 \pm 0,21^{\mathrm{e}}$ & $4,35 \pm 0,25^{\mathrm{c}}$ & $6,69 \pm 0,32^{\mathrm{e}}$ \\
$\mathrm{F}+\mathrm{N} 2$ & $2,83 \pm 0,35^{\mathrm{e}}$ & $4,93 \pm 0,30^{\mathrm{ab}}$ & $8,31 \pm 0,54^{\mathrm{d}}$ \\
$\mathrm{F}+\mathrm{Fi}$ & $79,14 \pm 2,21^{\mathrm{d}}$ & $4,22 \pm 0,28^{\mathrm{cd}}$ & $25,85 \pm 0,31^{\mathrm{c}}$ \\
$\mathrm{Fi}$ & $163,94 \pm 1,15^{\mathrm{a}}$ & $5,28 \pm 0,10^{\mathrm{a}}$ & $47,17 \pm 0,14^{\mathrm{a}}$ \\
$\mathrm{Fi}+\mathrm{A}$ & $160,12 \pm 3,97^{\mathrm{ab}}$ & $5,03 \pm 0,09^{\mathrm{ab}}$ & $44,47 \pm 0,27^{\mathrm{b}}$ \\
$\mathrm{Fi}+\mathrm{Fer} 1$ & $160,30 \pm 1,28^{\mathrm{ab}}$ & $4,54 \pm 0,22^{\mathrm{bc}}$ & $44,68 \pm 1,01^{\mathrm{b}}$ \\
$\mathrm{Fi}+\mathrm{N}$ & $159,47 \pm 3,27^{\mathrm{b}}$ & $4,71 \pm 0,47^{\mathrm{abc}}$ & $46,16 \pm 0,78^{\mathrm{a}}$ \\
$\mathrm{Fi}+\mathrm{C}$ & $85,91 \pm 0,71^{\mathrm{c}}$ & $3,12 \pm 0,16^{\mathrm{e}}$ & $25,33 \pm 0,65^{\mathrm{c}}$ \\
\hline
\end{tabular}

* Média \pm desvio padrão de 3 repetições. Valores na mesma coluna, seguidos por letras diferentes indicam diferença significativa $(\mathrm{p} \leq 0,05)$.

$\mathbf{C}=$ cenoura, $\mathbf{F}=$ feijão, $\mathbf{F i}=$ fígado, $\mathbf{A 1}=$ Arovit $(15 \mathrm{mg}), \mathbf{F e r} \mathbf{1}=$ Fer-In-Sol $(78,67 \mathrm{mg}), \mathbf{F e r} \mathbf{2}=$ Fer-InSol $(211,17 \mathrm{mg}), \mathbf{N} 1=$ Neutrofer $(78,67 \mathrm{mg}), \mathbf{N} 2=$ Neutrofer $(211,17 \mathrm{mg})$. 
Anexo D. Concentração de antinutricionais, em base úmida.

\begin{tabular}{crc}
\hline Amostra & Taninos $(\%)$ & Ácido fitico $(\mathrm{mg} / \mathrm{g})$ \\
\hline C+F & $0,05^{\mathrm{c}^{*}}$ & $1,12^{\mathrm{f}}$ \\
F & $0,05^{\mathrm{c}}$ & $2,71^{\mathrm{a}}$ \\
F+A1 & $0,06^{\mathrm{b}}$ & $1,77^{\mathrm{c}}$ \\
F+Fer2 & $0,03^{\mathrm{e}}$ & $1,38^{\mathrm{e}}$ \\
F+N2 & $0,04^{\mathrm{d}}$ & $2,00^{\mathrm{b}}$ \\
F+Fi & $0,12^{\mathrm{a}}$ & $1,45^{\mathrm{d}}$ \\
\hline
\end{tabular}

*Média \pm desvio padrão de 3 repetições. Valores na mesma coluna, seguidos por letras diferentes indicam diferença significativa $(\mathrm{p} \leq 0,05)$.

$\mathbf{C}=$ cenoura, $\mathbf{F}=$ feijão, $\mathbf{F i}=$ fígado, $\mathbf{A 1}=$ Arovit $(15 \mathrm{mg}), \mathbf{F e r 1}=$ Fer-In-Sol $(78,67 \mathrm{mg})$,

Fer2 = Fer- In-Sol $(211,17 \mathrm{mg}), \mathbf{N} 1=$ Neutrofer $(78,67 \mathrm{mg}), \mathbf{N} 2=$ Neutrofer $(211,17 \mathrm{mg})$.

Anexo E. Concentração de vitamina A, retinol e beta-caroteno, em base úmida.

\begin{tabular}{|c|c|c|c|}
\hline Amostra & $\begin{array}{c}\text { Vitamina A } \\
\text { (UI/100g) }\end{array}$ & Retinol (mg/100g) & $\begin{array}{c}\text { Beta-caroteno } \\
(\mathrm{mg} / 100 \mathrm{~g})\end{array}$ \\
\hline $\mathrm{C}$ & 3569 & nd & $6,42 \pm 0,07^{b}$ \\
\hline $\mathrm{C}+\mathrm{A}$ & 12113 & $3,09 \pm 0,40 * \mathrm{e}$ & $3,28 \pm 0,25^{\mathrm{e}}$ \\
\hline $\mathrm{C}+\mathrm{N} 1$ & 3024 & nd & $5,45 \pm 0,50^{\mathrm{bc}}$ \\
\hline $\mathrm{C}+\mathrm{N} 2$ & 2660 & nd & $4,79 \pm 0,0^{\mathrm{cd}}$ \\
\hline $\mathrm{C}+$ Fer 1 & 3131 & nd & $5,64 \pm 0,64^{\mathrm{bc}}$ \\
\hline $\mathrm{C}+\mathrm{Fer} 2$ & 3458 & nd & $6,23 \pm 0,33^{b}$ \\
\hline $\mathrm{C}+\mathrm{F}$ & 2247 & nd & $4,05 \pm 0,13^{\mathrm{de}}$ \\
\hline $\mathrm{F}$ & nd & nd & nd \\
\hline $\mathrm{F}+\mathrm{A}$ & 8607 & $2,58 \pm 0,10^{\mathrm{e}}$ & nd \\
\hline $\mathrm{F}+\mathrm{Fer} 2$ & nd & nd & nd \\
\hline $\mathrm{F}+\mathrm{N} 2$ & nd & nd & nd \\
\hline $\mathrm{F}+\mathrm{Fi}$ & 26543 & $7,96 \pm 0,45^{\mathrm{d}}$ & nd \\
\hline $\mathrm{Fi}$ & 71285 & $21,39 \pm 0,88^{\mathrm{a}}$ & nd \\
\hline $\mathrm{Fi}+\mathrm{A}$ & 63439 & $19,04 \pm 2,40^{\mathrm{ab}}$ & nd \\
\hline $\mathrm{Fi}+\mathrm{Fer} 1$ & 46782 & $14,04 \pm 1,41^{\mathrm{c}}$ & nd \\
\hline $\mathrm{Fi}+\mathrm{N} 1$ & 50073 & $15,03 \pm 1,22^{b c}$ & nd \\
\hline $\mathrm{Fi}+\mathrm{C}$ & 28550 & $6,98 \pm 0,21^{\mathrm{de}}$ & $9,50 \pm 0,07^{\mathrm{a}}$ \\
\hline
\end{tabular}

* Média \pm desvio padrão de 3 repetições. Valores na mesma coluna, seguidos por letras diferentes indicam diferença significativa $(\mathrm{p} \leq 0,05)$; nd - valor não determinado.

$\mathbf{C}=$ cenoura, $\mathbf{F}=$ feijão, $\mathbf{F i}=$ fígado, $\mathbf{A 1}=$ Arovit $(15 \mathrm{mg}), \mathbf{F e r} \mathbf{1}=$ Fer-In-Sol $(78,67 \mathrm{mg})$,

Fer2 $=$ Fer-In-Sol $(211,17 \mathrm{mg}), \mathbf{N} 1=$ Neutrofer $(78,67 \mathrm{mg}), \mathbf{N} \mathbf{2}=$ Neutrofer $(211,17 \mathrm{mg})$. 
Anexo F. Concentração de ferro heme e não heme, em base úmida.

\begin{tabular}{ccc}
\hline Amostra & Ferro heme $(\mathrm{mcg} / \mathrm{g})$ & Ferro não heme $(\mathrm{mcg} / \mathrm{g})$ \\
\hline $\mathrm{F}+\mathrm{Fi}$ & $13,06 \pm 0,04^{{ }_{\mathrm{f}}}$ & $7,11^{\mathrm{c}}$ \\
Fi & $31,85 \pm 0,41^{\mathrm{a}}$ & $7,42 \pm 0,01^{\mathrm{b}}$ \\
Fi+A & $27,20 \pm 0,18^{\mathrm{d}}$ & $3,42 \pm 0,02^{\mathrm{e}}$ \\
Fi+Fer1 & $29,00 \pm 0,06^{\mathrm{b}}$ & $9,48^{\mathrm{a}}$ \\
Fi+N1 & $27,84 \pm 0,11^{\mathrm{c}}$ & $6,97 \pm 0,03^{\mathrm{d}}$ \\
Fi+C & $17,21 \pm 0,21^{\mathrm{e}}$ & $2,54 \pm 0,01^{\mathrm{f}}$ \\
\hline
\end{tabular}

*Média \pm desvio padrão de 3 repetições. Valores na mesma coluna, seguidos por letras diferentes indicam diferença significativa $(\mathrm{p} \leq 0,05)$.

$\mathbf{C}=$ cenoura, $\mathbf{F}=$ feijão, $\mathbf{F i}=$ fígado, $\mathbf{A 1}=$ Arovit $(15 \mathrm{mg}), \mathbf{F e r} \mathbf{1}=$ Fer-In-Sol $(78,67 \mathrm{mg})$,

Fer2 = Fer-In-Sol $(211,17 \mathrm{mg}), \mathbf{N 1}=$ Neutrofer $(78,67 \mathrm{mg}), \mathbf{N} \mathbf{2}=$ Neutrofer $(211,17 \mathrm{mg})$.

Anexo G. Porcentagem de ferro dialisável e concentração de ferro dialisável (mg/kg), em base úmida.

\begin{tabular}{ccc}
\hline Amostra & Ferro dialisável (\%) & $\begin{array}{c}\text { Concentração de ferro } \\
\text { dialisável }(\mathrm{mg} / \mathrm{kg})\end{array}$ \\
\hline C & $8,71 \pm 0,01^{\mathrm{*}} \mathrm{e}$ & 0,35 \\
$\mathrm{C}+\mathrm{A}$ & $11,40 \pm 0,0^{\mathrm{d}}$ & 0,32 \\
$\mathrm{C}+\mathrm{N}$ & $13,59 \pm 0,91^{\mathrm{c}}$ & 0,76 \\
$\mathrm{C}+\mathrm{N} 2$ & $1,96 \pm 0,12^{\mathrm{h}}$ & 0,18 \\
C+Fer1 & $1,11 \pm 0,01^{\mathrm{ij}}$ & 0,15 \\
C+Fer2 & $1,06 \pm 0,01^{\mathrm{ij}}$ & 0,30 \\
C+F & $3,50 \pm 0,00^{\mathrm{fg}}$ & 0,28 \\
F & $0,81 \pm 0,03^{\mathrm{j}}$ & 0,12 \\
F+A & $1,04 \pm 0,00^{\mathrm{ij}}$ & 0,16 \\
F+Fer2 & $0,42 \pm 0,03^{\mathrm{j}}$ & 0,30 \\
F+N2 & $1,81 \pm 0,00^{\mathrm{h}}$ & 0,63 \\
F+Fi & $2,94 \pm 0,01^{\mathrm{g}}$ & 3,48 \\
Fi & $1,91 \pm 0,08^{\mathrm{h}}$ & 8,10 \\
Fi+A & $14,69 \pm 0,03^{\mathrm{b}}$ & 7,3 \\
Fi+Fer1 & $4,12 \pm 0,01^{\mathrm{f}}$ & 7,64 \\
Fi+N1 & $1,72 \pm 0,17^{\mathrm{h}}$ & 7,08 \\
Fi+C & $19,80 \pm 0,01^{\mathrm{a}}$ & 4,80 \\
\hline
\end{tabular}

*Média \pm desvio padrão de 3 repetições. Valores na mesma coluna, seguidos por letras diferentes indicam diferença significativa $(\mathrm{p} \leq 0,05)$.

$\mathbf{C}=$ cenoura, $\mathbf{F}=$ feijão, $\mathbf{F i}=$ fígado, $\mathbf{A 1}=$ Arovit $(15 \mathrm{mg}), \mathbf{F e r} \mathbf{1}=$ Fer-In-Sol $(78,67 \mathrm{mg})$, Fer2 $=$ Fer-In-Sol $(211,17 \mathrm{mg}), \mathbf{N} 1=$ Neutrofer $(78,67 \mathrm{mg}), \mathbf{N} \mathbf{2}=$ Neutrofer $(211,17 \mathrm{mg})$. 


\section{REFERÊNCIAS BIBLIOGRÁFICAS}

ANTUNES, P.L.; SGARBIERI, V.C. Fatores antinutricionais, toxicidade e valor nutricional do feijão comum (Phaseolus vulgaris, L.). Agros, v.15, n.1, p.39-62, 1980.

ASHMEAD, H.D. The absorption and metabolism of iron amino acid chelate. Archivos Latinoamericanos de Nutrición, v.51, n.1, p.13-21, 2001.

ASP, N.G.; JOHANSSON, C.G.; HALLMER, H. et al. Rapid enzymatic assay of insoluble and soluble dietary fiber. Journal Agricultural and Food Chemistry, v.31, n.3, p.476-482, 1983.

ASSOCIATION OF OFFICIAL ANALYTICAL CHEMISTS. Official methods of analysis of the Association of Official Analytical Chemists. 16.ed. Washington: AOAC, 1995. 2v.

AUGUSTIN, J.; KLEIN, B.P. Nutrient composition of raw, cooked, canned, and sprouted legumes. In: MATTHEWS, R.H. Legumes: chemistry, technology, and human nutrition. New York: Marcel Dekker, 1989. 389p.

BIANCHI, M.L.P.; SILVA, H.C.; OLIVEIRA, J.E.D. Considerações sobre a biodisponibilidade do ferro dos alimentos. Archivos Latinoamericanos de Nutrición, v.42, n.2, p.94-100, 1992. 
BLOEM, M.W.; WEDEL, M.; AGTMAAL, E.J. van et al. Vitamin A intervention: short-term effects of a single, oral, massive dose on iron metabolism. American Journal of Clinical Nutrition, v.51, p.76-79, 1990.

BOCCIO, J.R.; ZUBILLAGA, M.B.; CARO, R.A. et al. A new procedure to fortify fluid milk and dairy products with high-bioavailable ferrous sulfate. Nutrition Reviews, v.55, n.6, p.240-246, 1997.

BOOTH, S.L.; JOHNS, T.; KUHNLEIN, H.V. Natural food sources of vitamin A and provitamin A. Food and Nutrition Bulletin, v.14, n.1, p.6-19, 1992.

BUREAU, J.L.; BUSHWAY, R.J. HPLC determination of carotenoids in fruits and vegetables in the United States. Journal of Food Science, v.51, n.1, p.128-130, 1986.

CABALLERO, B. Interaciones entre los componentes de la dieta. Archivos Latinoamericanos de Nutrición, v.38, n.3, p.656-684, 1988.

CANDELA, M.; ASTIASARAN, I.; BELLO, J. Cooking and warm-holding: effect on general composition and amino acids of kidney beans (Phaseolus vulgaris), chickpeas (Cicer arietinu), and lentils (Lens culinaris). Journal Agricultural and Food Chemistry, v.45, n.12, p.4763-4767, 1997.

CANNIATTI-BRAZACA, S.G.; SALGADO, J.M.; NOVAES, N.J.; MANCINI FILHO, J. Composição centesimal e teores de alguns minerais de cultivares de feijão guandu (Cajanus cajan L. Mill). Revista de Farmácia e Bioquímica da Universidade de São Paulo, v.32, n.1, p.45-51, 1996. 
CANNIATTI-BRAZACA, S.G.; SILVA, F.C. Avaliação do aproveitamento do ferro de leguminosas por diálise "in vitro". In: CONGRESSO NACIONAL DA SOCIEDADE BRASILEIRA DE ALIMENTAÇÃO E NUTRIÇÃO, 20., São Paulo, 1999. Resumos. São Paulo: Sociedade Brasileira de Alimentação e Nutrição, 1999. p.258.

CARPENTER, C.E.; CLARK, E. Evaluation of methods used in meat iron analysis and iron content of raw and cooked meats. Journal Agricultural and Food Chemistry, v.43, n.7, p.1824-1827, 1995.

CARTER, P. Spectrophotometric determination of serum iron at the submicrogram level with a new reagent (Ferrozine). Analytical Biochemistry, v.40, p.450-458, 1971.

CARVALHO, P.R.N.; COLLINS, C.A.; RODRIGUEZ-AMAYA, D.B. Comparison of determination by normal-phase gravity-fow column chromatography and reversed phase high performance liquid chromatography. Chromatographia, v.33, p.133137, 1992.

CASPARIS, D.; CARLO, P. del; BRANCONI, F. Effectiveness and tolerability of oral liquid ferrous gluconate in iron-deficiency anaemia in pregnancy and in the immediate post-partum period: comparasion with other liquid or solid formulations containing bivalent or trivalent iron. Minerva Gynecologica, v.48, n.11, p.511-518, 1996. /Resumo/

CONSAUL, J.R.; LEE, K. Extrinsic tagging in iron bioavailability research: a critical review. Journal Agricultural and Food Chemistry, v.31, n.4, p.684-689, 1983.

COOK, J.D. Determinants of nonheme iron absorption in man. Food Technology, v.37, n.10, p.124-126, 1983. 
COOK, J.D.; DASSENKO, S.A.; WHITTAKER, P. Calcium supplementation: effect on iron absorption. American Journal of Clinical Nutrition, v.53, p.106-11, 1991.

COTRAN, R.S.; KUMAR, V.; ROBBINS, S.L. Patologia estrutural e funcional. 5.ed. Rio de Janeiro: Guanabara, 1996. 1277p.

DUHAIMAN, A.S. Total iron content and bioavailability from liver, meat and vegetables. Nutrition Reports International, v.37, n.3, p.645-651, 1988.

ELPO, E.R.S.; FREITAS, R.J.S. de; GOMES, E.C. Avaliação dos teores de ferro nos alimentos da cesta básica. Archivos Latinoamericanos de Nutrición, v.48, n.1, p.65-67, 1998.

FÁVARO, R.M.D.; OLIVEIRA, J.ED. de. Enrichment of the diet with synthetic and natural sources of provitamin A. Archivos Latinoamericanos de Nutrición, v.49, n.1S, p.34S-37S, 1999.

FOX, T.E.; EAGLES, J.; FAIRWEATHER-TAIT, S.J. Bioavailability of iron glycine as a fortificant in infant foods. American Journal of Clinical Nutrition, v.67, n.4, p.664-668, 1998. /Resumo/

FRANCO, G. Tabela de composição química dos alimentos. 9.ed. São Paulo: Atheneu, 1992.307p.

GARCÍA-CASAL, M.N.; LAYRISSE, M.; SOLANO, L. et al. Vitamin A and $\beta$ carotene can improve nonheme iron absorption from rice, wheat and corn by humans. Journal of Nutrition, v.128, n.3, p.646-650, 1998.

GIBSON, R.S. Technological approaches to combatting iron deficiency. European Journal of Clinical Nutrition, v.51, p.S25-S27, 1997. Supplement, 4. 
GOYCOOLERA, F.; MEJÍA, E.G.; BARRÓM, J.M. et al. Efecto de los tratamientos caseros en la preparacion de frijol pinto (Phaseolus vulgaris) sobre el contenido de taninos y valor nutritivo de las proteínas. Archivos Latinoamericanos de Nutrición, v.40, n.2, p.263-274, 1990.

GRYNSPAN, F.; CHERYAN, M. Phytate-calcium interaction with soy protein. Journal of the American Oil Chemists Society, v.66, n.1, p.93-97, 1989.

GUZMÁN-MALDONADO, S.H.; ACOSTA-GALLEGOS, J.; PAREDES-LÓPEZ, O. Protein and mineral content of a novel collection of wild and weedy common bean (Phaseolus vulgaris L). Journal of the Science of Food and Agriculture, v.80, p.1874-1881, 2000.

HAYTOWITZ, D.B.; MATTHEWS, R.H. Nutrient content of other legume products. In: MATTHEWS, R.H. Legumes: chemistry, technology, and human nutrition. New York: Marcel Dekker, 1989. 389p.

HEINONEN, M.I. Carotenoids and provitamin A activity of carrot (Daucus carota L.) cultivars. Journal Agricultural and Food Chemistry, v.38, n.3, p.609-612, 1990.

HEINONEN, M.I.; OLLILAINEN, V.; LINKOLA, E.K.; VARO, P.T.; KOIVISTOINEN, P.E. Carotenoids in finish foods: vegetables, fruits and berries. Journal Agricultural and Food Chemistry, v.37, n.3, p.655-659, 1989.

HORNSEY, H.C. The color of cooked cured pork. Journal of Science and Food Agricultural, v.7, n.8, p.534-540, 1956.

JEPPSEN, R.B. Toxicology and safety of Ferrochel and other iron amino acid chelates. Archivos Latinoamericanos de Nutrición, v.51, n.1, p.26-34, 2001. 
KOEHLER, H.H.; CHANG, C.H.; SCHEIER, G.; BURKE, D.W. Nutrient composition, protein quality, and sensory properties of thirty-six cultivars of dry beans (Phaseolus vulgaris L.). Journal of Food Science, v.52, n.5, p.1335-1340, 1987.

KOROLKOVAS, A.; BURCKHALTER, J.H. Química farmacêutica. Rio de Janeiro: Guanabara, 1988. 783p.

LAYRISSE, M.; GARCÍA-CASAL, M.N.; SOLANO, L.; BARON, M.A.; ARGUELLO, F.; LLOVERA, D.; RAMÍREZ, J.; LEETS, I.; TROPPER, E. The role of vitamin A on the inhibitors of nonheme iron absorption: preliminary results. Journal Nutritional Biochemistry, v.8, p.61-67, 1997.

LAYRISSE, M.; GARCÍA-CASAL, M.N.; SOLANO, L.; BARON, M.A.; ARGUELLO, F.; LlOVERA, D.; RAMÍREZ, J.; LEETS, I.; TROPPER, E. New property of vitamin $A$ and $\beta$-carotene on human iron absorption: effect on phytate and polyphenols as inhibitors of iron absorption. Archivos Latinoamericanos de Nutrición, v.50, n.3, p.243-247, 2000.

LEE, K.; CLYDESDALE, F.M. Iron sources used in food fortification and their changes due to food processing. Critical Reviews in Food Science and Nutriton, v.11, n.2, p.117-154, 1979.

LUTEN, J.; CREWS, H.; FLYNN, A. et al. Interlaboratory trial of the determination of the in vitro iron dialysability from food. Journal of Science and Food Agriculture, v.72, n.4, 415-424, 1996.

LYNCH, S.R. Interaction of iron with other nutrients. Nutrition Reviews, v.55, n.4, p.102-110, 1997. 
MacPHAIL, A.P. Iron deficiency and developing world. Archivos Latinoamericanos de Nutrición, v.51, n.1, p.2-6, 2001.

MAHAN, L.K.; ARLIN, M.T. Krause: alimentos, nutrição e dietoterapia. 8.ed. São Paulo: Roca, 1995. 957p.

MALDONADO, S; SAMMÁN, N.; Composición química y contenido de minerales de leguminosas y cereales producidos en el noreoeste argentino. Archivos Latinoamericanos de Nutrición, v.50, n.2, p.195-199, 2000.

MANZ, U; PHILIPP, K.; Determination of vitamin A in complete feeds and premixes and vitamin concentrates with HPLC. In: Analytical Methods for Vitamins and Carotenoids in Food, 1988.

MARTÍNEZ, C.; ROS, G.; PERIAGO, M.J.; LÓPEZ, G. Biodisponibilidad del hierro de los alimentos. Archivos Latinoamericanos de Nutrición, v.49, n.2, p.106-113, 1999.

MARTÍNEZ, C.; ROS, G.; PERIAGO, M.J.; ORTUÑO, J.; LÓPEZ, G.; RINCÓN, F. In vitro protein digestibility and mineral availability of green beans (Phaseolus vulgaris $L$ ) as influenced by variety and pod size. Journal of the Science of Food and Agriculture, v.77, p.414-420, 1998.

McCANCE, R.A.; WIDDOWSON, E.M. The composition of food. 5.ed. Cambridge: Royal Society of Chemistry, 1994. 462p.

MEJÍA, L.A.; HODGES, R.E.; RUCKER, R.B. Role of vitamin A in the absorption, retention and distribution of iron in the rat. Journal of Nutrition, v.109, p.129-137, 1979. 
MEJIA, L.A.; CHEW, F. Hematological effects of supplementing anemic children with vitamin A alone and in combination with iron. American Journal of Clinical Nutrition, v.48, p.595-600, 1988.

MOLINA, M.R.; FUENTE, G. de la; BRESSANI, R. Interrelationships between storage, soaking time, cooking time, nutritive value and other characteristics of the black bean (Phaseolus vulgaris ). Journal of Food Science, v.40, p.587-591, 1975.

MOSHA, T.C.; GAGA, H.E.; PACE, R.D.; LASWAI, H.S.; MTEBE, K. Effect of blanching on the content of antinutritional factors in selected vegetables. Plant Foods for Human Nutrition, v.47, p.361-367, 1995.

NATIONAL RESEARCH COUNCIL. Food and Nutrition Board. Recommended dietary allowances. 10.ed. Washington: National Academic Press, 1989. 284p.

NORTHROP-CLEWES, C.A.; PARACHA, P.I.; McLOONE, U.J.; THURNHAM, D.I. Effect of improved vitamin A status on response to iron supplementation in Pakistani infants. American Journal of Clinical Nutrition, v.64, p.694-699, 1996.

NWOKOLO, E.; Nutritional evaluation of pigeon pea meal. Plant Foods for Human Nutrition, v.37, p.283-290, 1987.

OLIVARES, M.G.; PIZARRO, F.A. Bioavailability of iron bis-glycinate chelate in water. Archivos Latinoamericanos de Nutrición, v.51, n.1, p.22-25, 2001.

OLIVEIRA, A.C. de; QUEIROZ, K.S.; HELBIG, E. et al. O processamento doméstico do feijão-comum ocasionou uma redução nos fatores antinutricionais fitatos e taninos, no teor de amido e em fatores de flatulência rafinose, estaquiose e verbascose. Archivos Latinoamericanos de Nutrición, v.51, n.3, p.276-283, 2001. 
OLIVEIRA, J.E.D.; FREITAS, M.L.; FERREIRA, J.F. et al. Iron from complex salts and its bioavailability to rats. International Journal for Vitamin and Nutrition Research, v.65, n.4, p.272-275, 1995. /Resumo/

OLSON, J.A. Bioavailability of carotenoids. Archivos Latinoamericanos de Nutrición, v.49, n.1-S, p.21-S-25-S, 1999.

PAREDES-LOPEZ, O.; HARRY, G.I. Changes in selected chemical and antinutritional components during tempeh preparation using fresh and hardened common beans. Journal of Food Science, v.54, n.4, p.968-970, 1989.

PEE, S. de; WEST, C.E. Dietary carotenoids and their role in combating vitamin A deficiency: a review of the literature. European Journal of Clinical Nutrition, v.50, p.S38-S53, 1996. Supplement, 3.

PHILIPPI, S.T. Tabela de composição de alimentos: suporte para decisão nutricional. Brasília: ANVISA/FINATEC/NUT.UNB, 2001. 133p.

PINEDA, O.; ASHMEAD, H.D.; PEREZ, J.M.; LEMUS, C.P. Effectiveness of iron amino acid chelate on the treatment of iron deficiency anemia in adolescents. Journal of Applied Nutrition, v.46, n.1 \& 2, p.2-13, 1994.

PRICE, M.L.; HAGERMAN, A.E.; BUTLER, L.G. Tannin content of cowpeas, chickpeas, pigeonpeas and mug beans. Journal Agricultural and Food Chemistry, v.28, n.2, p.459-461, 1980.

RANGAN, A.M.; HO, R.W.L.; BLIGHT, G.D.; BINNS, C.W. Haem iron content of Australian meats and fish. Food Australia, v.49, n.11, p.508-511, 1997. 
REYES-MORENO, C.; PAREDES-LOPEZ, O. Hard-to-cook phenomenon in commom beans: a review. Critical Reviews in Food Science and Nutrition, v.33, n.3, p.227286, 1993.

RODRIGUEZ-AMAYA, D.B. Os carotenóides como precursores de vitamina A. Boletim da Sociedade Brasileira de Ciência e Tecnologia de Alimentos, v.19, n.4, p.227-242, 1985.

RODRIGUEZ-AMAYA, D.B. Assessment of the provitamin A contents of foods - the Brazilian experience. Journal of Food Composition and Analysis, v.9, n.3, p.196230, 1996.

ROODENBURG, A.J.C.; WEST, C.E.; YU, S.; BEYNEN, A.C. Comparison between time-dependent changes in iron metabolism of rats as induced by marginal deficiency of either vitamin A or iron. British Journal of Nutrition, v.71, p.687699, 1994.

ROSSANDER-HULTEN, L.; BRUNE, M.; SANDSTROM, B.; LONNERDAL, B.; HALLBERG, L. Competitive inhibition of iron absorption by manganese and zinc in humans. American Journal of Clinical Nutrition, v.54, p.152-156, 1991.

SALES, A.M.; BRAGA, N.R.; DRAETTA, I.S.; MORI, E.E.M.; TRAVAGLINI, M.M.E.; PIZZINATTO, A. Feijão-guandu. I. Avaliação organoléptica e nutricional para fins de alimentação humana. Boletim ITAL, v.17, n.2, p.147-180, 1980.

SAMMÁN, N.; MALDONADO, S.; ALFARO, M.E.; FARFÁN, N.; GUTIERREZ, J. Composition of different bean varieties (Phaseolus vulgaris) of northwestern Argentina (region NOA): cultivation zone influence. Journal Agricultural and Food Chemistry, v.47, n.7, p.2685-2689, 1999. 
SARRUGE, J.R.; HAAG, H.P. Análises químicas em plantas. Piracicaba: USP/ESALQ, 1974. p.56.

SAS, G.; NEMESANSZKY, E.; BRÄUER, H.; SCHEFFER, K. On the therapeutic effects of trivalent and divalent iron in iron deficiency anaemia. ArzneimittelForsh, v.34, n.11, p.1575-1579, 1984.

SCHRICKER, B.R.; MILLER, D.D; STOUFFER, J.R. Measurement and content of nonheme and total iron in muscle. Journal of Food Science, v.47, p.740-743, 1982.

SGARBIERI, V.C. Alimentação e nutrição. Campinas: UNICAMP, 1987. 387p.

SGARBIERI, V.C.; ANTUNES, P.L.; ALMEIDA, L.D. Nutritional evaluation of four varieties of dry beans (Phaseolus vulgaris, L.). Journal of Food Science, v.44, p.1306-1308, 1979.

SHATRUGNA, V.; RAMAN, L.; UMA, K.; SUJATHA, T. Interaction between vitamin A and iron: effects of supplements in pregnancy. International Journal for Vitamin and Nutrition Research, v.67, p.145-148, 1997.

SILVA, P. Farmacologia. 4.ed. Rio de Janeiro: Guanabara, 1994. 1450p.

SINGH, K.; FONG, Y.F.; KUPERAN, P. A comparison between intravenous iron polymaltose complex (Ferrum Hausmann) and oral ferrous fumarate in the treatment of iron deficiency anaemia in pregnancy. European Journal of Haematology, v.60, n.2, p.119-124, 1998. /Resumo/

SINGH, U.; JAIN, K.C.; JAMBUNATHAN, R.; FARIS, D.G. Nutritional quality of vegetable pigeonpeas [Cajanus cajan (L.) Mill sp.]: mineral and trace elements. Journal of Food Science, v.49, n.2, p.645-646, 1984. 
STATISTICAL ANALYSIS SYSTEM INSTITUTE. Sas/Qc software: usage and reference. 2.ed. Cary, 1996. 2v.

STOOKEY, L.L. A new spectrophotometric reagent for iron. Analytical Chemistry, v.42, n.7, p.779-781, 1970.

STUIJVENBERG, M.E.van; KRUGER, M.; BADENHORST, C.J. et al. Response to an iron fortification programme in relation to vitamin A status in 6-12-year-old school children. International Journal of Food Sciences and Nutrition, v.48, p.41-49, 1997.

SZARFARC, S.C.; CASSANA, L.M.N.; FUJIMORI, E. et al. Relative effectiveness of iron bis-glycinate chelate (Ferrochel) and ferrous sulfate in the control of iron deficiency in pregnant women. Archivos Latinoamericanos de Nutrición, v.51, n.1, p.42-47, 2001.

TORRE, M.; RODRIGUEZ, A.R.; SAURA-CALIXTO, F. Effects of dietary fiber and phytic acid on mineral availability. Critical Reviews in Food Science and Nutrition, v.1,n.1, p.1-22, 1991.

UNIVERSIDADE DE SÃO PAULO. Faculdade de Ciências Farmacêuticas. Tabela brasileira de composição de alimentos: projeto integrado de composição de alimentos. http://www.fcf.usp.br/tabela (07 Out. 2001)

VITERI, F.E. Iron supplementation for the control of iron deficiency in populations at risk. Nutrition Reviews, v.55, n.6, p.195-209, 1997.

VORA, H.M.; KYLE, W.S.A; SMALL,D.M. Composition and juicing potential of Australian varieties of carrot. Food Australia, v.50, n.1, p.24-26, 1998. 
WEDER, J.K.P.; TELEK, L.; VOZÁRI-HAMPE, M.; SAINI, H.S. Antinutritional factors in anasazi and other pinto beans (Phaseolus vulgaris L). Plant Foods for Human Nutrition, v.51, p.85-98, 1997.

WHITTAKER, P.; SPIVEY FOX, M.R.; FORBES, A.L. In vitro prediction of iron bioavailability for food fortification. Nutrition Reporter International, v.39, n.6, p.1205-1215, 1989.

WORLD HEALTH ORGANIZATION. Nutrition. http://www.who.int/nut/ida.htm (10 May 2002)

YOUNG, N.R.; JANGHORBANI, M. Soy proteins in human diet in relation to bioavailability of iron and zinc: a brief overview. Cereal Chemistry, v.58, n.1, p.12-18, 1981. 